ANDRESSA DALMAZZO

Utilização da lecitina de soja para a refrigeração e criopreservação do sêmen de cães

São Paulo 
ANDRESSA DALMAZZO

\title{
Utilização da lecitina de soja para a refrigeração e criopreservação do sêmen de cães
}

\begin{abstract}
Dissertação apresentada ao Programa de PósGraduação em Reprodução Animal da Faculdade de Medicina Veterinária e Zootecnia da Universidade de São Paulo para obtenção do título de Mestre em Ciências.
\end{abstract}

\section{Departamento:}

Reprodução Animal

Área de concentração:

Reprodução Animal

Orientador:

Profa. Dra. Valquiria Hyppólito Barnabe

De acordo:

$$
\text { Orientadora }
$$

São Paulo

\section{2}

Obs.: A versão original se encontra disponível na Biblioteca da FMVZ-USP 
Autorizo a reprodução parcial ou total desta obra, para fins acadêmicos, desde que citada a fonte.

\section{DADOS INTERNACIONAIS DE CATALOGAÇÃO-NA-PUBLICAÇÃO}

(Biblioteca Virginie Buff D’Ápice da Faculdade de Medicina Veterinária e Zootecnia da Universidade de São Paulo)

Dalmazzo, Andressa

Utilização da lecitina de soja para a refrigeração e criopreservação do sêmen de cães / Andressa Dalmazzo. -- 2012. $103 \mathrm{f}$. : il.

Dissertação (Mestrado) - Universidade de São Paulo. Faculdade de Medicina Veterinária e Zootecnia. Departamento de Reprodução Animal, São Paulo, 2012.

Programa de Pós-Graduação: Reprodução Animal.

Área de concentração: Reprodução Animal.

Orientador: Profa. Dra. Valquiria Hyppólito Barnabe.

1. Refrigeração. 2. Criopreservação. 3. Sêmen. 4. Cães. 5. Lecitina de Soja. I. Título. 


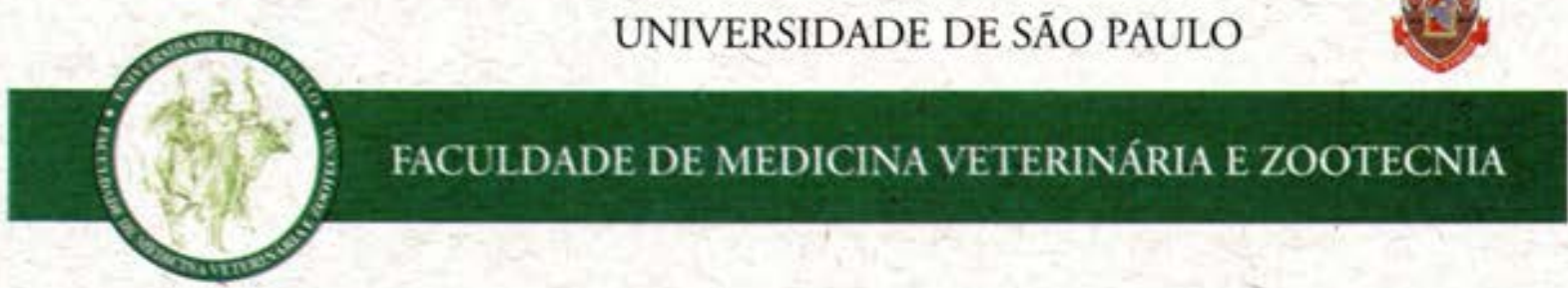

Comissão de Ética no uso de animais

\section{CERTIFICADO}

Certificamos que o Projeto intitulado "Utilização de lecitina de soja para a refrigeração e çriopreservação de sêmen de cães", protocolado sob o $\mathrm{n}^{\circ}$ 2472/2011, utilizando 12 (doze) cães, sob a responsabilidade do(a) Profa. Dra. Valquiria Hyppólito Barnabe, está de acordo com os princípios éticos de experimentação animal da "Comissão de Ética no uso de animais" da Faculdade de Medicina Veterinária e Zootecnia da Universidade de São Paulo e foi aprovado em reunião de 23/11/2011.

We certify that the Research "Effect of soy lecithin on dog semen refrigeration and cryopreservation", protocol number 2472/2011, utilizing 12 (twelve) dogs, under the responsibility Profa. Dra. Valquiria Hyppólito Barnabe, agree with Ethical Principles in Animal Research adopted by "Ethic Committee in the use of animals" of the School of Veterinary Medicine and Animal Science of University of São Paulo and was approved in the meeting of day 11/23/2011.

São Paulo, 24 de novembro de 2011.

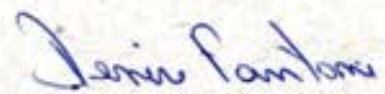

Denise Tabacchi Fantoni

Presidente 
Nome: DALMAZZO, Andressa

Título: Utilização da lecitina de soja para a refrigeração e criopreservação do sêmen de cães

Dissertação apresentada ao Programa de PósGraduação em Reprodução Animal da Faculdade de Medicina Veterinária e Zootecnia da Universidade de São Paulo para obtenção do título de Mestre em Ciências.

Data:

1

Banca Examinadora

Prof. Dr.

Instituição:

Julgamento:

Prof. Dr.

Instituição:

Julgamento:

Prof. Dr.

Instituição:

Julgamento: 
Aos meus queridos pais, meu amado marido Ricardo, e meus grandes amigos 


\section{AGRADECIMENTOS}

Gostaria de agradecer imensamente a ajuda de todos que colaboraram direta ou indiretamente em mais essa etapa concluída em minha vida.

Primeiramente, agradeço a Deus por iluminar o meu caminho, pela proteção e por mais uma conquista alcançada.

Aos meus pais, Antonio Carlos e Bernadette, pelo incentivo, apoio, suporte, amor, ensinamentos, dedicação e compreensão. Pelo exemplo de honestidade e força de vontade. Tudo o que sou eu devo a vocês! Muito obrigada por tudo! Inclusive pelas marmitas que me ajudaram a ganhar tempo nesse momento tão exaustivo!

Ao meu marido Ricardo, por sempre estar ao meu lado nos muitos momentos de alegrias, mas também nos de tristeza, estresse, cansaço, crises de choro... sempre recarregando as minhas energias, me dando forças para seguir em frente. Por apoiar constantemente as minhas decisões, me dar conselhos, compreender os muitos momentos distantes, me amar do jeito que sou e por ser a chave da minha felicidade. Te amo muito!

À minha irmã Priscilla e ao meu sobrinho Enzo, que apesar da distância e da saudade, estão sempre me mandando mensagens de apoio, incentivo e pensamentos positivos. Vocês estão sempre em meus pensamentos e no meu coração.

Ao meu inseparável companheiro Frajola, por sempre se deitar no meu colo enquanto escrevia este trabalho, me "obrigando" a continuar firme e forte em frente ao computador.

À Professora Valquiria e ao Professor Renato, por me abrirem as portas a esse fascinante mundo da pesquisa em Reprodução Animal. Muito obrigada pelo grande carinho, pelos inúmeros momentos de descontração, pela confiança, amizade, ensinamentos, incentivo, mas acima de tudo, por sua orientação e pela oportunidade de fazer parte de sua equipe. É um imenso privilégio e motivo de muito orgulho!

Ao meu amigo Marcilio, que desde o início, me ajudou em todas as etapas deste projeto, me orientando, incentivando e ensinando a ser uma profissional. Obrigada por toda a dedicação, mesmo quando eu ultrapassava os limites da sua paciência. Não sei o que seria de mim sem sua ajuda. Não tenho palavras para agradecer tudo o que você sempre fez por mim!

Aos meus amigos, Diego, Carol, Roberta, Pedro Ivo, João Rafael, pelos muitos momentos que passamos juntos, pelas conversas, risadas e pipocas com guaraná. Por deixarem de fazer suas coisas para me ajudar nas análises e leituras das milhares de lâminas, de domingo a domingo, mesmo nos momentos em que achava que tudo iria por água abaixo. Vocês sempre estiveram ao meu lado para me dar forças, soluções e incentivo para continuar em frente. Esse trabalho é uma conquista 
de todos nós! Nunca esquecerei tudo o que vocês fizeram por mim. Serei eternamente grata pela ajuda e amizade! Podem contar sempre comigo!

À Cláudia Minazaki, pela amizade que tem se fortalecido a cada dia, pelo apoio, conselhos, por toda a ajuda na correção deste trabalho e pelo incentivo para continuar.

À Silvia Crusco, por ter me dado a oportunidade de conhecer melhor a área da reprodução animal, me proporcionando o prazer de trabalhar com o que gosto. Por ter me incentivado a fazer o mestrado, me recomendando à professora Valquiria, e pelo auxílio na escolha do tema. Sou muito grata por tudo o que você sempre fez por mim, pelas portas que me foram abertas e por todos os ensinamentos que me fizeram ser quem eu sou hoje!

Ao Major Sobrinho, por ter cedido os cães da Seção de Cães de Guerra do $2^{\circ}$ BPE, por mudar toda sua rotina para que pudéssemos realizar o experimento, pela amizade, suporte, paciência e confiança.

À Tenente Nívea e aos Militares da Seção de Cães de Guerra do $2^{\circ}$ BPE, que sempre foram muito prestativos, atenciosos e pelo auxílio no manejo e contenção dos animais.

Aos meus Amigos de Departamento, pelas conversas na hora do almoço, no corredor, pelas risadas e churrascos, que deixavam os dias mais descontraídos e divertidos.

Ao Eduardo, pela amizade, pelo companheirismo nas viagens e pelos corantes utilizados no experimento.

À Professora Camila, que me ajudou desde o início, principalmente em meu estágio obrigatório, me permitindo participar da rotina do laboratório, onde aprendi muitas das coisas que me encantam nesta área.

À Professora Mayra, pelo uso do Laboratório de Fecundação in vitro, Clonagem e Transgenia Animal do Departamento de Reprodução Animal - FMVZ - USP para a realização do SCSA.

À Camilla Motta e todos do laboratório que me auxiliaram com o citômetro de fluxo e no preparo das amostras.

Ao Professor Ricardo e ao Dinho do VPT, que sempre muito solícitos, me forneceram os ovos para o preparo do diluidor.

Ao Professor Marcelo, que desde o início sempre me auxiliou e me apoiou, pelas conversas e pela oportunidade de acompanhar a área de animais selvagens, que me fascina desde os tempos do colégio.

À todos os professores do Departamento de Reprodução Animal. 
Ao Miguel, que aguentou fortemente durante semanas a nossa "bagunça" no laboratório, por ouvir muita besteira, pelas conversas, por nos ensinar a deixar tudo organizado e por se tornar um grande amigo.

À Harumi, que fez de sua sala muitas vezes um confessionário, ouviu meus desabafos, me deu conselhos e sempre me ajudou em tudo o que precisei, tanto nas questões burocráticas quanto pessoais. Muito obrigada pela amizade!

À Thais, Roberta, Anderson e Alice, por toda a ajuda e apoio.

À querida Dona Silvia, pela alegria de viver, sendo sempre um exemplo de força.

Aos funcionários da Biblioteca, principalmente à Elza.

Aos funcionários da Pós Graduação, Daura, Cláudia, Henrique, Marli.

A todos os funcionários do VRA, Cláudia, Belau, Irailton, Luiz, Jocimar, Sandra.

À Universidade de São Paulo, à Faculdade de Medicina Veterinária e Zootecnia e ao Departamento de Reprodução Animal, pela oportunidade.

À empresa Solae pelo fornecimento das lecitinas utilizadas no experimento.

À Coordenação de Aperfeiçoamento de Pessoal de Nível Superior (CAPES) pela concessão da bolsa de mestrado.

À Fundação de Amparo à Pesquisa do Estado de São Paulo (FAPESP) pelo auxílio financeiro (Processo nº 2011/09222-0). 
“O valor das coisas não está no tempo em que elas duram, mas na intensidade com que acontecem. Por isso existem momentos inesquecíveis, coisas inexplicáveis e pessoas incomparáveis."

Fernando Pessoa 


\section{RESUMO PORTUGUÊS}

DALMAZZO, A. Utilização da lecitina de soja para a refrigeração e criopreservação do sêmen de cães. [Effect of soy lecithin on dog semen refrigeration and cryopreservation]. 2012. 103 f. Dissertação (Mestrado em Ciências) - Faculdade de Medicina Veterinária e Zootecnia, Universidade de São Paulo, São Paulo, 2012.

Sabe-se que a criopreservação do sêmen provoca uma perda significativa na qualidade espermática. Apesar de diversos estudos visando à melhora na qualidade do sêmen pós-descongelamento, é de consenso geral que a gema de ovo apresenta uma significante capacidade em evitar as crio-injúrias. No entanto, a grande variação na sua composição, assim como o risco potencial para a contaminação do diluidor, caso certos contaminantes estejam no produto in natura, são empecilhos para sua utilização para a exportação do sêmen, assim como sua utilização em humanos. Deste modo, estudos visando substituir a gema de ovo por produtos quimicamente definidos e de origem não-animal, são de extrema importância. Neste contexto, a lecitina da soja, por possuir uma fração de lipoproteína de baixa densidade semelhante à encontrada na gema de ovo, pode ser uma alternativa interessante. $\mathrm{O}$ presente estudo visa comparar diluidores a base de lecitina de soja e aqueles contendo gema de ovo utilizados rotineiramente para a refrigeração e criopreservação do sêmen canino. Para isto, foi utilizado o sêmen de 12 cães adultos, que foi refrigerado e criopreservado em diluidores a base de gema de ovo (OVO) e a base de lecitina de soja (LEC) em diferentes concentrações $(0,01 ; 0,05$ e 0,1\%) e apresentações (FP40, 8160 e Solec F). O sêmen foi avaliado após refrigeração (2, 24, 48, 72, 96 e 120 horas; Experimento 1) e após criopreservação (pós refrigeração, pós glicerolização e pós descongelação; Experimento 2) através da análise convencional do sêmen (i.e., motilidade - CASA) e funcionais (i.e., integridade de membrana - eosina/nigrosina; integridade de acrossomo - Fast Green / Rosa Bengala; atividade mitocondrial - 3’3 Diaminobenzidina; fragmentação do DNA - SCSA; susceptibilidade ao estresse oxidativo - substâncias reativas ao ácido tiobarbitúrico). Os resultados do Experimento 1 indicaram que, semelhante ao ovo, todas as lecitinas na concentração 0,01\% foram capazes de manter a motilidade em torno de $50 \%$ por até 72 horas. Após 96 horas, o diluidor Solec F 
apresentou melhor resultado em relação ao ovo na atividade mitocondrial, e após 120 horas a concentração 0,01\%, apresentou maior motilidade do que o ovo (30,00 $\pm 10,69 ; 8,33 \pm 1,84$, respectivamente). No sêmen criopreservado (Experimento 2), as menores concentrações de lecitina apresentaram resultados semelhantes ao ovo tanto na motilidade quanto na atividade mitocondrial. Os resultados indicam que a lecitina pode ser uma boa alternativa à gema de ovo para a refrigeração e criopreservação do sêmen canino.

Palavras-chave: Refrigeração. Criopreservação. Sêmen. Cães. Lecitina de Soja. 
ABSTRACT

DALMAZZO, A. Effect of soy lecithin on dog semen refrigeration and cryopreservation. [Utilização da lecitina de soja para a refrigeração e criopreservação do sêmen de cães]. 2012. 103 f. Dissertação (Mestrado em Ciências) - Faculdade de Medicina Veterinária e Zootecnia, Universidade de São Paulo, São Paulo, 2012.

Semen cryopreservation, an essential step on biotechnologies applied to reproduction, is known to induce significant loss on sperm quality. Despite several studies aiming to improve post-thaw quality, it is generally agreed that egg yolk is the most effective in protecting sperm against cryo-injuries. However, the considerable variation on egg yolk composition as well as the potential risk of disseminating diseases when used in natura, are obstacles to semen exportation as well as the use in human. Therefore, studies aiming to substitute the egg yolk for chemically defined components or animal free products are extremely important. In this context, soy lecithin, which contains a fraction of low density lipoprotein, appears to be an interesting alternative. Thus, the present study aims to compare semen extenders containing soy lecithin or egg yolk on dog semen cryopreservation and refrigeration. Towards this aim, semen of 12 adult dogs were be refrigerated and cryopreserved in Tris-Fructose-Citric acid extenders with egg yolk (OVO) or soy lecithin (LEC; in different concentrations - 0,01; 0,05; 0,1\% and presentations - FP40; 8160; Solec F). Semen was evaluated after chilling (2, 24, 48, 72, 96 and 120 hours; Experiment 1) and after cryopreservation (post refrigeration, post-glycerolization, and post-thaw; Experiment 2) for routine semen analysis (e.g., motility, CASA) and functional tests (e.g., membrane integrity - eosin/nigrosin; acrosome integrity - fast green/Bengal rose; mitochondrial activity - 3'3 diaminobenzidine; DNA fragmentation - SCSA; susceptibility to oxidative stress - thiobarbituric acid reactive substances). Results were statistically analyzed using the SAS System for Windows. Results of experiment 1 indicate that, similar to the egg yolk, all types of lecithin used in the $0.01 \%$ concentration, were able to maintain sperm motility around $50 \%$ for $72 \mathrm{~h}$. After $96 \mathrm{~h}$, the extender containing the lecithin Solec $F$ showed better results regarding mitochondrial activity when compared to the egg yolk. Furthermore, after $120 \mathrm{~h}$, the same extender with the $0.01 \%$ concentration, showed higher motility when compared to the egg yolk (30.00 \pm 10.69 and $8.33 \pm 1.84 \%$, respectively). On the other hand, 
for the cryopreserved samples (Experiment 2), lower concentrations of lecithin showed similar results for mitochondrial activity and motility when compared to the egg yolk. Results found in the present study indicate that soy lecithin may be a good alternative to substitute the egg yolk for both refrigeration and cryopreservation of dog semen.

Key words: Refrigeration. Cryopreservation. Sperm. Dog. Soy Lecithin. 


\section{LISTA DE FIGURAS}

Figura 1 - Delineamento Experimental

.42

Figura 2 - Movimento esquemático do espermatozóide avaliado pelo CASA .45 


\section{LISTA DE TABELAS}

Tabela 1 - Probabilidades dos efeitos do tempo de refrigeração, diluidor e da interação tempo * diluidor sobre a porcentagem de células com membrana plasmática e acrossomal íntegra, variáveis analisadas pelo CASA (VAP, VSL, VCL, ALH, BCF, STR, LIN, MOT, PROG, RAP, MED, SLOW, STATIC), susceptibilidade ao estresse oxidativo (TBARS), atividade mitocondrial (DAB I atividade total, DAB II atividade alta, DAB III atividade baixa, DAB IV atividade nula) e integridade do DNA (ensaio da estrutura da cromatina espermática - SCSA) no sêmen refrigerado de cães - São Paulo 2012

Tabela 2 - Comparação entre diluidor a base de lecitina de soja em diferentes apresentações (8160, FP40, Solec F) e concentrações $(0,01 \%, 0,05 \%$ e $0,1 \%)$ e o diluidor a base de gema de ovo na atividade mitocondrial (DAB I atividade total, DAB II atividade alta, DAB III atividade baixa, DAB IV atividade nula) e nas variáveis analisadas pelo CASA (VAP, VSL, VCL, ALH, BCF, MOT, PROG, RAP, MED, STATIC), em amostras de sêmen de cães refrigeradas $\left(5^{\circ} \mathrm{C}\right)$ por 2 horas - São Paulo - 2012

Tabela 3 - Comparação entre diluidor a base de lecitina de soja em diferentes apresentações (8160, FP40, Solec F) e concentrações $(0,01 \%, 0,05 \%$ e $0,1 \%)$ e o diluidor a base de gema de ovo na atividade mitocondrial (DAB I atividade total, DAB II atividade alta, DAB III atividade baixa, DAB IV atividade nula) e nas variáveis analisadas pelo CASA (VAP, VSL, VCL, ALH, BCF, MOT, PROG, RAP, MED, STATIC), em amostras de sêmen de cães refrigeradas $\left(5^{\circ} \mathrm{C}\right)$ por 24 horas - São Paulo - 2012

Tabela 4 - Comparação entre diluidor a base de lecitina de soja em diferentes apresentações (8160, FP40, Solec F) e concentrações $(0,01 \%, 0,05 \%$ e $0,1 \%)$ e o diluidor a base de gema de ovo na atividade mitocondrial (DAB I atividade total, DAB II atividade alta, DAB III atividade baixa, DAB IV atividade nula) e nas variáveis analisadas pelo CASA (VAP, VSL, VCL, ALH, BCF, MOT, PROG, RAP, MED, STATIC), em amostras de sêmen de cães refrigeradas $\left(5^{\circ} \mathrm{C}\right)$ por 48 horas - São Paulo - 2012

Tabela 5 - Comparação entre diluidor a base de lecitina de soja em diferentes apresentações (8160, FP40, Solec F) e concentrações $(0,01 \%, 0,05 \%$ e $0,1 \%)$ e o diluidor a base de gema de ovo na atividade mitocondrial (DAB I atividade total, DAB II atividade alta, DAB III atividade baixa, DAB IV atividade nula) e nas variáveis analisadas pelo CASA (VAP, VSL, VCL, ALH, BCF, MOT, PROG, RAP, MED, STATIC), em amostras de sêmen de cães refrigeradas $\left(5^{\circ} \mathrm{C}\right)$ por 72 horas - São Paulo - 2012 
Tabela 6 - Comparação entre diluidor a base de lecitina de soja em diferentes apresentações (8160, FP40, Solec F) e concentrações $(0,01 \%, 0,05 \%$ e $0,1 \%)$ e o diluidor a base de gema de ovo na atividade mitocondrial (DAB I atividade total, DAB II atividade alta, DAB III atividade baixa, DAB IV atividade nula) e nas variáveis analisadas pelo CASA (VAP, VSL, VCL, ALH, BCF, MOT, PROG, RAP, MED, STATIC), em amostras de sêmen de cães refrigeradas $\left(5^{\circ} \mathrm{C}\right)$ por 96 horas - São Paulo - 2012

Tabela 7 - Comparação entre diluidor a base de lecitina de soja em diferentes apresentações (8160, FP40, Solec F) e concentrações $(0,01 \%, 0,05 \%$ e $0,1 \%)$ e o diluidor a base de gema de ovo na atividade mitocondrial (DAB I atividade total, DAB II atividade alta, DAB III atividade baixa, DAB IV atividade nula) e nas variáveis analisadas pelo CASA (VAP, VSL, VCL, ALH, BCF, MOT, PROG, RAP, MED, STATIC), em amostras de sêmen de cães refrigeradas $\left(5^{\circ} \mathrm{C}\right)$ por 120 horas - São Paulo - 2012

Tabela 8 - Efeito do tempo (2, 24, 48, 96, 120 horas) na atividade mitocondrial (DAB I atividade total, DAB II atividade alta, DAB III atividade baixa, DAB IV atividade nula) e nas variáveis analisadas pelo CASA (VAP, VSL, VCL, ALH, BCF, MOT, PROG, RAP, MED, STATIC), em amostras de sêmen de cães refrigeradas $\left(5^{\circ} \mathrm{C}\right)$ em diluidor à base de gema de ovo - São Paulo - 2012

Tabela 9 - Efeito do tempo (2, 24, 48, 96, 120 horas) na atividade mitocondrial (DAB I atividade total, DAB II atividade alta, DAB III atividade baixa, DAB IV atividade nula) e nas variáveis analisadas pelo CASA (VAP, VSL, VCL, ALH, BCF, MOT, PROG, RAP, MED, STATIC), em amostras de sêmen de cães refrigeradas $\left(5^{\circ} \mathrm{C}\right)$ em diluidor a base de lecitina de soja 8160 0,01\% - São Paulo - 2012.

Tabela 10 - Efeito do tempo (2, 24, 48, 96, 120 horas) na atividade mitocondrial (DAB I atividade total, DAB II atividade alta, DAB III atividade baixa, DAB IV atividade nula) e nas variáveis analisadas pelo CASA (VAP, VSL, VCL, ALH, BCF, MOT, PROG, RAP, MED, STATIC), em amostras de sêmen de cães refrigeradas $\left(5^{\circ} \mathrm{C}\right) \mathrm{em}$ diluidor a base de lecitina de soja 8160 0,05\% - São Paulo - 2012.......63 63

Tabela 11 - Efeito do tempo (2, 24, 48, 96, 120 horas) na atividade mitocondrial (DAB I atividade total, DAB II atividade alta, DAB III atividade baixa, DAB IV atividade nula) e nas variáveis analisadas pelo CASA (VAP, VSL, VCL, ALH, BCF, MOT, PROG, RAP, MED, STATIC), em amostras de sêmen de cães refrigeradas $\left(5^{\circ} \mathrm{C}\right)$ em diluidor a base de lecitina de soja 8160 0,1\% - São Paulo - 2012. 
Tabela 12 - Efeito do tempo (2, 24, 48, 96, 120 horas) na atividade mitocondrial (DAB I atividade total, DAB II atividade alta, DAB III atividade baixa, DAB IV atividade nula) e nas variáveis analisadas pelo CASA (VAP, VSL, VCL, ALH, BCF, MOT, PROG, RAP, MED, STATIC), em amostras de sêmen de cães refrigeradas $\left(5^{\circ} \mathrm{C}\right) \mathrm{em}$ diluidor a base de lecitina de soja FP40 0,01\% - São Paulo - 2012

Tabela 13 - Efeito do tempo (2, 24, 48, 96, 120 horas) na atividade mitocondrial (DAB I atividade total, DAB II atividade alta, DAB III atividade baixa, DAB IV atividade nula) e nas variáveis analisadas pelo CASA (VAP, VSL, VCL, ALH, BCF, MOT, PROG, RAP, MED, STATIC), em amostras de sêmen de cães refrigeradas $\left(5^{\circ} \mathrm{C}\right)$ em diluidor a base de lecitina de soja FP40 0,05\% - São Paulo - 2012

Tabela 14 - Efeito do tempo (2, 24, 48, 96, 120 horas) na atividade mitocondrial (DAB I atividade total, DAB II atividade alta, DAB III atividade baixa, DAB IV atividade nula) e nas variáveis analisadas pelo CASA (VAP, VSL, VCL, ALH, BCF, MOT, PROG, RAP, MED, STATIC), em amostras de sêmen de cães refrigeradas $\left(5^{\circ} \mathrm{C}\right)$ em diluidor a base de lecitina de soja FP40 0,1\% - São Paulo - 2012.

Tabela 15 - Efeito do tempo (2, 24, 48, 96, 120 horas) na atividade mitocondrial (DAB I atividade total, DAB II atividade alta, DAB III atividade baixa, DAB IV atividade nula) e nas variáveis analisadas pelo CASA (VAP, VSL, VCL, ALH, BCF, MOT, PROG, RAP, MED, STATIC), em amostras de sêmen de cães refrigeradas $\left(5^{\circ} \mathrm{C}\right)$ em diluidor a base de lecitina de soja Solec F 0,01\% - São Paulo 2012

Tabela 16 - Efeito do tempo (2, 24, 48, 96, 120 horas) na atividade mitocondrial (DAB I atividade total, DAB II atividade alta, DAB III atividade baixa, DAB IV atividade nula) e nas variáveis analisadas pelo CASA (VAP, VSL, VCL, ALH, BCF, MOT, PROG, RAP, MED, STATIC), em amostras de sêmen de cães refrigeradas $\left(5^{\circ} \mathrm{C}\right)$ em diluidor a base de lecitina de soja Solec F 0,05\% - São Paulo 2012

Tabela 17 - Efeito do tempo (2, 24, 48, 96, 120 horas) na atividade mitocondrial (DAB I atividade total, DAB II atividade alta, DAB III atividade baixa, DAB IV atividade nula) e nas variáveis analisadas pelo CASA (VAP, VSL, VCL, ALH, BCF, MOT, PROG, RAP, MED, STATIC), em amostras de sêmen de cães refrigeradas $\left(5^{\circ} \mathrm{C}\right)$ em diluidor a base de lecitina de soja Solec F 0,1\% - São Paulo 2012 
Tabela 18 - Comparação entre diluidor a base de lecitina de soja em diferentes apresentações (8160, FP40, Solec F) e concentrações $(0,01 \%, 0,05 \%$ e $0,1 \%)$ e o diluidor a base de gema de ovo nas porcentagens de células com membranas plasmática e acrossomal íntegras, nas variáveis analisadas pelo CASA (STR, LIN, SLOW), na susceptibilidade ao estresse oxidativo (TBARS) e na integridade do DNA (ensaio da estrutura da cromatina espermática - SCSA) em amostras de sêmen de cães refrigeradas $\left(5^{\circ} \mathrm{C}\right)$ - São Paulo - 2012

Tabela 19 - Efeito do tempo (2, 24, 48, 96, 120 horas) nas porcentagens de células com membranas plasmática e acrossomal íntegras, nas variáveis analisadas pelo CASA (STR, LIN, SLOW), na susceptibilidade ao estresse oxidativo (TBARS) e na integridade do DNA (ensaio da estrutura da cromatina espermática - SCSA) em amostras de sêmen de cães refrigeradas $\left(5^{\circ} \mathrm{C}\right)$ em diluidores a base de lecitina de soja e gema de ovo - São Paulo - 2012.

Tabela 20 - Probabilidades dos efeitos dos momentos da criopreservação (pós-refrigeração, pós-glicerolização e pós-descongelação), diluidor e da interação momento da criopreservação * diluidor sobre a porcentagem de células com membrana plasmática e acrossomal íntegra, variáveis analisadas pelo CASA (VAP, VSL, VCL, ALH, BCF, STR, LIN, MOT, PROG, RAP, MED, SLOW, STATIC), e atividade mitocondrial (DAB I atividade total, DAB II atividade alta, DAB III atividade baixa, DAB IV atividade nula) no sêmen criopreservado de cães - São Paulo - 2012

Tabela 21 - Comparação entre diluidor a base de lecitina de soja em diferentes apresentações (8160, FP40, Solec F) e concentrações $(0,01 \%, 0,05 \%$ e $0,1 \%)$ e o diluidor a base de gema de ovo na atividade mitocondrial (DAB II atividade alta, DAB III atividade baixa, DAB IV atividade nula) e nas variáveis analisadas pelo CASA (VAP, VCL, ALH, BCF, STR, LIN, MOT, SLOW), em amostras de sêmen de cães refrigeradas pré criopreservação (2 horas, $5^{\circ} \mathrm{C}$ ) - São Paulo - 2012

Tabela 22 - Comparação entre diluidor a base de lecitina de soja em diferentes apresentações (8160, FP40, Solec F) e concentrações $(0,01 \%, 0,05 \%$ e $0,1 \%)$ e o diluidor a base de gema de ovo na atividade mitocondrial (DAB II atividade alta, DAB III atividade baixa, DAB IV atividade nula) e nas variáveis analisadas pelo CASA (VAP, VCL, ALH, BCF, STR, LIN, MOT, SLOW), em amostras de sêmen de cães refrigeradas após a adição da fração do diluidor contendo glicerol (pós-glicerolização) pré criopreservação (2 horas refrigeração +1 hora glicerolização, $5^{\circ} \mathrm{C}$ ) - São Paulo - 2012 
Tabela 23 - Comparação entre diluidor a base de lecitina de soja em diferentes apresentações (8160, FP40, Solec F) e concentrações $(0,01 \%, 0,05 \%$ e $0,1 \%)$ e o diluidor a base de gema de ovo na atividade mitocondrial (DAB II atividade alta, DAB III atividade baixa, DAB IV atividade nula), nas variáveis analisadas pelo CASA (VAP, VCL, ALH, BCF, STR, LIN, MOT, SLOW) e na susceptibilidade ao estresse oxidativo (TBARS), em amostras de sêmen de cães criopreservadas após o descongelamento - São Paulo - 2012

Tabela 24 - Efeito dos momentos da criopreservação (pós-refrigeração, pósglicerolização e pós-descongelação) na atividade mitocondrial (DAB II: atividade alta; DAB III: atividade baixa; DAB IV: atividade nula) e nas variáveis analisadas pelo CASA (VAP, VCL, ALH, BCF, STR, LIN, MOT, SLOW), em amostras de sêmen de cães criopreservadas em diluidor a base de gema de ovo - São Paulo 2012

Tabela 25 - Efeito dos momentos da criopreservação (pós-refrigeração, pósglicerolização e pós-descongelação) na atividade mitocondrial (DAB II: atividade alta; DAB III: atividade baixa; DAB IV: atividade nula) e nas variáveis analisadas pelo CASA (VAP, VCL, ALH, BCF, STR, LIN, MOT, SLOW), em amostras de sêmen de cães criopreservadas em diluidor a base de lecitina de soja 8160 0,01\%

- São Paulo - 2012

Tabela 26 - Efeito dos momentos da criopreservação (pós-refrigeração, pósglicerolização e pós-descongelação) na atividade mitocondrial (DAB II: atividade alta; DAB III: atividade baixa; DAB IV: atividade nula) e nas variáveis analisadas pelo CASA (VAP, VCL, ALH, BCF, STR, LIN, MOT, SLOW), em amostras de sêmen de cães criopreservadas em diluidor a base de lecitina de soja 8160 0,05\% - São Paulo - 2012

Tabela 27 - Efeito dos momentos da criopreservação (pós-refrigeração, pósglicerolização e pós-descongelação) na atividade mitocondrial (DAB II: atividade alta; DAB III: atividade baixa; DAB IV: atividade nula) e nas variáveis analisadas pelo CASA (VAP, VCL, ALH, BCF, STR, LIN, MOT, SLOW), em amostras de sêmen de cães criopreservadas em diluidor a base de lecitina de soja 8160 0,1\% São Paulo - 2012.

Tabela 28 - Efeito dos momentos da criopreservação (pós-refrigeração, pósglicerolização e pós-descongelação) na atividade mitocondrial (DAB II: atividade alta; DAB III: atividade baixa; DAB IV: atividade nula) e nas variáveis analisadas pelo CASA (VAP, VCL, ALH, BCF, STR, LIN, MOT, SLOW), em amostras de sêmen de cães criopreservadas em diluidor a base de lecitina de soja FP40 0,01\% - São Paulo - 2012 
Tabela 29 - Efeito dos momentos da criopreservação (pós-refrigeração, pósglicerolização e pós-descongelação) na atividade mitocondrial (DAB II: atividade alta; DAB III: atividade baixa; DAB IV: atividade nula) e nas variáveis analisadas pelo CASA (VAP, VCL, ALH, BCF, STR, LIN, MOT, SLOW), em amostras de sêmen de cães criopreservadas em diluidor a base de lecitina de soja FP40 0,05\% - São Paulo - 2012

Tabela 30 - Efeito dos momentos da criopreservação (pós-refrigeração, pósglicerolização e pós-descongelação) na atividade mitocondrial (DAB II: atividade alta; DAB III: atividade baixa; DAB IV: atividade nula) e nas variáveis analisadas pelo CASA (VAP, VCL, ALH, BCF, STR, LIN, MOT, SLOW), em amostras de sêmen de cães criopreservadas em diluidor a base de lecitina de soja FP40 0,1\% - São Paulo - 2012

Tabela 31 - Efeito dos momentos da criopreservação (pós-refrigeração, pósglicerolização e pós-descongelação) na atividade mitocondrial (DAB II: atividade alta; DAB III: atividade baixa; DAB IV: atividade nula) e nas variáveis analisadas pelo CASA (VAP, VCL, ALH, BCF, STR, LIN, MOT, SLOW), em amostras de sêmen de cães criopreservadas em diluidor a base de lecitina de soja Solec $\mathrm{F}$ 0,01\% - São Paulo - 2012

Tabela 32 - Efeito dos momentos da criopreservação (pós-refrigeração, pósglicerolização e pós-descongelação) na atividade mitocondrial (DAB II: atividade alta; DAB III: atividade baixa; DAB IV: atividade nula) e nas variáveis analisadas pelo CASA (VAP, VCL, ALH, BCF, STR, LIN, MOT, SLOW), em amostras de sêmen de cães criopreservadas em diluidor a base de lecitina de soja Solec $F$ 0,05\% - São Paulo - 2012.

Tabela 33 - Efeito dos momentos da criopreservação (pós-refrigeração, pósglicerolização e pós-descongelação) na atividade mitocondrial (DAB II: atividade alta; DAB III: atividade baixa; DAB IV: atividade nula) e nas variáveis analisadas pelo CASA (VAP, VCL, ALH, BCF, STR, LIN, MOT, SLOW), em amostras de sêmen de cães criopreservadas em diluidor a base de lecitina de soja Solec $F$ 0,1\% - São Paulo - 2012

Tabela 34 - Comparação entre diluidor a base de lecitina de soja em diferentes apresentações (8160, FP40, Solec F) e concentrações $(0,01 \%, 0,05 \%$ e $0,1 \%)$ e o diluidor a base de gema de ovo nas porcentagens de células com membranas plasmática e acrossomal íntegras, na atividade mitocondrial (DAB I atividade total) e nas variáveis analisadas pelo CASA (VSL, PROG, RAP, MED, STATIC ) em amostras de sêmen de cães criopreservadas São Paulo - 2012. 
Tabela 35 - Efeito dos momentos da criopreservação (pós-refrigeração, pósglicerolização e pós-descongelação) nas porcentagens de células com membranas plasmática e acrossomal íntegras, na atividade mitocondrial (DAB I atividade total) e nas variáveis analisadas pelo CASA (VSL, PROG, RAP, MED, STATIC), em amostras de sêmen de cães criopreservadas em diluidores a base de lecitina de soja e gema de ovo - São Paulo - 2012 


\section{LISTA DE QUADROS}

Quadro 1 - Abreviações e significados das variáveis analisadas pelo CASA...........46

Quadro 2 - Composição das lecitinas de soja utilizadas nos experimentos ..............90 


\section{SUMÁRIO}

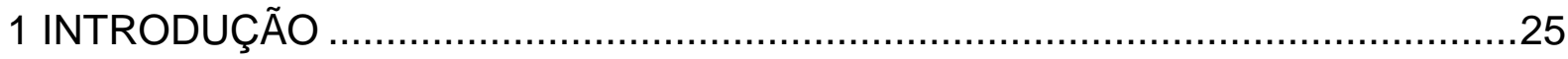

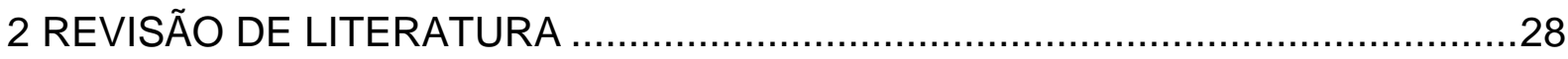

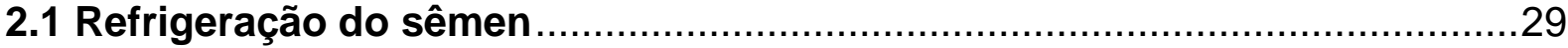

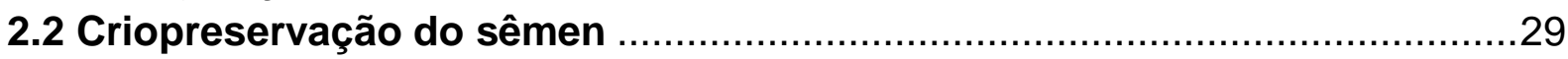

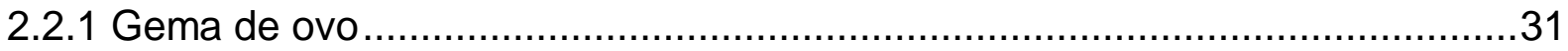

2.2 .2 Lecitina de soja......................................................................... 33

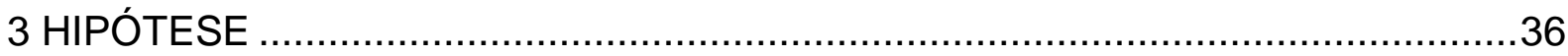

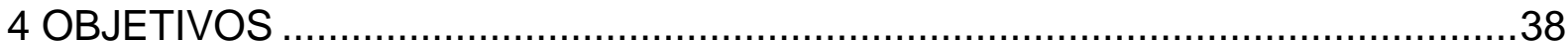

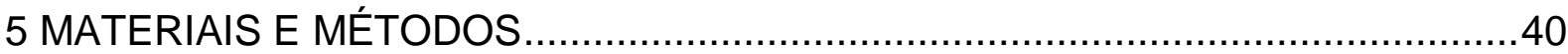

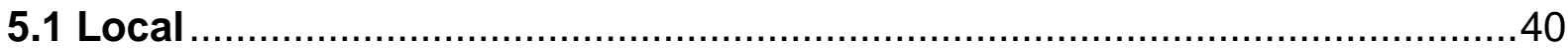

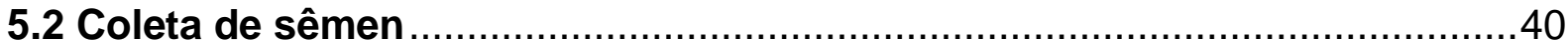

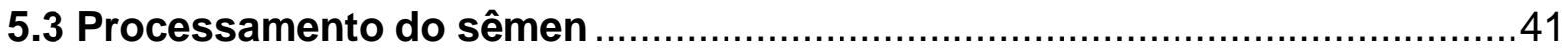

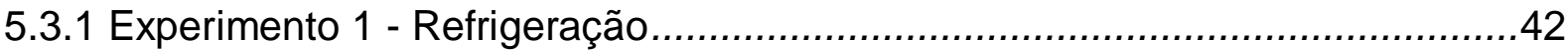

5.3.2 Experimento 2 - Criopreservação .......................................................... 43

5.3.2.1 Descongelação do sêmen .........................................................44

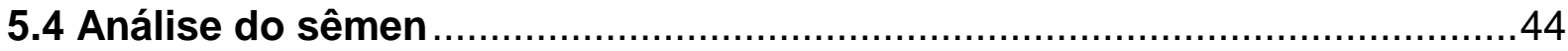

5.4.1 Análise computadorizada do movimento espermático ..............................45

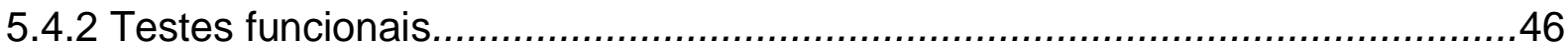

5.4.2.1 Avaliação da integridade da membrana acrossomal ..................................46

5.4.2.2 Avaliação da integridade da membrana plasmática .................................47

5.4.2.3 Avaliação da atividade mitocondrial .................................................. 47

5.4.2.4 Resistência ao estresse oxidativo ..........................................................48

5.4.2.5 Ensaio da estrutura da cromatina espermática .......................................49

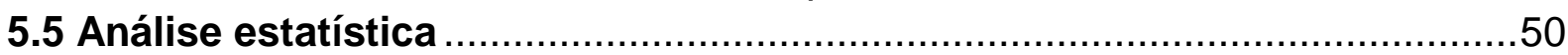

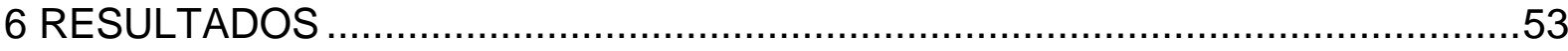

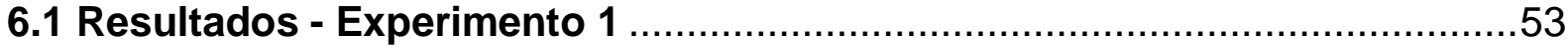

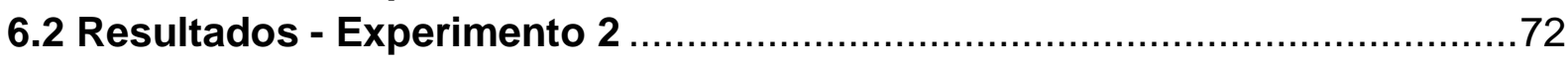

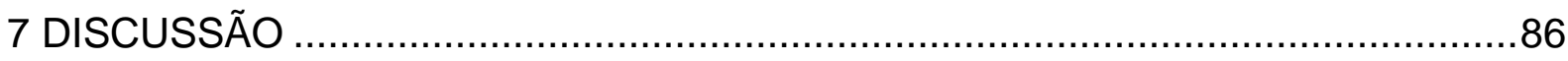

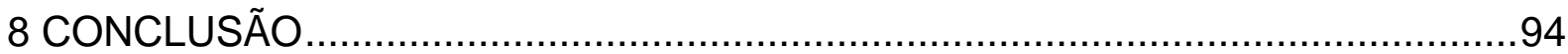

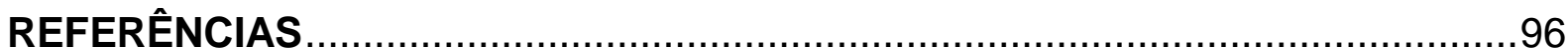




\section{INTRODUÇÃO}

Em todo o mundo, muitas pessoas mantêm animais de estimação, e os cães, como uma das espécies preferidas, têm desempenhado um papel importante na sociedade humana (JANG; KIM; LEE, 2010). Eles são utilizados pelo homem em diversas situações, como cães de guarda, guia, caça, pastoreio e principalmente como animais de companhia, o que os torna muitas vezes integrantes da família (ELLEGREN, 2005). Por sua semelhança genética, os cães também servem como modelo experimental para espécies ameaçadas de extinção e seres humanos.

Ao longo dos séculos, através da domesticação, o ser humano realizou uma seleção artificial dos cães por suas aptidões, características físicas ou tipos de comportamento, o que resultou numa grande diversidade de raças caninas. $E$, para manter esses padrões até os dias de hoje, métodos que possam perpetuar as raças vêm sendo uma busca frequente dos criadores (THOMASSEN; FARSTAD, 2009).

A biotecnologia da reprodução em pequenos animais tem sido amplamente utilizada e desenvolvida nos últimos anos. Este avanço levou à necessidade do aperfeiçoamento das técnicas utilizadas na inseminação artificial, como a criopreservação do sêmen (THOMASSEN; FARSTAD, 2009), que tem se tornado uma ferramenta valiosa por permitir a troca de material genético de alto valor zootécnico entre distantes localidades e seu armazenamento por períodos indefinidos (SILVA, 2007).

No entanto, poucas alterações nos protocolos de refrigeração e criopreservação têm sido observadas desde 0 desenvolvimento da técnica (WATSON, 1995). Este método ainda causa uma grande perda na viabilidade espermática pós-descongelação e por isso se faz necessário um estudo aprofundado de todos os procedimentos utilizados.

A gema de ovo é um dos principais componentes nos diluidores rotineiramente utilizados para a refrigeração e criopreservação do sêmen em várias espécies, inclusive nos cães (WITTE et al., 2009). Porém, por ser um produto de origem animal, a gema de ovo apresenta diversas desvantagens, dentre as quais a falta de padronização e o risco de contaminação (AIRES et al., 2003; BECCAGLIA; 
ANASTASI; LUVONI, 2009; REED et al., 2009; ZHANG et al., 2009; KMENTA et al., 2011; PAPA et al., 2011), o que, por questões sanitárias, causa uma grande preocupação aos países, pelo risco de introdução de doenças.

Sendo assim, a busca de diluidores alternativos que possam vir a substituir a gema de ovo é constante e de suma importância. E a lecitina de soja, por ser um produto de origem vegetal de composição similar ao ovo, pode ser uma boa alternativa. 
Revisão de Literatura 


\section{REVISÃO DE LITERATURA}

A biotecnologia da reprodução na espécie canina ao longo dos anos assumiu um papel importante, colaborando em programas de melhoramento genético de raças, principalmente com o desenvolvimento e aperfeiçoamento das técnicas de inseminação artificial. Assim, técnicas envolvendo a refrigeração e a criopreservação do sêmen estão sendo estudadas e novas fronteiras se abrem para a criação de cães, permitindo a troca de material genético de alto valor entre localidades distantes e o armazenamento desse material por períodos indefinidos (BUCAK et al., 2007; SILVA, 2007).

Atualmente o mercado que envolve os animais de companhia tem sido ampliado de maneira exponencial devido ao papel que os pequenos animais assumiram na sociedade. Deste modo, a procura por programas de inseminação artificial (IA) em cães tem aumentado assim como a necessidade da melhora na qualidade dos métodos empregados. No final do século 18, Lázaro Spallanzani realizou a primeira IA notificada cientificamente, utilizando sêmen fresco obtido da vagina de uma cadela acasalada por monta natural e depositando-o na vagina de outra cadela com uma seringa, obtendo como resultado o nascimento de 3 filhotes (JOHNSTON; KUSTRITZ; OLSON, 2001). Após um longo vazio científico, Harrop, em 1954, descreveu a primeira IA com sêmen de cães refrigerado a $4^{\circ} \mathrm{C}$. E, após 15 anos, Seager (1969) realizou a primeira inseminação artificial com sucesso utilizando sêmen criopreservado de cão, resultando em 2 filhotes.

A IA tem sido utilizada como um método alternativo quando não há possibilidade de ser realizada monta natural, devido a problemas anatômicos, comportamentais e sanitários ou ainda quando se utiliza sêmen refrigerado ou criopreservado. Apresentando resultados de fertilidade similares aos obtidos por monta natural, no caso de sêmen fresco, que seria em torno de 85\%. No sêmen refrigerado os resultados são geralmente inferiores quando comparados com sêmen fresco, aproximadamente de $70 \%$, e a taxa de sucesso quando utilizado sêmen criopreservado é ainda bastante heterogênea, em torno de 50\% (SILVA; CARDOSO; SILVA, 2003). 


\subsection{Refrigeração do sêmen}

A utilização de sêmen refrigerado tem vantagens como o seu menor custo, diminuição do estresse dos animais durante o transporte, redução dos riscos de doenças, permitindo que os criadores utilizem o sêmen de cães geneticamente superiores dentro e entre países (MICHAEL et al., 2010).

Estudos demonstraram que as taxas de sucesso da IA são maiores para o sêmen refrigerado em comparação ao sêmen criopreservado, quando utilizados os mesmos métodos para a sincronização do ciclo estral e para IA (SHAHIDUZZAMAN; LINDE-FORSBERG, 2007). Outras vantagens da refrigeração em relação à criopreservação incluem a facilidade do procedimento e do transporte, baixo custo, simplicidade do regulamento para importação e exportação. Devido a estes fatos, o uso e o embarque internacional de sêmen refrigerado na criação de cães têm se tornado cada dia mais frequentes (PONGLOWHAPAN; ESSEN-GUSTAVSSON; LINDE FORSBERG, 2004).

Apesar das diversas vantagens, uma desvantagem para a utilização do sêmen refrigerado é o tempo limitado de sobrevivência do espermatozóide, que geralmente é de 1 a 4 dias. Portanto, o transporte deste sêmen para o seu destino requer um planejamento cuidadoso para que os espermatozóides permaneçam férteis e estejam disponíveis no dia ideal do ciclo estral da cadela, para ser realizada a IA (PONGLOWHAPAN; ESSEN-GUSTAVSSON; LINDE FORSBERG, 2004). É possível o sêmen ser mantido refrigerado por até 2 dias a $5^{\circ} \mathrm{C}$ e posteriormente ser criopreservado, sem apresentar danos na vitalidade e longevidade após a descongelação (HERMANSSON; LINDE FORSBERG, 2006).

\subsection{Criopreservação do sêmen}

A demanda para a criopreservação de sêmen tem aumentado mundialmente entre os criadores e principalmente durante grandes exposições, visando manter uma linhagem de criação após um longo período de tempo, permitindo a propagação 
post mortem do material genético e minimizando os custos de manter ou transportar animais vivos (THOMASSEN; FARSTAD, 2009).

Um protocolo de preservação adequado deve manter o potencial fertilizante das células espermáticas, que, ao final de todo o processo, deverão apresentar a vitalidade necessária para atingir o local da fertilização e estarem aptas a concluir o estágio final da maturação espermática, que consiste na capacitação e reação acrossômica, possibilitando a fecundação do oócito (WATSON, 1995).

A pesquisa sobre a preservação do sêmen tem uma longa história, ao redor de dois séculos, mas a maioria dos trabalhos data das últimas quatro décadas. $O$ problema até os dias de hoje continua sendo que, mesmo utilizando a melhor técnica de preservação, a taxa de sobrevivência após a descongelação se restringe ao redor de 50\% da população de espermatozóides (WATSON, 1995).

Para tentar evitar essa perda, diferentes pesquisas têm sido realizadas para testar diluidores e metódos de congelação (IGUER-OUADA; VERSTEGEN, 2001).

Um diluidor deve conter um substrato fonte de energia (glicose ou frutose), uma fonte de lipoproteína ou material de alto peso molecular para prevenir o choque frio (como a gema de ovo, leite ou lecitina de soja), substâncias iônicas ou não iônicas para manter uma pressão osmótica e pH adequados, e outros aditivos como enzimas e antibióticos (AIRES et al., 2003; FOROUZANFAR et al., 2010).

Para a criopreservação do sêmen utiliza-se, adicionado ao diluidor, um crioprotetor denominado glicerol, que é permeável na membrana celular, embora a base de suas propriedades crioprotetoras ainda não esteja completamente compreendida (AIRES et al., 2003). A necessidade do crioprotetor ocorre porque o processo de congelamento e descongelamento do sêmen pode ocasionar danos nas células espermáticas, resultando na morte celular. Estudos de literatura revelaram que mudanças bruscas de temperatura - tanto choque frio quanto quente - , a formação de gelo e a dissolução durante o processo de congelamento e descongelamento afetam a integridade morfológica das células (FOROUZANFAR et al., 2010).

Até o momento, nenhum método padronizado demonstrou ser ideal para todos os cães e ejaculados devido a variações intrínsecas nas propriedades que envolvem a sensibilidade osmótica das células espermáticas como também à 
variação da resposta ao processo de criopreservação, que pode ser imprevisível (EILTS, 2005).

\subsubsection{Gema de ovo}

A gema de ovo tem sido o componente mais utilizado em diluidores de sêmen canino, com o objetivo principal de proteger os espermatozóides do choque frio e perturbações durante o processo de congelamento e descongelamento (ABE et al., 2008). Porém, o mecanismo preciso através do qual ela auxilia na proteção dos espermatozóides ainda é desconhecido (MOUSSA et al., 2002).

Estudos indicam que a gema de ovo estabiliza a membrana do espermatozóide através de uma interação com as proteínas do plasma seminal, dificultando o efluxo excessivo de fosfolipídeos, mantendo a pressão coloidal e prevenindo a perda excessiva de cátions, regulando o fluxo de $\mathrm{Ca}^{2+}(\mathrm{KMENTA}$ et al., 2011). E também, que podem impedir a capacitação prematura causada pelo choque frio (KMENTA et al., 2011) e reduzir os efeitos tóxicos do plasma seminal, fornecendo substratos para neutralizar o peróxido de hidrogênio $\left(\mathrm{H}_{2} \mathrm{O}_{2}\right)$ produzido pelo sêmen durante o seu metabolismo (PAPA et al., 2011).

Diversos trabalhos científicos indicam que pequenas frações da gema compostas por lipoproteínas de baixa densidade (LDL) poderiam ser, em grande parte, responsáveis pela resistência ao choque frio (HOLT, 2000; MANJUNATH et al., 2002; MOUSSA et al., 2002; BERGERON et al., 2004).

Acredita-se que em bovinos as LDLs interagem com proteínas de baixo peso molecular presentes no plasma seminal (família das BSPs) e que por sua vez atuam na potencialização de moléculas capacitantes, como as proteínas de alto peso molecular e glicosaminoglicanos. As BSPs agem diretamente na desestabilização da membrana plasmática pela remoção direta de fosfolipídeos e colesterol, atuação que é minimizada através da interação protéica com as LDLs. Desse modo, reduzindo o efeito deletério das proteínas do plasma seminal nas membranas espermáticas, as lipoproteínas da gema de ovo podem oferecer proteção aos espermatozóides (MANJUNATH et al., 2002). 
Nos últimos anos têm surgido diversos argumentos contra a utilização da gema de ovo na base de diluidores utilizados na criopreservação de sêmen (AIRES et al., 2003). Dentre estes argumentos estão a grande variação na composição, dificultando a sua padronização, e o risco potencial de contaminação do diluidor se houver contaminantes no produto in natura (BITTENCOURT et al., 2008), além da produção de endotoxinas que podem causar danos na capacidade de fertilização dos espermatozóides, podendo levar à disseminação de doenças (AIRES et al., 2003).

Bousseau et al. (1998) realizaram uma série de análises microbiológicas, quantitativas e qualitativas, em três tipos de diluidores de sêmen comerciais para bovinos com a adição de gema de ovo, leite ou com lecitina de soja. Foi observado que todas as amostras analisadas $(n=17)$ dos diluidores contendo produtos de origem animal, mesmo adicionadas de antibióticos de amplo espectro (penicilina, estreptomicina, lincomicina, gentamicina, tilosina, espectinomicina), apresentaram uma contaminação moderada (10 - $60 \mathrm{UFC} / \mathrm{ml})$ de agentes bacterianos e em alguns casos associada ao mycoplasma. Porém nenhuma contaminação foi observada nos seis lotes examinados do diluidor contendo lecitina de soja.

Como consequência direta, a maioria dos países teme o risco de introdução de doenças exóticas veiculadas através de produtos de origem animal (AIRES et al., 2003). Além do impacto na comercialização de sêmen, a utilização de produtos de origem animal influencia significantemente a criopreservação de sêmen humano. Os diluidores utilizados atualmente para essa finalidade utilizam a gema de ovo, o que, por razões sanitárias, representa um perigo para a disseminação de zoonoses.

Os diversos aspectos negativos, principalmente os sanitários, relacionados à utilização da gema de ovo tornaram a busca por diluidores alternativos, como os produtos de origem vegetal, um fator de extrema importância e essencial para a criopreservação de sêmen animal e humano (FOROUZANFAR et al., 2010). Nesse sentido, a soja tem assumido posição de destaque como possível substituto aos produtos de origem animal. 


\subsubsection{Lecitina de soja}

A soja (Glycine max), planta lendária conhecida na China há mais de 5000 anos, descrita na obra médica de She-non (3000 A.C.), em vários países do Oriente é um alimento básico. Do Oriente, onde se difundiu intensamente, propagou-se para o Ocidente e a utilidade de suas sementes - para a extração do óleo comestível, para os mais variados pratos, para a fabricação de leite e de queijo, bem como o emprego de sua planta como forragem para animais e como adubo verde - , representa um valioso investimento na economia de numerosas nações (MASSOTI, 1964).

A lecitina de soja é uma mistura complexa de fosfolipídeos, triglicérides e outras substâncias derivadas de vários processos de refinamento do óleo de soja. Devido à sua disponibilidade abundante e excelentes propriedades, incluindo sua ação emulsificante, cor e sabor, torna-se um importante aditivo industrial (NASIR; BERNARDS; CHARPENTIER, 2007).

Os fosfolipídeos, principalmente a fosfatidilcolina, fosfatidiletilenoamina, fosfatidilinositol e ácido fosfatídico são os principais componentes da lecitina de soja bruta. É possível encontrar muitas aplicações dos fosfolipídeos nas indústrias farmacêutica, cosmética e alimentar como um efetivo emulsificante biocompatível, estabilizante, biosurfactante e antioxidante (NASIR; BERNARDS; CHARPENTIER, 2007).

A lecitina de soja possui uma fração de lipoproteína de baixa densidade, assim como a da gema de ovo, com a função de proteger a integridade da membrana fosfolipídica durante a criopreservação (FOROUZANFAR et al., 2010), e, por ser de origem vegetal, proporciona diversas vantagens, entre elas a padronização dos componentes e a eliminação dos riscos de contaminação (FUKUI et al., 2008).

Alguns estudos têm sido realizados sobre o efeito da lecitina de soja na refrigeração e criopreservação de sêmen em diferentes espécies, como ovinos (FUKUl et al., 2008; DE PAZ et al., 2010; FOROUZANFAR et al., 2010), bovinos (AIRES et al., 2003), cães (BECCAGLIA et al., 2009; BECCAGLIA; ANASTASI; LUVONI, 2009; KMENTA et al., 2011), equinos (AURICH; SEEBER; MULLER- 
SCHLOSSER, 2007; PAPA et al., 2011), suínos (ZHANG et al., 2009) e humanos (REED et al., 2009), apresentando resultados significativos em comparação com a gema de ovo.

Os estudos demonstram similaridade nos resultados quando comparados diluidores com lecitina de soja e gema de ovo. A lecitina mantém a motilidade espermática e a integridade da membrana plasmática, de forma similar ao que ocorre com os diluidores contendo gema de ovo (PAPA et al., 2011). Segundo Reed et al. (2009), é possível substituir a gema de ovo pela lecitina de soja na criopreservação do sêmen sem alterar a motilidade, morfologia, integridade de DNA e capacidade fecundante em humanos. Outras aplicações similares podem incluir o meio de transporte para o sêmen e o meio utilizado durante a capacitação dos espermatozóides antes da injeção intracitoplasmática (ICSI) ou fertilização in vitro convencional (REED et al., 2009)

No entanto, existem estudos em bovinos (DELEEUW et al., 1993; CELEGHINI et al., 2008), nos quais o diluidor a base de gema de ovo demonstrou ser mais eficiente na congelação do sêmen, e em equinos (PAPA et al., 2011) o diluidor a base de lecitina apresentou como resultado uma redução na fertilidade, indicando que ainda são necessários mais estudos para esclarecimento.

Desse modo, os diluidores sem os componentes de origem animal podem se tornar uma alternativa segura para a conservação e disseminação do material genético de animais de alto valor (AIRES et al., 2003; BITTENCOURT et al., 2008). 
Hipótese 


\section{HIPÓTESE}

A lecitina de soja pode substituir a gema de ovo na refrigeração e criopreservação do sêmen de cães. 
Objetivos 


\section{OBJETIVOS}

Os objetivos do presente estudo são:

- Comparar diluidores a base de lecitina de soja com diluidor a base de gema de ovo na refrigeração e criopreservação do sêmen de cães, utilizando diferentes concentrações e apresentações de lecitina.

- Avaliar qual a concentração ideal da lecitina de soja para obter um diluidor com resultados satisfatórios tanto na refrigeração quanto na criopreservação do sêmen.

- Analisar o tempo de viabilidade espermática sob refrigeração.

- Avaliar o potencial crioprotetor da lecitina em comparação com a gema de OVo.

- Viabilizar a utilização de um diluidor para sêmen de cães livre de produtos de origem animal. 
Materiais e Métodos 


\section{MATERIAIS E MÉTODOS}

O período experimental foi de dezembro de 2011 a maio de 2012, sendo as coletas de sêmen realizadas semanalmente.

\subsection{Local}

O presente estudo foi realizado nas instalações da Seção de Cães de Guerra do $2^{\circ}$ Batalhão de Polícia do Exército, latitude $23^{\circ} 30^{\prime} 25^{\prime \prime}$ S e longitude 4647'29" W, situado no município de Osasco, e nos Laboratórios de Andrologia e de Fecundação in vitro, Clonagem e Transgenia Animal, do Departamento de Reprodução Animal da Faculdade de Medicina Veterinária e Zootecnia da Universidade de São Paulo.

\subsection{Coleta de sêmen}

Para o estudo foram utilizados 12 cães militares de trabalho, das raças Rottweiler, Pastor Alemão, Pastor Belga Malinois e Doberman, com idade média de 4 anos e peso médio de $30 \mathrm{~kg}$, obtendo-se a fração rica do ejaculado através da manipulação digital.

Para cada um dos cães, imediatamente após a obtenção da amostra seminal, foi realizada análise macroscópica do sêmen (aspecto, cor, odor, mensuração do volume com a leitura direta do tubo graduado utilizado na coleta), detectando possíveis alterações como presença de urina, sangue, pus, sendo a amostra descartada na presença destas anormalidades. Seguiu-se a análise microscópica prévia do sêmen para a avaliação da motilidade e vigor espermático. Para tanto foi colocado $10 \mu \mathrm{l}$ de sêmen em uma lâmina e por cima a lamínula, ambas previamente aquecidas e mantidas em placa aquecedora $\left(37^{\circ} \mathrm{C}\right)$. A amostra foi observada no microscópio óptico de luz no aumento de 100 vezes. Para a avaliação da motilidade 
verificou-se o percentual de células móveis que apresentavam movimento retilíneo progressivo. Foi estabelecida como critério mínimo de qualidade para inclusão no "pool" motilidade total do sêmen superior a 70\%.

Não havendo nenhuma alteração na análise seminal dos cães, foi realizada a mistura integral de 2 ejaculados formando um "pool" de sêmen, considerado como unidade experimental. A formação dos "pools" era realizada de forma aleatória em relação aos cães de forma a diminuir as variações individuais.

Foi analisada a viabilidade do "pool" (motilidade e vigor) e retirada uma alíquota que foi diluída em solução de formol salino na concentração 1:20, para posteriormente ser realizada a análise de concentração espermática, sendo feita a contagem de células através de câmara hematocimétrica de Newbauer e a concentração expressa em milhões de espermatozóides por mililitro.

\subsection{Processamento do sêmen}

O presente estudo foi dividido em dois experimentos. O Experimento 1 constituiu-se na refrigeração do sêmen de cães por 120 horas, tratado com diluidores a base de lecitina de soja e gema de ovo, sendo as amostras avaliadas a cada 24 horas. No Experimento 2, foi realizada a criopreservação do sêmen, com os mesmos diluidores acrescidos de glicerol na segunda fração, sendo as análises realizadas nos tempos pós-refrigeração, pós-glicerolização e pós-descongelação (Figura 1). 
Figura 1 - Delineamento Experimental

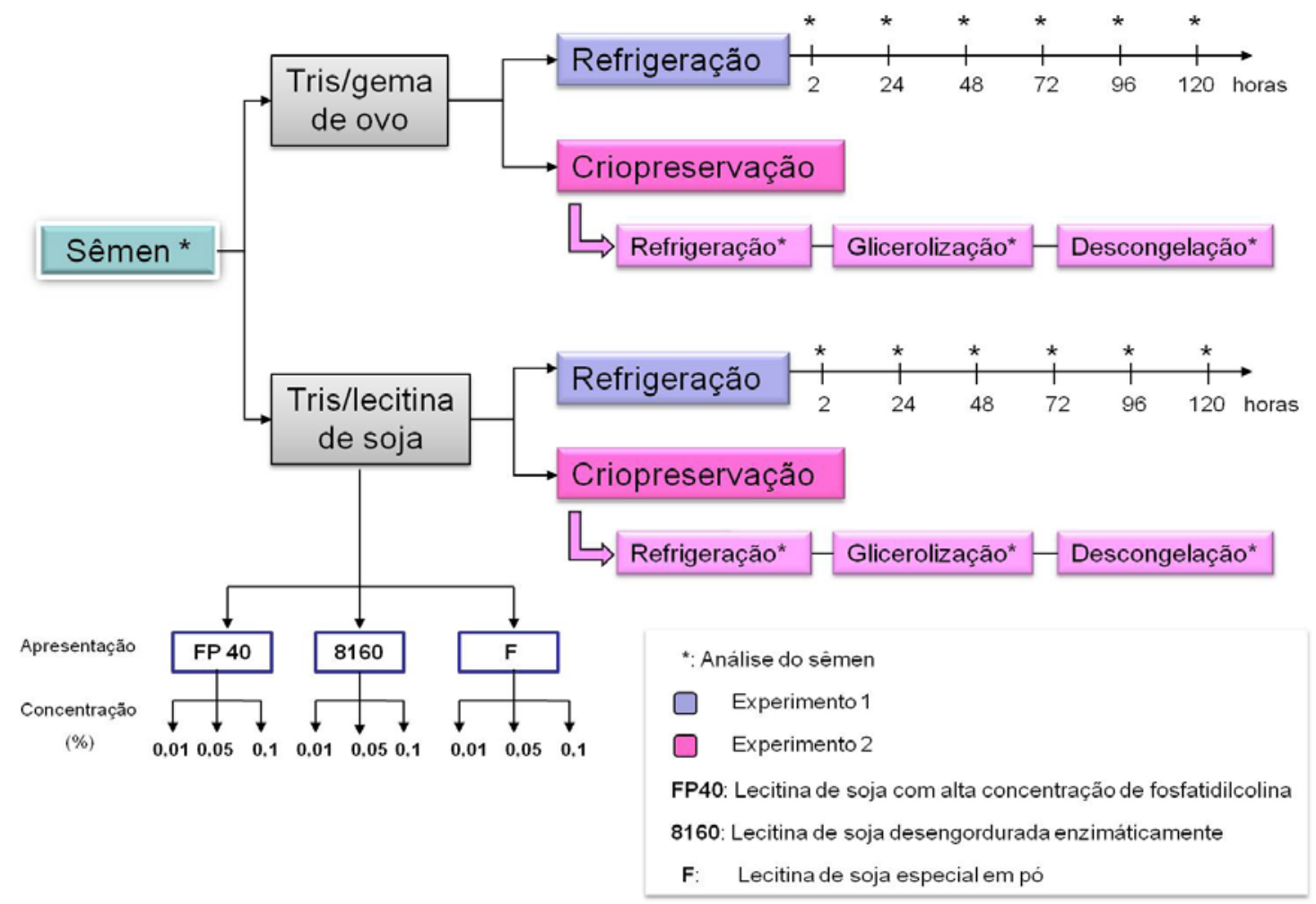

5.3.1 Experimento 1 - Refrigeração

Foram utilizados dez diluidores para a refrigeração do sêmen, sendo todos confeccionados em fração única isenta do crioprotetor glicerol.

- Tris - Gema de ovo (3,187g Tris; $1,781 \mathrm{~g}$ frutose; $1,316 \mathrm{~g}$ ácido cítrico; $25 \mu \mathrm{g} / \mathrm{ml}$ gentamicina; $20 \%$ gema de ovo).

- Tris - Lecitina de Soja (sendo a gema de ovo inteiramente substituída) foram testadas lecitinas em três diferentes apresentações: FP40 - lecitina de soja com alta concentração de fosfatidilcolina; a 8160 - lecitina de soja desengordurada enzimaticamente; e a Solec F - lecitina de soja especial em pó (Solae Company). E cada uma foi testada em três diferentes concentrações:

$$
\begin{array}{ll}
\checkmark & 0,01 \% \\
\checkmark & 0,05 \% \\
\checkmark & 0,1 \%
\end{array}
$$


Após as análises imediatas, cada "pool", num total de 6, foi dividido em 10 alíquotas iguais em criotubos de $3 \mathrm{ml}$, contendo previamente $2 \mathrm{ml}$ de diluidor, mantidos a $37^{\circ} \mathrm{C}$.

Todas as amostras foram acondicionadas em recipientes com água a $37^{\circ} \mathrm{C} \mathrm{e}$ colocadas em uma geladeira de transporte com temperatura constante de $5^{\circ} \mathrm{C}$ por 2 horas. Decorrido esse tempo, necessário para o sêmen atingir $5^{\circ} \mathrm{C}$, uma alíquota de sêmen foi retirada e as amostras foram laboratorialmente avaliadas, sendo a mensuração da motilidade feita através da análise computadorizada do movimento espermático (Computer Assisted Sperm Analyzer - CASA; Hamilton Thorne IVOS) e testes funcionais através de colorações específicas.

Estas análises foram repetidas nas amostras nos tempos 24 horas, 48 horas, 72 horas, 96 horas e 120 horas de refrigeração.

\subsubsection{Experimento 2 - Criopreservação}

Foram utilizados 10 diluidores para a criopreservação do sêmen, de formulação idêntica ao do Experimento 1, porém o total do volume do diluidor foi dividido em duas frações de volume igual. Em uma delas foi adicionado $10 \%$ de glicerol, para que na diluição final, na proporção de 1:1, a concentração fosse de $5 \%$.

O processo de criopreservação foi realizado pelo sistema de congelação lenta ou em duas etapas. Após as análises imediatas, cada "pool", sendo em um total de 7, foi dividido em 10 alíquotas iguais e completado com a fração sem glicerol (Fração A) previamente aquecida até 1,5ml. As mesmas foram acondicionadas em recipientes com água a $37^{\circ} \mathrm{C}$ e mantidas em refrigeração por 2 horas até atingirem $5^{\circ} \mathrm{C}$. Após este período foi retirada uma alíquota de sêmen para serem realizados testes convencionais e funcionais de avaliação de sêmen e então adicionado lentamente o mesmo volume de diluidor com glicerol (Fração B) e as amostras foram mantidas por mais 1 hora em refrigeração, sendo avaliadas novamente após esse período. 
Decorrido o período de glicerolização, as amostras foram envasadas em palhetas de 0,5ml, devidamente identificadas e vedadas com álcool polivinílico. Durante 20 minutos, foram expostas ao vapor de nitrogênio e, subsequentemente, submersas no nitrogênio líquido. A seguir foram colocadas em raques e transferidas rapidamente para as canecas do botijão contendo nitrogênio líquido e mantidas até a análise, que foi decorrida após um mês do procedimento de criopreservação.

\subsubsection{Descongelação do sêmen}

A descongelação das amostras foi realizada pela imersão de duas palhetas de cada diluidor em água a $37^{\circ} \mathrm{C}$ por 30 segundos. Após este período cada palheta foi seca com auxílio de um papel toalha e seccionada na extremidade em que foi vedada, sendo o sêmen transferido para um microtubo de plástico de $2 \mathrm{ml}$, para posterior avaliação.

\subsection{Análise do sêmen}

Foram analisadas as amostras refrigeradas nos diferentes períodos (Experimento 1) e as amostras submetidas à criopreservação nos momentos pósrefrigeração, pós-glicerolização e pós-descongelação (Experimento 2). A análise incluiu a avaliação da motilidade pela análise computadorizada do movimento espermático e a análise funcional da célula espermática. No Experimento 2 foi realizada a análise da resistência ao estresse oxidativo e o ensaio da estrutura da cromatina espermática apenas no tempo pós-descongelação. 
5.4.1 Análise computadorizada do movimento espermático

Após cada tempo, a amostra foi homogeneizada e $7 \mu l$ foram inseridos em uma câmara de contagem Leja previamente aquecida a $37^{\circ} \mathrm{C}$. Foram observados 5 campos aleatórios, resultando em uma média, que foi armazenada para posterior análise.

Os parâmetros de movimento espermático gerados pelo CASA (Hamilton Thorne IVOS) e analisados no experimento corresponderam à velocidade média de percurso (VAP, $\mu \mathrm{m} / \mathrm{s}$ ), velocidade retilínea (VSL, $\mu \mathrm{m} / \mathrm{s}$ ), velocidade curvilínea (VCL, $\mu \mathrm{m} / \mathrm{s}$ ) (Figura 2), amplitude do deslocamento lateral da cabeça (ALH, $\mu \mathrm{m})$, frequência de batimento cruzado (BCF, Hz), retilinearidade (STR, \%), linearidade (LIN, \%), motilidade (MOT, \%) e motilidade progressiva (PROG, \%) (Quadro 1).

Adicionalmente, os espermatozóides foram divididos em 4 grupos, baseandose na velocidade de movimento, que consistiram de: rápidos (RAP; VAP > $50 \mu \mathrm{m} / \mathrm{s}$; $\%$ ), médios (MED, $30 \mu \mathrm{m} / \mathrm{s}<$ VAP < $50 \mu \mathrm{m} / \mathrm{s}$; \%) lentos (SLOW; VAP < $30 \mu \mathrm{m} / \mathrm{s}$ ou VSL < $15 \mu \mathrm{m} / \mathrm{s} ; \%$ ) e espermatozóides imóveis (STATIC; \%).

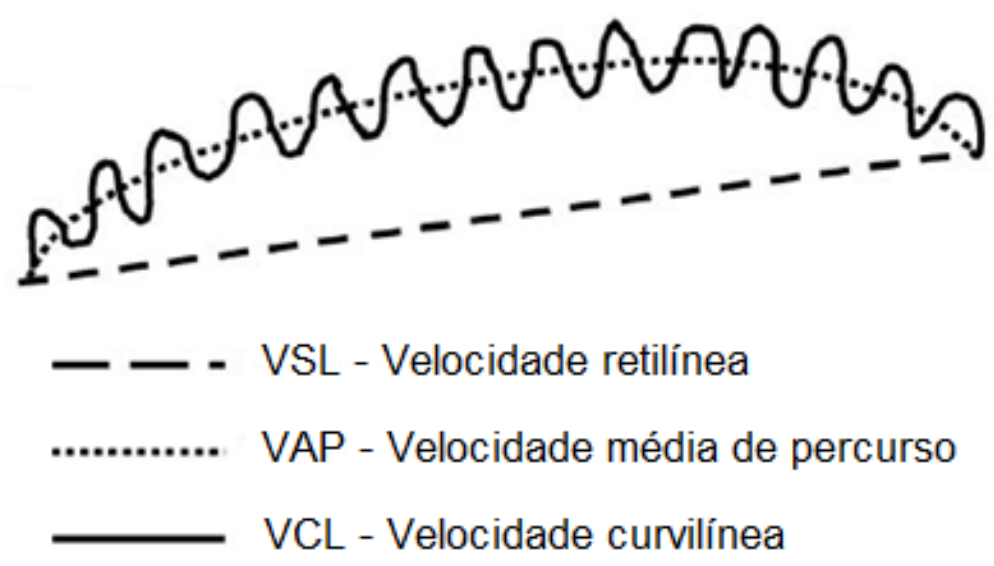

Fonte: Adaptado de GOOVAERTS et al., 2006. 
Quadro 1 - Abreviações e significados das variáveis analisadas pelo CASA

\begin{tabular}{|c|c|c|}
\hline & Terminologia & Significado \\
\hline VAP & Velocidade média de percurso $(\mu \mathrm{m} / \mathrm{s})$ & $\begin{array}{l}\text { Velocidade média do espermatozóide } \\
\text { considerando-se um caminho suavizado }\end{array}$ \\
\hline VSL & Velocidade retilínea $(\mu \mathrm{m} / \mathrm{s})$ & $\begin{array}{l}\text { Distância mínima que o espermatozóide percorre } \\
\text { durante o tempo entre duas avaliações (scans) }\end{array}$ \\
\hline VCL & Velocidade curvilínea ( $\mu \mathrm{m} / \mathrm{s})$ & $\begin{array}{l}\text { Média da velocidade espermática medida através } \\
\text { do percurso real percorrido }\end{array}$ \\
\hline ALH & $\begin{array}{l}\text { Amplitude do movimento } \\
\text { lateral da cabeça }(\mu \mathrm{m})\end{array}$ & $\begin{array}{l}\text { Comprimento médio da oscilação da cabeça do } \\
\text { espermatozóide }\end{array}$ \\
\hline BCF & $\begin{array}{l}\text { Frequência de batimento cruzado } \\
(\mathrm{Hz})\end{array}$ & $\begin{array}{l}\text { Frequência do movimento lateral, que faz com que } \\
\text { a cabeça do espermatozóide cruze o percurso em } \\
\text { ambas as direções }\end{array}$ \\
\hline STR & Retilinearidade (VSL/VAP, \%) & $\begin{array}{l}\text { Qualidade do movimento retilíneo suavizado } \\
\text { percorrido }\end{array}$ \\
\hline LIN & Linearidade (VSLNCL, \%) & Qualidade do movimento retilíneo real percorrido \\
\hline MOT & Motilidade (\%) & Porcentagem de células móveis \\
\hline PROG & Motilidade progressiva (\%) & $\begin{array}{l}\text { Porcentagem de células com motilidade } \\
\text { progressiva }\end{array}$ \\
\hline
\end{tabular}

Fonte: Adaptado de GOOVAERTS et al., 2006.

\subsubsection{Testes funcionais}

Os testes funcionais realizados foram a avaliação da integridade da membrana acrossomal, da membrana plasmática, da atividade mitocondrial, da resistência ao estresse oxidativo e da estrutura do DNA espermático.

\subsubsection{Avaliação da integridade da membrana acrossomal}

Para avaliar a integridade da membrana acrossomal foi utilizada a coloração simples Fast Green / Rosa Bengala (POPE; ZHANG; DRESSER, 1991). Para isso, a cada tempo, sobre uma lâmina de microscopia, uma alíquota de cada amostra $(5 \mu)$ 
foi adicionada a $5 \mu \mathrm{l}$ de corante, sendo mantida em uma mesa aquecida a $37^{\circ} \mathrm{C}$ durante 70 segundos.

Após a incubação, foram feitos esfregaços, que foram analisados em microscópio óptico convencional, sob aumento de 1000 vezes, em imersão. Foram contadas 100 células por lâmina, classificadas como:

- Acrossoma Íntegro: região acrossomal de coloração lilás a roxa, levemente mais escura que a região pós-acrossomal.

- Acrossoma Não Íntegro: região acrossomal de coloração rosa, levemente mais claro que a região pós-acrossomal.

\subsubsection{Avaliação da integridade da membrana plasmática}

Para avaliar a integridade da membrana plasmática foi utilizada a coloração Eosina - Nigrosina (E/N) técnica one step, que foi descrita por Campbell et al. (1956).

Uma alíquota de sêmen $(5 \mu l)$ foi misturada ao corante $(5 \mu l)$, em mesa aquecida a $37^{\circ} \mathrm{C}$, e realizado esfregaço sobre lâminas de microscopia. Sendo analisadas em microscópio óptico convencional, sob aumento de 1000 vezes, em imersão. Foram contadas 100 células por lâmina, classificadas como:

- Membrana Íntegra: coloração branca, pois não permitem a entrada do corante eosina, e há um contraste com o plano de fundo escuro da nigrosina.

- Membrana Não Íntegra: coloração rosa, devido à alteração na permeabilidade da membrana, a eosina consegue penetrar na célula.

\subsubsection{Avaliação da Atividade Mitocondrial}

Para determinar a atividade mitocondrial espermática, o método proposto por Hrudka (1987) foi utilizado, baseado na oxidação de 3’3 diaminobenzidina (DAB) 
pelo Complexo Citocromo C (incluindo o Citocromo C Oxidase, que possui um papel importante no processo de respiração celular e metabolismo energético das células) numa reação em cadeia em que o reagente é polimerizado e depositado nos locais aonde ocorre a reação (mitocôndria), podendo ser identificada pela sua coloração marrom, através de microscopia com contraste de fase.

Para a realização dessa técnica, foram incubados $25 \mu$ l de amostra no DAB (1mg/ml de PBS), na proporção 1:1, a $37^{\circ} \mathrm{C}$, por uma hora. Após a incubação, foram feitos esfregaços em lâmina de vidro, em uma sala escura, e estas fixadas em formol a 10\% durante 10 minutos. As lâminas então foram secas no ar sob proteção da luz.

Através de um microscópio com contraste de fase, sob aumento de 1000 vezes, em imersão, foram contadas 100 células e classificadas de acordo com o grau de coloração da peça intermediária em 4 classes:

- Classe I (DABI): células espermáticas com peça intermediária totalmente corada, indicando atividade mitocondrial total.

- Classe II (DABII): células espermáticas com mais da metade da peça intermediária corada, indicando alta atividade mitocondrial.

- Classe III (DABIII): células espermáticas com menos da metade da peça intermediária corada, indicando baixa atividade mitocondrial.

- Classe IV (DABIV): células espermáticas com a peça intermediária totalmente descorada, indicando ausência de atividade mitocondrial (atividade nula)

\subsubsection{Resistência ao estresse oxidativo}

A avaliação foi realizada de acordo com a metodologia descrita por Nichi et al. (2006). Esse método é baseado na reação de duas moléculas de ácido tiobarbitúrico (TBA) com uma molécula de malondialdeído (MDA), subproduto da peroxidação lipídica, em alta temperatura e pH ácido, resultando em um cromógeno de coloração rósea que pode ser quantificado através de um espectofotômetro.

Foi utilizado um sistema gerador de espécies reativas ao oxigênio (ROS) com posterior mensuração da concentração de espécies reativas ao ácido tiobarbitúrico 
(TBARS), mensurando-se, portanto, a susceptibilidade das células à peroxidação lipídica.

Para isso, uma alíquota de $200 \mu$ de sêmen foi retirada e o diluidor foi removido através de dupla centrifugação (1200G, durante 10 minutos) seguida de ressuspensão em solução tampão de fosfato (PBS).

Para a indução da peroxidação lipídica, foi adicionado o sistema gerador de ROS, formado pelo sulfato de ferro $(50 \mu \mathrm{l}, 4 \mathrm{mM})$ e ascorbato de sódio $(50 \mu \mathrm{l}, 20 \mathrm{mM})$. Em seguida, a mistura foi incubada por 1 hora e 30 minutos a $37^{\circ} \mathrm{C}$, com a tampa dos microtubos aberta.

Após esse período, foi adicionado 600 $\mu$ l de ácido tricloroacético a 10\% (TCA) gelado, proporção 1:2, e centrifugado ( ${ }^{*} 20817$ durante 15 minutos) a $15^{\circ} \mathrm{C}$, para a precipitação das proteínas. Foram retirados $800 \mu$ l do sobrenadante e transferidos para criotubos, os quais foram armazenados no freezer para posterior análise.

Posteriormente, no momento das análises, as amostras foram descongeladas, e adicionou-se 800 $\mu$ l de ácido tiobarbitúrico 1\% (TBA). Os criotubos foram incubados a $100^{\circ} \mathrm{C}$ por 15 minutos em banho-maria e resfriados imediatamente no gelo, com o intuito de parar a reação.

A concentração de TBARS foi então quantificada através da leitura em espectofotômetro (Ultrospec 3300 Pro), com comprimento de onda de 532nm. Os resultados foram comparados a uma curva padrão previamente estabelecida com malondialdeído e foram expressos em nanogramas de TBARS por $1 \times 10^{6}$ espermatozóides (ng/10 $\left.{ }^{6} \mathrm{sptz}\right)$.

\subsubsection{Ensaio da estrutura da cromatina espermática}

Nos últimos anos, tem sido crescente a atenção sobre a estrutura da cromatina espermática como um dos parâmetros que determinam a fertilidade masculina, demonstrando ser melhor marcador do que os parâmetros convencionais para a análise do sêmen (ZINI et al., 2001).

A cromatina espermática é uma estrutura compacta e organizada, que consiste em DNA e proteínas heterogêneas. A qualidade da estrutura da cromatina 
espermática é influenciada fortemente pela presença de protaminas (EVENSON et al., 1989), que no sêmen de cães, em contraste com outros mamíferos (ratos, hamster, cavalos e humanos), contém somente a protamina $\mathrm{P} 1$, o que torna a cromatina relativamente estável (LEE; CHO, 1999).

Existem vários métodos para detectar a integridade da cromatina espermática. Dentre eles, o ensaio da estrutura da cromatina espermática (SCSA) é considerado como o mais apropriado, fornecendo evidências da relação entre estrutura e função da cromatina espermática (EVENSON; LARSON; JOST, 2002).

O SCSA define a estrutura anormal da cromatina como um aumento da susceptibilidade do DNA espermático por uma denaturação induzida por ácido in situ (EVENSON; LARSON; JOST, 2002).

Para a realização deste teste, foi utilizada a metodologia proposta por Prinosilova (2012). Uma alíquota de sêmen, contendo 125.000 espermatozóides, foi separada e nela foram adicionados $500 \mu$ de PBS e centrifugados durante 2 minutos a 6000G. Após esse período, foi removido o sobrenadante, mantendo somente o pellet no menor volume possível, sendo armazenado a $-20^{\circ} \mathrm{C}$ para posterior análise.

No dia da leitura, as amostras foram descongeladas e diluídas em tampão TNE. Um volume de $25 \mu l$ da diluição foi incubado com $50 \mu l$ de solução detergenteácido (1\% de Triton X 100) por exatamente 30 segundos para induzir a denaturação do DNA. Posteriormente, $150 \mu$ da solução de laranja de acridina foram adicionados para intercalar as fitas simples (desnaturadas) ou duplas (nativa) de DNA, emitindo uma luz vermelha e verde, respectivamente.

As amostras foram analisadas utilizando o citômetro de fluxo Guava EasyCyte ${ }^{\circledR}$, com excitação de 488 nm e 15 mW.

\subsection{Análise Estatística}

Os dados obtidos foram analisados através do programa SAS System for Windows (SAS, 2000).

Através do aplicativo Guided Data Analisys, os dados foram testados quanto à normalidade dos resíduos (distribuição normal) e homogeneidade das variâncias. 
Caso não obedecessem a estas premissas, seriam transformados (logaritmo na base 10 - $\log _{10} X$; Raiz quadrada - RQ X; Quadrado - $X^{2}$ ) e se a normalidade não fosse obtida, empregaria-se, então, o procedimento NPAR1WAY de análise de variância não paramétrica. Para a avaliação do efeito dos tempos de refrigeração (Experimento 1; 2, 24, 48, 72, 96 e 120 horas) ou de criopreservação (Experimento 2; pós-refrigeração, pós-glicerolização, pós-descongelação) dos diferentes diluidores (OVO; 8160, FP40 e Solec F nas concentrações 0,01\%, 0,05\% e 0,1\%) e da interação entre tempos e diluidores foi utilizado o PROC MIXED de medidas repetidas no tempo. Na presença de interação significante, foi avaliado o efeito dos tempos em cada diluidor e dos diluidores em cada tempo. Caso não houvesse interação significante, seriam avaliados os efeitos principais de tempos e diluidores separadamente. Para estas análises era utilizado o teste Least Significant Differences (LSD).

Para descrição dos resultados, foram empregadas as médias e seus respectivos erros padrões (média \pm erro padrão da média) dos dados originais e os níveis de significância $(p)$ dos dados originais, quando obedecessem às premissas; dos dados transformados, quando necessária a transformação; e dos dados analisados através da análise não paramétrica, quando não obedecessem às premissas e não houvesse transformações possíveis.

O nível de significância utilizado para rejeitar HO (hipótese de nulidade) foi de $5 \%$, isto é, para um nível de significância menor que 0,05 , considerou-se que ocorreram diferenças estatísticas entre os diferentes tempos e diluidores. 
Resultados 


\section{RESULTADOS}

Os resultados do presente estudo foram divididos em duas seções referentes aos experimentos realizados.

\subsection{Resultados - Experimento 1}

Foram observadas interações significativas $(p<0,05)$ entre tempo e diluidor para VAP, VSL, VCL, ALH, BCF, MOT, PROG, RAP, MED, STATIC, DABI, DABII, DABIII, DABIV (Tabela 1). Essas variáveis foram então avaliadas quanto ao efeito do diluidor em cada tempo (Tabelas 2 a 7) e quanto ao efeito do tempo em cada diluidor (Tabelas 8 a 17). As variáveis em que não foram observadas interações significantes (Membrana, Acrossoma, STR, LIN, SLOW, TBARS, SCSA) foram avaliadas quanto ao diluidor (Tabela 18) e ao tempo (Tabela 19), separadamente. 
Tabela 1 - Probabilidades dos efeitos do tempo de refrigeração, diluidor e da interação tempo * diluidor sobre a porcentagem de células com membrana plasmática e acrossomal íntegra, variáveis analisadas pelo CASA (VAP, VSL, VCL, ALH, BCF, STR, LIN, MOT, PROG, RAP, MED, SLOW, STATIC), susceptibilidade ao estresse oxidativo (TBARS), atividade mitocondrial (DAB I, atividade total; DAB II, atividade alta; DAB III, atividade baixa; DAB IV atividade nula) e integridade do DNA (ensaio da estrutura da cromatina espermática - SCSA) no sêmen refrigerado de cães - São Paulo - 2012

\begin{tabular}{lccc} 
& Diluidor & Tempo & $\begin{array}{c}\text { Diluidor } \\
\text { Tempo }\end{array}$ \\
\hline MEMBRANA (\%) & $<0,0001$ & $<0,0001$ & 0,9252 \\
ACROSSOMA (\%) & $<0,0001$ & 0,0001 & 0,9997 \\
VAP $(\mu \mathrm{m} / \mathrm{s})$ & $<0,0001$ & $<0,0001$ & $<0,0001$ \\
VSL $(\mu \mathrm{m} / \mathrm{s})$ & $<0,0001$ & $<0,0001$ & 0,0050 \\
VCL $(\mu \mathrm{m} / \mathrm{s})$ & $<0,0001$ & $<0,0001$ & $<0,0001$ \\
ALH $(\mu \mathrm{m} / \mathrm{s})$ & $<0,0001$ & $<0,0001$ & $<0,0001$ \\
BCF $(\mathrm{Hz})$ & $<0,0001$ & 0,0102 & 0,0002 \\
STR $(\%)$ & $<0,0001$ & $<0,0001$ & 0,2059 \\
LIN $(\%)$ & $<0,0001$ & 0,0005 & 0,5351 \\
MOT (\%) & $<0,0001$ & $<0,0001$ & $<0,0001$ \\
PROG (\%) & $<0,0001$ & $<0,0001$ & $<0,0001$ \\
RAP (\%) & $<0,0001$ & $<0,0001$ & $<0,0001$ \\
MED (\%) & $<0,0001$ & $<0,0001$ & $<0,0001$ \\
SLOW $(\%)$ & $<0,0001$ & 0,0040 & 0,3458 \\
STATIC $(\%)$ & $<0,0001$ & $<0,0001$ & $<0,0001$ \\
TBARS $\left(\mathrm{ng} / 10^{6}\right)$ & $<0,0001$ & 0,2193 & 0,9062 \\
DABI $(\%)$ & $<0,0001$ & $<0,0001$ & 0,0011 \\
DABII $(\%)$ & 0,3119 & $<0,0001$ & 0,0005 \\
DABIII $(\%)$ & $<0,0001$ & $<0,0001$ & 0,0006 \\
DABIV $(\%)$ & $<0,0001$ & $<0,0001$ & 0,0001 \\
SCSA & 0,6571 & 0,0021 & 0,8914 \\
\hline \hline
\end{tabular}


Tabela 2 - Comparação entre diluidor a base de lecitina de soja em diferentes apresentações (8160, FP40, Solec F) e concentrações (0,01\%, 0,05\% e 0,1\%) e o diluidor a base de gema de ovo na atividade mitocondrial (DAB I, atividade total; DAB II, atividade alta; DAB III, atividade baixa; DAB IV, atividade nula) e nas variáveis analisadas pelo CASA (VAP, VSL, VCL, ALH, BCF, MOT, PROG, RAP, MED, STATIC), em amostras de sêmen de cães refrigeradas $\left(5^{\circ} \mathrm{C}\right)$ por 2 horas - São Paulo - 2012

\begin{tabular}{|c|c|c|c|c|c|c|c|c|c|c|}
\hline & \multirow[b]{2}{*}{ OVo } & \multicolumn{3}{|c|}{8160} & \multicolumn{3}{|c|}{ FP40 } & \multicolumn{3}{|c|}{ SOLEC F } \\
\hline & & $0,01 \%$ & $0,05 \%$ & $0,1 \%$ & $0,01 \%$ & $0,05 \%$ & $0,1 \%$ & $0,01 \%$ & $0,05 \%$ & $0,1 \%$ \\
\hline DABI (\%) & $86,50 \pm 3,55^{a}$ & $61,83 \pm 12,50^{a b c}$ & $56,33 \pm 8,34^{a b c}$ & $45,33 \pm 11,39^{c}$ & $53,80 \pm 15,85^{\mathrm{bc}}$ & $63,17 \pm 13,73^{\mathrm{abc}}$ & $64,67 \pm 10,11^{\mathrm{abc}}$ & $77,60 \pm 5,21^{a b}$ & $46,00 \pm 9,26^{c}$ & $59,00 \pm 11,24^{\mathrm{abc}}$ \\
\hline DABII (\%) & $10,67 \pm 3,42^{b}$ & $35,83 \pm 12,95^{\mathrm{ab}}$ & $34,00 \pm 6,41^{\mathrm{ab}}$ & $43,33 \pm 10,73^{a}$ & $24,60 \pm 11,12^{\mathrm{ab}}$ & $16,83 \pm 5,02^{b}$ & $28,83 \pm 8,92^{\mathrm{ab}}$ & $16,60 \pm 4,04^{b}$ & $45,60 \pm 13,18^{a}$ & $34,00 \pm 10,74^{\mathrm{ab}}$ \\
\hline DABIII (\%) & $0,83 \pm 0,31$ & $1,17 \pm 0,83$ & $5,00 \pm 3,33$ & $5,17 \pm 2,64$ & $0,80 \pm 0,49$ & $2,67 \pm 2,28$ & $4,83 \pm 1,99$ & $1,20 \pm 0,73$ & $2,40 \pm 1,47$ & $2,50 \pm 1,15$ \\
\hline DABIV (\%) & $2,00 \pm 0,52$ & $1,17 \pm 0,75$ & $4,67 \pm 3,32$ & $6,17 \pm 4,07$ & $20,80 \pm 19,55$ & $17,33 \pm 16,54$ & $1,67 \pm 0,67$ & $4,00 \pm 2,61$ & $2,40 \pm 1,69$ & $4,50 \pm 2,36$ \\
\hline $\operatorname{VAP}(\mu \mathrm{m} / \mathrm{s})$ & $112,45 \pm 3,89^{\mathrm{a}}$ & $96,80 \pm 7,23^{a b}$ & $67,53 \pm 11,47^{d}$ & $44,63 \pm 8,80^{\mathrm{e}}$ & $78,83 \pm 8,73^{\mathrm{bcd}}$ & $74,63 \pm 8,38^{\mathrm{cd}}$ & $71,18 \pm 8,35^{d}$ & $98,22 \pm 6,48^{\mathrm{ab}}$ & $93,17 \pm 5,50^{\mathrm{abc}}$ & $83,97 \pm 4,05^{\mathrm{bcd}}$ \\
\hline $\operatorname{VSL}(\mu \mathrm{m} / \mathrm{s})$ & $87,50 \pm 5,37^{a}$ & $41,95 \pm 2,82^{\mathrm{bc}}$ & $31,90 \pm 6,53^{\mathrm{cd}}$ & $18,15 \pm 4,10^{d}$ & $39,52 \pm 6,07^{\mathrm{bc}}$ & $35,47 \pm 2,94^{c}$ & $32,05 \pm 3,02^{\mathrm{cd}}$ & $49,73 \pm 8,49^{b}$ & $45,88 \pm 3,98^{\mathrm{bc}}$ & $36,37 \pm 3,17^{\mathrm{bc}}$ \\
\hline $\operatorname{VCL}(\mu \mathrm{m} / \mathrm{s})$ & $157,25 \pm 10,17^{\mathrm{b}}$ & $200,02 \pm 11,14^{a}$ & $162,63 \pm 19,45^{\mathrm{ab}}$ & $112,67 \pm 22,01^{\mathrm{C}}$ & $170,22 \pm 13,50^{\mathrm{ab}}$ & $171,05 \pm 15,38^{\mathrm{ab}}$ & $165,73 \pm 13,36^{\mathrm{ab}}$ & $185,48 \pm 13,10^{a b}$ & $192,55 \pm 6,48^{\mathrm{ab}}$ & $171,05 \pm 8,94^{\mathrm{ab}}$ \\
\hline $\mathrm{ALH}(\mu \mathrm{m})$ & $7,92 \pm 0,58^{\mathrm{a}}$ & $8,77 \pm 0,27^{\mathrm{a}}$ & $6,70 \pm 1,42^{\mathrm{ab}}$ & $4,93 \pm 1,75^{b}$ & $7,92 \pm 0,59^{\mathrm{a}}$ & $8,02 \pm 0,32^{a}$ & $7,92 \pm 0,50^{\mathrm{a}}$ & $8,28 \pm 0,86^{a}$ & $8,70 \pm 0,61^{a}$ & $8,12 \pm 0,38^{a}$ \\
\hline $\mathrm{BCF}(\mathrm{Hz})$ & $25,97 \pm 1,94^{\mathrm{b}}$ & $35,92 \pm 2,20^{\mathrm{a}}$ & $36,45 \pm 2,31^{a}$ & $37,18 \pm 2,65^{\mathrm{a}}$ & $35,42 \pm 2,38^{\mathrm{a}}$ & $33,60 \pm 1,50^{a}$ & $33,28 \pm 1,41^{a}$ & $35,02 \pm 1,28^{a}$ & $35,02 \pm 1,71^{a}$ & $36,00 \pm 2,25^{a}$ \\
\hline MOT (\%) & $70,67 \pm 6,29^{a}$ & $76,67 \pm 5,22^{a}$ & $62,50 \pm 10,85^{a}$ & $37,67 \pm 10,12^{b}$ & $75,33 \pm 6,71^{a}$ & $74,50 \pm 3,87^{a}$ & $67,50 \pm 5,80^{a}$ & $65,50 \pm 7,59^{\mathrm{a}}$ & $70,50 \pm 7,57^{a}$ & $68,33 \pm 8,62^{a}$ \\
\hline PROG(\%) & $42,67 \pm 5,96^{\mathrm{a}}$ & $7,50 \pm 1,65^{\mathrm{bc}}$ & $5,00 \pm 1,57^{\mathrm{bc}}$ & $0,83 \pm 0,48^{\mathrm{C}}$ & $7,83 \pm 2,20^{\mathrm{bc}}$ & $6,17 \pm 1,38^{\mathrm{bc}}$ & $4,00 \pm 0,77^{\mathrm{bc}}$ & $11,67 \pm 4,92^{b}$ & $8,67 \pm 2,44^{\mathrm{bc}}$ & $5,67 \pm 1,15^{\mathrm{bc}}$ \\
\hline RAP (\%) & $58,83 \pm 5,50^{a}$ & $62,00 \pm 6,68^{a}$ & $40,67 \pm 10,97^{a}$ & $14,67 \pm 8,13^{b}$ & $51,67 \pm 7,86^{\mathrm{a}}$ & $49,17 \pm 7,16^{a}$ & $44,33 \pm 7,90^{a}$ & $50,00 \pm 9,43^{a}$ & $56,33 \pm 7,05^{a}$ & $47,17 \pm 6,99^{a}$ \\
\hline MED (\%) & $11,67 \pm 3,70^{\mathrm{b}}$ & $14,33 \pm 3,14^{\mathrm{ab}}$ & $21,67 \pm 6,62^{\mathrm{ab}}$ & $23,17 \pm 6,55^{\mathrm{ab}}$ & $23,50 \pm 3,76^{\mathrm{ab}}$ & $25,17 \pm 4,89^{\mathrm{a}}$ & $23,67 \pm 4,37^{\mathrm{ab}}$ & $15,50 \pm 3,54^{\mathrm{ab}}$ & $13,83 \pm 0,87^{\mathrm{ab}}$ & $21,17 \pm 4,55^{\mathrm{ab}}$ \\
\hline STATIC (\%) & $16,83 \pm 5,26^{b}$ & $14,83 \pm 2,71^{b}$ & $26,33 \pm 10,40^{\mathrm{ab}}$ & $36,33 \pm 6,26^{a}$ & $17,17 \pm 6,02^{\mathrm{b}}$ & $14,83 \pm 2,63^{b}$ & $18,33 \pm 3,78^{b}$ & $22,33 \pm 6,24^{\mathrm{ab}}$ & $13,17 \pm 4,56^{b}$ & $18,00 \pm 7,07^{b}$ \\
\hline
\end{tabular}

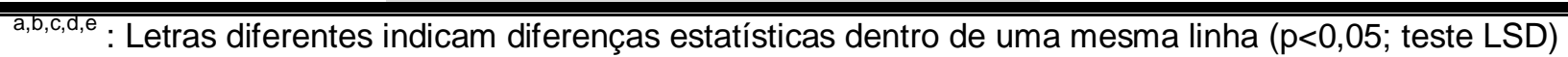

Verificou-se que após 2 horas de incubação (Tabela 2) ocorreu uma diminuição na porcentagem de células com atividade mitocondrial total (DAB I) nos diluidores 8160 0,1\% (45,33 \pm 11,39), FP40 0,01\% (53,80 \pm 15,85), Solec 0,05\% (46,00 \pm 9,26) quando comparada com amostras refrigeradas com diluidor a base de ovo (86,50 $\pm 3,55)$. Além disto, as amostras tratadas com o diluidor 8160 0,1\% apresentaram menor percentual de células móveis e com movimento rápido em relação a todos os outros diluidores. Por outro lado, houve uma diminuição da porcentagem de células com motilidade progressiva em todos os diluidores a base de lecitina de soja em comparação com a gema de ovo. 
Tabela 3 - Comparação entre diluidor a base de lecitina de soja em diferentes apresentações (8160, FP40, Solec F) e concentrações (0,01\%, 0,05\% e 0,1\%) e o diluidor a base de gema de ovo na atividade mitocondrial (DAB I, atividade total; DAB II, atividade alta; DAB III, atividade baixa; DAB IV atividade nula) e nas variáveis analisadas pelo CASA (VAP, VSL, VCL, ALH, BCF, MOT, PROG, RAP, MED, STATIC), em amostras de sêmen de cães refrigeradas $\left(5^{\circ} \mathrm{C}\right)$ por 24 horas - São Paulo - 2012

\begin{tabular}{|c|c|c|c|c|c|c|c|c|c|c|}
\hline & \multirow[b]{2}{*}{ OVo } & \multicolumn{3}{|c|}{8160} & \multicolumn{3}{|c|}{ FP40 } & \multicolumn{3}{|c|}{ SOLEC F } \\
\hline & & $0,01 \%$ & $0,05 \%$ & $0,1 \%$ & $0,01 \%$ & $0,05 \%$ & $0,1 \%$ & $0,01 \%$ & $0,05 \%$ & $0,1 \%$ \\
\hline DABI (\%) & $79,50 \pm 3,78^{a}$ & $62,40 \pm 8,84^{\mathrm{ab}}$ & $22,80 \pm 9,13^{\mathrm{de}}$ & $14,17 \pm 7,67^{\mathrm{e}}$ & $69,00 \pm 2,92^{a b}$ & $51,40 \pm 13,08^{\mathrm{bC}}$ & $38,33 \pm 8,59^{\mathrm{cd}}$ & $59,00 \pm 7,46^{\mathrm{abc}}$ & $55,20 \pm 8,49^{\mathrm{bc}}$ & $53,00 \pm 8,16^{\mathrm{bC}}$ \\
\hline DABII (\%) & $18,00 \pm 3,64^{c}$ & $35,80 \pm 9,11^{\mathrm{abc}}$ & $49,20 \pm 14,82^{\mathrm{ab}}$ & $57,50 \pm 11,58^{a}$ & $27,20 \pm 2,82^{\mathrm{bc}}$ & $25,60 \pm 7,08^{\mathrm{bc}}$ & $49,17 \pm 7,32^{\mathrm{ab}}$ & $36,20 \pm 6,40^{\mathrm{abc}}$ & $39,00 \pm 7,48^{\mathrm{abc}}$ & $44,83 \pm 8,67^{\mathrm{ab}}$ \\
\hline DABIII (\%) & $2,00 \pm 0,73^{b}$ & $1,20 \pm 0,37^{\mathrm{b}}$ & $7,00 \pm 3,74^{\mathrm{b}}$ & $21,00 \pm 6,76^{a}$ & $2,60 \pm 1,54^{\mathrm{b}}$ & $3,00 \pm 1,38^{\mathrm{b}}$ & $9,50 \pm 2,57^{b}$ & $3,40 \pm 1,99^{\mathrm{b}}$ & $3,00 \pm 1,14^{\mathrm{b}}$ & $1,17 \pm 0,54^{\mathrm{b}}$ \\
\hline DABIV (\%) & $0,50 \pm 0,22$ & $0,60 \pm 0,40$ & $21,00 \pm 19,76$ & $7,33 \pm 2,50$ & $1,20 \pm 0,73$ & $20,00 \pm 20,00$ & $3,17 \pm 0,87$ & $1,60 \pm 0,81$ & $2,80 \pm 1,71$ & $1,00 \pm 0,52$ \\
\hline $\operatorname{VAP}(\mu \mathrm{m} / \mathrm{s})$ & $108,85 \pm 5,00^{a}$ & $85,25 \pm 10,35^{b}$ & $9,27 \pm 6,05^{\mathrm{de}}$ & $3,43 \pm 3,43^{\mathrm{e}}$ & $57,37 \pm 10,42^{c}$ & $24,93 \pm 8,15^{d}$ & $25,38 \pm 5,34^{d}$ & $87,95 \pm 4,17^{\mathrm{b}}$ & $83,28 \pm 8,05^{b}$ & $71,50 \pm 7,68^{\mathrm{bc}}$ \\
\hline $\operatorname{VSL}(\mu \mathrm{m} / \mathrm{s})$ & $62,27 \pm 5,14^{a}$ & $38,00 \pm 1,90^{\mathrm{bc}}$ & $5,58 \pm 3,54^{\mathrm{ef}}$ & $1,37 \pm 1,37^{\dagger}$ & $27,97 \pm 5,21^{\mathrm{cd}}$ & $13,72 \pm 5,25^{\mathrm{e}}$ & $10,48 \pm 2,44^{\mathrm{ef}}$ & $28,40 \pm 1,89^{c d}$ & $40,60 \pm 5,23^{b}$ & $27,08 \pm 2,90^{d}$ \\
\hline $\operatorname{VCL}(\mu \mathrm{m} / \mathrm{s})$ & $170,02 \pm 13,44^{\mathrm{ab}}$ & $185,00 \pm 13,18^{\mathrm{ab}}$ & $25,05 \pm 18,44^{\mathrm{de}}$ & $5,05 \pm 5,05^{\mathrm{e}}$ & $146,52 \pm 16,12^{\mathrm{b}}$ & $61,28 \pm 20,87^{c d}$ & $66,42 \pm 15,35^{c}$ & $189,12 \pm 8,69^{a}$ & $179,15 \pm 13,26^{\mathrm{ab}}$ & $169,17 \pm 11,16^{\mathrm{ab}}$ \\
\hline $\mathrm{ALH}(\mu \mathrm{m})$ & $7,17 \pm 0,61^{a}$ & $7,68 \pm 0,28^{a}$ & $1,78 \pm 1,78^{\mathrm{bc}}$ & $0,00 \pm 0,00^{c}$ & $6,60 \pm 1,34^{a}$ & $2,40 \pm 1,31^{\mathrm{bc}}$ & $4,65 \pm 2,42^{\mathrm{ab}}$ & $7,20 \pm 0,56^{a}$ & $7,38 \pm 0,27^{a}$ & $7,48 \pm 0,25^{a}$ \\
\hline $\mathrm{BCF}(\mathrm{Hz})$ & $35,10 \pm 2,12^{\mathrm{a}}$ & $35,18 \pm 2,03^{a}$ & $6,33 \pm 6,33^{b}$ & $0,00 \pm 0,00^{b}$ & $37,30 \pm 2,97^{\mathrm{a}}$ & $25,88 \pm 8,32^{a}$ & $36,62 \pm 8,26^{a}$ & $38,15 \pm 1,41^{a}$ & $36,43 \pm 0,94^{a}$ & $38,55 \pm 2,11^{a}$ \\
\hline MOT (\%) & $60,83 \pm 9,63^{\mathrm{abc}}$ & $81,83 \pm 4,55^{a}$ & $6,83 \pm 6,83^{\mathrm{et}}$ & $0,00 \pm 0,00^{\dagger}$ & $57,17 \pm 12,20^{\mathrm{bc}}$ & $25,00 \pm 11,4^{\mathrm{de}}$ & $12,50 \pm 7,70^{\mathrm{et}}$ & $46,67 \pm 7,29^{d}$ & $76,33 \pm 5,42^{\mathrm{ab}}$ & $55,67 \pm 9,80^{\mathrm{bc}}$ \\
\hline PROG(\%) & $21,50 \pm 6,40^{\mathrm{a}}$ & $9,00 \pm 1,06^{\mathrm{cb}}$ & $0,17 \pm 0,17^{d}$ & $0,00 \pm 0,00^{d}$ & $5,33 \pm 2,32^{\mathrm{cbd}}$ & $2,00 \pm 1,03^{d}$ & $0,33 \pm 0,21^{d}$ & $3,00 \pm 0,86^{\mathrm{cd}}$ & $9,83 \pm 2,71^{b}$ & $3,17 \pm 0,87^{\mathrm{cbd}}$ \\
\hline RAP (\%) & $54,17 \pm 9,33^{\mathrm{ab}}$ & $63,50 \pm 7,84^{\mathrm{a}}$ & $0,50 \pm 0,50^{d}$ & $0,00 \pm 0,00^{a}$ & $31,33 \pm 10,08^{c}$ & $4,83 \pm 2,61^{\mathrm{d}}$ & $1,00 \pm 0,63^{\mathrm{d}}$ & $33,17 \pm 5,65^{c}$ & $56,17 \pm 7,94^{\mathrm{a}}$ & $37,00 \pm 8,18^{\mathrm{bc}}$ \\
\hline MED (\%) & $6,83 \pm 1,87^{\mathrm{bc}}$ & $18,50 \pm 4,40^{\mathrm{ab}}$ & $6,33 \pm 6,33^{\mathrm{bc}}$ & $0,00 \pm 0,00^{c}$ & $26,00 \pm 7,43^{\mathrm{a}}$ & $20,17 \pm 8,92^{\mathrm{ab}}$ & $11,50 \pm 7,07^{\mathrm{abc}}$ & $13,50 \pm 2,00^{\mathrm{abc}}$ & $20,33 \pm 4,51^{\mathrm{ab}}$ & $18,83 \pm 2,83^{\mathrm{ab}}$ \\
\hline STATIC (\%) & $23,83 \pm 7,73^{\mathrm{de}}$ & $12,00 \pm 3,30^{\mathrm{e}}$ & $69,83 \pm 10,43^{\mathrm{ab}}$ & $77,83 \pm 7,32^{\mathrm{a}}$ & $25,67 \pm 8,06^{\mathrm{de}}$ & $53,67 \pm 8,98^{\mathrm{bc}}$ & $52,00 \pm 11,51^{\mathrm{bc}}$ & $42,50 \pm 5,28^{d c}$ & $11,17 \pm 2,21^{\mathrm{e}}$ & $18,67 \pm 5,39^{e}$ \\
\hline
\end{tabular}

$\overline{\mathrm{a}, \mathrm{b}, \mathrm{c}, \mathrm{d}, \mathrm{e}, \mathrm{f}}$ : Letras diferentes indicam diferenças estatísticas dentro de uma mesma linha ( $p<0,05 ;$ teste LSD)

Após 24 horas de refrigeração (Tabela 3) ocorreu uma diminuição na porcentagem de células DAB I nos diluidores a base de lecitina de soja nas concentrações $0,05 \%$ e 0,1\%, independente da apresentação, em relação ao diluidor a base de gema de ovo. Da mesma forma observou-se uma diminuição na porcentagem de células móveis, exceto na lecitina Solec $F$, que apresentou diminuição apenas na concentração 0,01\%, quando comparada com a gema de ovo. Além disto, como na avaliação após 2 horas de refrigeração, todos os diluidores apresentaram uma diminuição na porcentagem de células com motilidade progressiva em relação à gema de ovo. 
Tabela 4 - Comparação entre diluidor a base de lecitina de soja em diferentes apresentações (8160, FP40, Solec F) e concentrações (0,01\%, 0,05\% e 0,1\%) e o diluidor a base de gema de ovo na atividade mitocondrial (DAB I, atividade total; DAB II, atividade alta; DAB III, atividade baixa; DAB IV atividade nula) e nas variáveis analisadas pelo CASA (VAP, VSL, VCL, ALH, BCF, MOT, PROG, RAP, MED, STATIC), em amostras de sêmen de cães refrigeradas $\left(5^{\circ} \mathrm{C}\right)$ por 48 horas - São Paulo - 2012

\begin{tabular}{|c|c|c|c|c|c|c|c|c|c|c|}
\hline & \multirow{2}{*}{ OVo } & \multicolumn{3}{|c|}{8160} & \multicolumn{3}{|c|}{ FP40 } & \multicolumn{3}{|c|}{ SOLEC F } \\
\hline & & $0,01 \%$ & $0,05 \%$ & $0,1 \%$ & $0,01 \%$ & $0,05 \%$ & $0,1 \%$ & $0,01 \%$ & $0,05 \%$ & $0,1 \%$ \\
\hline DABI (\%) & $56,17 \pm 3,88^{a}$ & $53,17 \pm 12,49^{\text {ab }}$ & $10,00 \pm 4,34^{\mathrm{cd}}$ & $3,83 \pm 3,25^{\mathrm{d}}$ & $60,67 \pm 10,43^{\mathrm{a}}$ & $30,50 \pm 12,09^{b c}$ & $15,50 \pm 7,42^{\mathrm{cd}}$ & $46,00 \pm 10,19^{\text {ab }}$ & $53,50 \pm 9,02^{a b}$ & $55,50 \pm 9,58^{\mathrm{ab}}$ \\
\hline DABII (\%) & $37,33 \pm 4,79$ & $38,83 \pm 10,41$ & $36,67 \pm 12,06$ & $23,00 \pm 9,34$ & $35,50 \pm 10,85$ & $39,00 \pm 6,50$ & $47,50 \pm 6,96$ & $45,50 \pm 9,19$ & $41,33 \pm 8,43$ & $32,50 \pm 5,60$ \\
\hline DABIII (\%) & $7,17 \pm 2,09^{\mathrm{e}}$ & $6,67 \pm 3,61^{\mathrm{e}}$ & $41,00 \pm 9,49^{a b}$ & $49,00 \pm 5,93^{\mathrm{a}}$ & $4,50 \pm 1,09^{\mathrm{e}}$ & $24,17 \pm 8,82^{\mathrm{dc}}$ & $32,00 \pm 8,45^{\mathrm{bc}}$ & $5,83 \pm 1,58^{\mathrm{e}}$ & $4,67 \pm 1,71^{\mathrm{e}}$ & $10,33 \pm 4,78^{\mathrm{de}}$ \\
\hline DABIV (\%) & $1,17 \pm 0,75^{c}$ & $1,33 \pm 0,99^{c}$ & $12,50 \pm 6,34^{b}$ & $24,17 \pm 9,56^{a}$ & $1,00 \pm 0,45^{c}$ & $6,33 \pm 3,75^{\mathrm{bc}}$ & $5,00 \pm 1,86^{\mathrm{bc}}$ & $2,67 \pm 0,84^{\mathrm{bc}}$ & $0,67 \pm 0,33^{c}$ & $1,67 \pm 0,99^{\mathrm{bc}}$ \\
\hline $\operatorname{VAP}(\mu \mathrm{m} / \mathrm{s})$ & $94,52 \pm 4,61^{a}$ & $56,38 \pm 10,10^{c}$ & $4,50 \pm 4,50^{d}$ & $0,00 \pm 0,00^{d}$ & $50,30 \pm 10,38^{c}$ & $14,38 \pm 6,50^{d}$ & $14,28 \pm 6,91^{d}$ & $87,30 \pm 11,39^{\mathrm{ab}}$ & $66,47 \pm 10,61^{\mathrm{bc}}$ & $57,23 \pm 5,37^{c}$ \\
\hline $\operatorname{VSL}(\mu \mathrm{m} / \mathrm{s})$ & $57,32 \pm 4,95^{a}$ & $25,07 \pm 4,00^{\mathrm{bc}}$ & $1,15 \pm 1,15^{\mathrm{e}}$ & $0,00 \pm 0,00^{\mathrm{e}}$ & $19,18 \pm 4,49^{\mathrm{cd}}$ & $7,98 \pm 3,99^{\mathrm{de}}$ & $7,98 \pm 3,76^{\mathrm{de}}$ & $34,15 \pm 7,42^{b}$ & $30,65 \pm 7,28^{\mathrm{bc}}$ & $28,37 \pm 2,80^{b c}$ \\
\hline $\operatorname{VCL}(\mu \mathrm{m} / \mathrm{s})$ & $145,48 \pm 5,68^{\mathrm{ab}}$ & $142,02 \pm 19,15^{b}$ & $10,98 \pm 10,98^{c}$ & $0,00 \pm 0,00^{c}$ & $129,55 \pm 15,79^{b}$ & $34,37 \pm 18,48^{c}$ & $27,08 \pm 13,07^{c}$ & $181,02 \pm 9,27^{a}$ & $152,93 \pm 15,77^{\mathrm{ab}}$ & $137,83 \pm 7,68^{b}$ \\
\hline $\mathrm{ALH}(\mu \mathrm{m})$ & $5,73 \pm 0,38^{\mathrm{ab}}$ & $7,62 \pm 0,39^{a}$ & $0,00 \pm 0,00^{d}$ & $0,00 \pm 0,00^{d}$ & $5,95 \pm 0,56^{\mathrm{ab}}$ & $3,27 \pm 2,23^{\mathrm{bc}}$ & $1,82 \pm 1,82^{\mathrm{cd}}$ & $7,35 \pm 0,88^{a}$ & $5,57 \pm 1,23^{\text {ab }}$ & $6,52 \pm 0,49^{a}$ \\
\hline $\mathrm{BCF}(\mathrm{Hz})$ & $37,13 \pm 1,51^{a}$ & $38,20 \pm 2,53^{\mathrm{a}}$ & $7,75 \pm 7,75^{\mathrm{bc}}$ & $0,00 \pm 0,00^{c}$ & $43,62 \pm 0,71^{a}$ & $13,83 \pm 8,90^{\mathrm{bc}}$ & $17,77 \pm 11,37^{\mathrm{b}}$ & $39,38 \pm 2,43^{\mathrm{a}}$ & $42,68 \pm 2,76^{a}$ & $38,85 \pm 2,17^{a}$ \\
\hline MOT (\%) & $48,67 \pm 5,53^{a}$ & $61,33 \pm 13,64^{a}$ & $0,17 \pm 0,17^{\mathrm{b}}$ & $0,00 \pm 0,00^{b}$ & $53,83 \pm 6,24^{a}$ & $12,00 \pm 8,30^{b}$ & $0,50 \pm 0,50^{b}$ & $55,17 \pm 10,73^{a}$ & $53,67 \pm 5,79^{a}$ & $49,83 \pm 7,33^{a}$ \\
\hline PROG(\%) & $17,67 \pm 4,18^{a}$ & $4,67 \pm 1,41^{\mathrm{bc}}$ & $0,00 \pm 0,00^{c}$ & $0,00 \pm 0,00^{c}$ & $2,33 \pm 1,17^{\mathrm{bc}}$ & $0,00 \pm 0,00^{c}$ & $0,00 \pm 0,00^{c}$ & $6,00 \pm 3,67^{b}$ & $5,33 \pm 2,53^{\mathrm{bc}}$ & $3,50 \pm 1,34^{\mathrm{bc}}$ \\
\hline RAP (\%) & $41,00 \pm 4,86^{a}$ & $35,67 \pm 13,51^{\mathrm{ab}}$ & $0,00 \pm 0,00^{c}$ & $0,00 \pm 0,00^{c}$ & $20,00 \pm 9,32^{b c}$ & $0,33 \pm 0,21^{c}$ & $0,00 \pm 0,00^{c}$ & $41,67 \pm 11,49^{a}$ & $29,17 \pm 8,27^{\mathrm{ab}}$ & $26,00 \pm 7,18^{\mathrm{ab}}$ \\
\hline MED (\%) & $7,67 \pm 1,52$ & $25,83 \pm 6,57$ & $0,17 \pm 0,17$ & $0,00 \pm 0,00$ & $33,83 \pm 6,36$ & $11,50 \pm 7,96$ & $0,50 \pm 0,50$ & $13,50 \pm 1,77$ & $24,67 \pm 5,24$ & $23,83 \pm 1,78$ \\
\hline STATIC (\%) & $26,83 \pm 8,60^{c d}$ & $25,33 \pm 8,71^{a}$ & $79,33 \pm 3,59^{d}$ & $76,00 \pm 11,90^{d}$ & $31,67 \pm 5,64^{a}$ & $67,50 \pm 9,79^{\mathrm{cd}}$ & $66,17 \pm 9,80^{d}$ & $37,00 \pm 9,67^{b c}$ & $29,33 \pm 4,90^{\mathrm{ab}}$ & $32,33 \pm 6,88^{a b}$ \\
\hline
\end{tabular}

$\overline{\mathrm{a}, \mathrm{b}, \mathrm{c}, \mathrm{d}}$ : Letras diferentes indicam diferenças estatísticas dentro de uma mesma linha $(\mathrm{p}<0,05 ;$ teste LSD)

Como observado na Tabela 4, após 48 horas de refrigeração ocorreu uma diminuição na porcentagem de células DAB I e na porcentagem de células móveis nos diluidores a base de lecitina de soja 8160 e FP40 nas concentrações 0,05\% e 0,1\%. Havendo também um aumento na porcentagem de células com atividade mitocondrial nula (DAB IV) no diluidor 8160 0,05\% e $0,1 \%$ quando comparado com o diluidor a base de gema de ovo. Igualmente aos tempos 2 e 24 horas, a porcentagem de células com motilidade progressiva apresentaram-se menores em todos os diluidores em comparação com o diluidor com gema de ovo. 
Tabela 5 - Comparação entre diluidor a base de lecitina de soja em diferentes apresentações (8160, FP40, Solec F) e concentrações (0,01\%, 0,05\% e 0,1\%) e o diluidor a base de gema de ovo na atividade mitocondrial (DAB I, atividade total; DAB II, atividade alta; DAB III, atividade baixa; DAB IV, atividade nula) e nas variáveis analisadas pelo CASA (VAP, VSL, VCL, ALH, BCF, MOT, PROG, RAP, MED, STATIC), em amostras de sêmen de cães refrigeradas $\left(5^{\circ} \mathrm{C}\right)$ por 72 horas - São Paulo - 2012

\begin{tabular}{|c|c|c|c|c|c|c|c|c|c|c|}
\hline & \multirow[b]{2}{*}{ OVo } & \multicolumn{3}{|c|}{8160} & \multicolumn{3}{|c|}{ FP40 } & \multicolumn{3}{|c|}{ SOLEC F } \\
\hline & & $0,01 \%$ & $0,05 \%$ & $0,1 \%$ & $0,01 \%$ & $0,05 \%$ & $0,1 \%$ & $0,01 \%$ & $0,05 \%$ & $0,1 \%$ \\
\hline DABI (\%) & $29,83 \pm 5,39^{a b}$ & $47,67 \pm 13,51^{a}$ & $9,17 \pm 5,31^{b}$ & $7,33 \pm 2,46^{b}$ & $46,33 \pm 10,05^{a}$ & $29,33 \pm 14,00^{\mathrm{ab}}$ & $15,67 \pm 5,36^{b}$ & $44,67 \pm 9,36^{a}$ & $46,50 \pm 11,44^{a}$ & $52,33 \pm 10,76^{a}$ \\
\hline DABII (\%) & $49,50 \pm 5,94^{a}$ & $40,83 \pm 9,86^{a b}$ & $36,50 \pm 11,68^{\mathrm{ab}}$ & $19,50 \pm 7,31^{\mathrm{b}}$ & $41,17 \pm 7,85^{\mathrm{ab}}$ & $34,50 \pm 10,71^{a b}$ & $45,17 \pm 10,32^{a}$ & $43,67 \pm 6,44^{a b}$ & $42,50 \pm 7,41^{\mathrm{ab}}$ & $35,67 \pm 9,39^{\mathrm{ab}}$ \\
\hline DABIII (\%) & $15,67 \pm 4,50^{\mathrm{bdc}}$ & $9,33 \pm 3,06^{c d}$ & $36,50 \pm 10,93^{a}$ & $37,17 \pm 6,23^{a}$ & $10,33 \pm 2,59^{\mathrm{cd}}$ & $27,67 \pm 10,14^{\mathrm{abc}}$ & $30,00 \pm 9,43^{a b}$ & $8,67 \pm 4,56^{d}$ & $8,83 \pm 4,03^{a}$ & $8,83 \pm 2,68^{d}$ \\
\hline DABIV (\%) & $5,00 \pm 3,24^{\mathrm{bc}}$ & $2,17 \pm 1,78^{\mathrm{c}}$ & $17,83 \pm 8,60^{b}$ & $36,00 \pm 10,21^{a}$ & $2,17 \pm 0,95^{c}$ & $8,50 \pm 3,32^{\mathrm{bc}}$ & $9,17 \pm 2,99^{\mathrm{bc}}$ & $3,00 \pm 1,41^{c}$ & $2,17 \pm 0,91^{\mathrm{c}}$ & $3,17 \pm 1,38^{\mathrm{c}}$ \\
\hline $\operatorname{VAP}(\mu \mathrm{m} / \mathrm{s})$ & $78,08 \pm 3,53^{\mathrm{a}}$ & $50,68 \pm 6,11^{\mathrm{bc}}$ & $8,00 \pm 5,08^{\dagger}$ & $15,08 \pm 6,85^{\mathrm{ef}}$ & $42,47 \pm 6,03^{\mathrm{cd}}$ & $4,75 \pm 4,75^{\dagger}$ & $11,10 \pm 4,98^{\dagger}$ & $65,68 \pm 10,46^{a b}$ & $43,62 \pm 4,78^{\mathrm{cd}}$ & $30,95 \pm 6,32^{\mathrm{de}}$ \\
\hline $\operatorname{VSL}(\mu \mathrm{m} / \mathrm{s})$ & $52,80 \pm 5,15^{a}$ & $22,88 \pm 3,70^{\mathrm{bc}}$ & $6,00 \pm 3,93^{\mathrm{de}}$ & $7,80 \pm 4,01^{\mathrm{de}}$ & $19,27 \pm 3,38^{\mathrm{bc}}$ & $1,30 \pm 1,30^{\mathrm{e}}$ & $7,00 \pm 3,46^{\mathrm{de}}$ & $28,47 \pm 4,28^{b}$ & $19,18 \pm 2,86^{\mathrm{bc}}$ & $14,20 \pm 3,28^{\mathrm{cd}}$ \\
\hline $\operatorname{VCL}(\mu \mathrm{m} / \mathrm{s})$ & $124,32 \pm 6,83^{\mathrm{abc}}$ & $127,53 \pm 14,24^{\mathrm{ab}}$ & $14,58 \pm 9,39^{d}$ & $27,85 \pm 13,59^{d}$ & $115,57 \pm 12,42^{\mathrm{bc}}$ & $13,37 \pm 13,37^{d}$ & $27,73 \pm 14,60^{d}$ & $157,02 \pm 15,81^{a}$ & $121,48 \pm 6,46^{\mathrm{abc}}$ & $88,27 \pm 17,82^{c}$ \\
\hline $\mathrm{ALH}(\mu \mathrm{m})$ & $5,82 \pm 0,38^{a}$ & $6,70 \pm 0,46^{a}$ & $0,00 \pm 0,00^{b}$ & $0,00 \pm 0,00^{b}$ & $5,25 \pm 1,15^{a}$ & $0,00 \pm 0,00^{b}$ & $0,00 \pm 0,00^{b}$ & $5,77 \pm 1,42^{\mathrm{a}}$ & $5,07 \pm 1,12^{\mathrm{a}}$ & $6,20 \pm 1,54^{a}$ \\
\hline $\mathrm{BCF}(\mathrm{Hz})$ & $38,45 \pm 1,74^{\mathrm{ab}}$ & $40,43 \pm 1,73^{a b}$ & $11,47 \pm 9,81^{\mathrm{cd}}$ & $18,20 \pm 8,56^{d}$ & $39,60 \pm 2,20^{a b}$ & $8,28 \pm 8,28^{\mathrm{d}}$ & $22,23 \pm 10,79^{\mathrm{bcd}}$ & $40,12 \pm 1,54^{\mathrm{ab}}$ & $2,05^{a}$ & $34,92 \pm 7,08^{\mathrm{abc}}$ \\
\hline MOT (\%) & $44,33 \pm 9,78^{\mathrm{abc}}$ & $57,67 \pm 6,93^{\mathrm{a}}$ & $0,00 \pm 0,00^{d}$ & $0,17 \pm 0,17^{d}$ & $50,50 \pm 10,57^{\mathrm{ab}}$ & $3,83 \pm 3,83^{d}$ & $0,17 \pm 0,17^{d}$ & $43,67 \pm 9,91^{\mathrm{abc}}$ & $34,00 \pm 6,21^{\mathrm{bc}}$ & $25,83 \pm 6,91^{\mathrm{c}}$ \\
\hline PROG(\%) & $16,17 \pm 5,17^{\mathrm{a}}$ & $3,83 \pm 0,95^{b}$ & $0,00 \pm 0,00^{b}$ & $0,00 \pm 0,00^{b}$ & $3,17 \pm 1,30^{b}$ & $0,00 \pm 0,00^{b}$ & $0,00 \pm 0,00^{b}$ & $2,33 \pm 1,17^{b}$ & $0,67 \pm 0,49^{b}$ & $1,17 \pm 0,40^{\mathrm{b}}$ \\
\hline RAP (\%) & $29,33 \pm 5,39^{\mathrm{a}}$ & $25,50 \pm 8,94^{\mathrm{a}}$ & $0,00 \pm 0,00^{d}$ & $0,00 \pm 0,00^{d}$ & $17,67 \pm 8,08^{\mathrm{abc}}$ & $0,00 \pm 0,00^{d}$ & $0,00 \pm 0,00^{d}$ & $24,83 \pm 9,06^{\mathrm{ab}}$ & $10,00 \pm 4,23^{\mathrm{bcd}}$ & $5,00 \pm 1,91^{\mathrm{cd}}$ \\
\hline MED (\%) & $15,00 \pm 5,08^{b}$ & $32,00 \pm 4,69^{a}$ & $0,00 \pm 0,00^{c}$ & $0,17 \pm 0,17^{c}$ & $32,50 \pm 5,44^{a}$ & $3,83 \pm 3,83^{c}$ & $0,17 \pm 0,17^{c}$ & $18,67 \pm 3,04^{b}$ & $24,00 \pm 4,24^{b}$ & $20,83 \pm 5,17^{b}$ \\
\hline STATIC (\%) & $27,67 \pm 7,06^{c}$ & $29,50 \pm 6,78^{c}$ & $79,33 \pm 7,18^{\mathrm{a}}$ & $72,33 \pm 7,24^{\mathrm{ab}}$ & $35,17 \pm 10,63^{c}$ & $75,17 \pm 10,16^{\mathrm{ab}}$ & $52,33 \pm 11,70^{\mathrm{bc}}$ & $45,50 \pm 8,86^{c}$ & $44,50 \pm 8,53^{c}$ & $49,33 \pm 12,75^{b c}$ \\
\hline
\end{tabular}

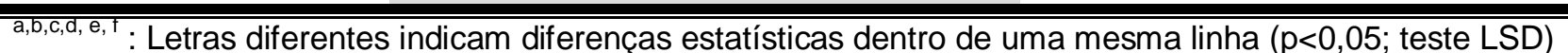

Em relação à porcentagem de células DABI com 72 horas de refrigeração (Tabela 5), observou-se que os diluidores a base de lecitina de soja passaram a não apresentar diferenças estatísticas em relação à gema de ovo, como observado nos tempos anteriores. Porém, a porcentagem de células DABIV no diluidor 8160 0,1\% $(36,00 \pm 10,21)$ foi maior quando comparada com a gema de ovo $(5,00 \pm 3,24)$. Além disso, a porcentagem de células móveis demonstrou ser menor nos diluidores $81600,05 \%$ e 0,1\%, e no FP40 nas mesmas concentrações em comparação com a gema de ovo. Como nos tempos 2, 24 e 48 horas, todos os diluidores apresentaram uma menor porcentagem de células com motilidade progressiva em comparação com o diluidor contendo gema de ovo. 
Tabela 6 - Comparação entre diluidor a base de lecitina de soja em diferentes apresentações (8160, FP40, Solec F) e concentrações (0,01\%, 0,05\% e 0,1\%) e o diluidor a base de gema de ovo na atividade mitocondrial (DAB I, atividade total; DAB II, atividade alta; DAB III, atividade baixa; DAB IV atividade nula) e nas variáveis analisadas pelo CASA (VAP, VSL, VCL, ALH, BCF, MOT, PROG, RAP, MED, STATIC), em amostras de sêmen de cães refrigeradas $\left(5^{\circ} \mathrm{C}\right)$ por 96 horas - São Paulo - 2012

\begin{tabular}{|c|c|c|c|c|c|c|c|c|c|c|}
\hline & \multirow[b]{2}{*}{ OVO } & \multicolumn{3}{|c|}{8160} & \multicolumn{3}{|c|}{ FP40 } & \multicolumn{3}{|c|}{ SOLEC F } \\
\hline & & $0,01 \%$ & $0,05 \%$ & $0,1 \%$ & $0,01 \%$ & $0,05 \%$ & $0,1 \%$ & $0,01 \%$ & $0,05 \%$ & $0,1 \%$ \\
\hline DABI (\%) & $39,83 \pm 2,88^{\mathrm{d}}$ & $55,17 \pm 10,54^{\text {bcd }}$ & $5,83 \pm 4,17^{\mathrm{e}}$ & $0,33 \pm 0,21^{\mathrm{e}}$ & $71,67 \pm 4,54^{\mathrm{ab}}$ & $17,17 \pm 9,43^{\mathrm{e}}$ & $9,17 \pm 5,31^{\mathrm{e}}$ & $50,33 \pm 10,03^{\mathrm{cd}}$ & $79,67 \pm 3,55^{a}$ & $64,67 \pm 4,10^{\mathrm{abc}}$ \\
\hline DABII (\%) & $48,00 \pm 5,85^{a}$ & $37,17 \pm 9,11^{\mathrm{ab}}$ & $20,67 \pm 12,26^{\mathrm{bc}}$ & $11,33 \pm 9,96^{c}$ & $20,83 \pm 3,59^{b c}$ & $29,17 \pm 8,80^{\mathrm{abc}}$ & $31,33 \pm 10,95^{\mathrm{abc}}$ & $27,33 \pm 5,74^{\mathrm{abc}}$ & $17,83 \pm 2,57^{\mathrm{bc}}$ & $27,50 \pm 2,38^{\mathrm{abc}}$ \\
\hline DABIII (\%) & $8,00 \pm 1,77^{c}$ & $5,33 \pm 2,47^{c}$ & $28,17 \pm 7,54^{\mathrm{ab}}$ & $25,00 \pm 8,02^{b}$ & $4,50 \pm 1,54^{c}$ & $27,50 \pm 7,90^{\mathrm{ab}}$ & $39,33 \pm 7,14^{a}$ & $3,00 \pm 1,26^{c}$ & $3,00 \pm 0,37^{c}$ & $6,00 \pm 2,22^{c}$ \\
\hline DABIV (\%) & $4,17 \pm 2,24^{\mathrm{c}}$ & $2,33 \pm 0,84^{c}$ & $45,33 \pm 14,19^{\mathrm{ab}}$ & $63,50 \pm 14,53^{a}$ & $3,00 \pm 1,34^{c}$ & $26,33 \pm 14,49^{\mathrm{bc}}$ & $20,17 \pm 7,88^{\mathrm{bc}}$ & $19,33 \pm 15,68^{\mathrm{bc}}$ & $1,33 \pm 0,42^{c}$ & $2,00 \pm 1,29^{c}$ \\
\hline $\operatorname{VAP}(\mu \mathrm{m} / \mathrm{s})$ & $72,98 \pm 3,63^{a}$ & $31,10 \pm 2,20^{\mathrm{cd}}$ & $3,60 \pm 3,60^{\mathrm{e}}$ & $4,18 \pm 4,18^{\mathrm{e}}$ & $43,23 \pm 7,56^{\mathrm{bc}}$ & $12,00 \pm 5,45^{\mathrm{e}}$ & $16,15 \pm 8,82^{\mathrm{de}}$ & $53,72 \pm 11,23^{b}$ & $33,48 \pm 3,34^{c}$ & $32,20 \pm 0,78^{\mathrm{cd}}$ \\
\hline $\operatorname{VSL}(\mu \mathrm{m} / \mathrm{s})$ & $52,27 \pm 2,98^{\mathrm{a}}$ & $12,72 \pm 1,8^{\mathrm{cd}}$ & $1,45 \pm 1,45^{\mathrm{e}}$ & $3,33 \pm 3,33^{\mathrm{de}}$ & $16,12 \pm 3,50^{b c}$ & $8,35 \pm 4,36^{\text {cde }}$ & $10,40 \pm 6,71^{\text {cde }}$ & $23,72 \pm 4,69^{b}$ & $11,20 \pm 2,42^{\text {cde }}$ & $14,87 \pm 1,90^{\mathrm{bc}}$ \\
\hline $\operatorname{VCL}(\mu \mathrm{m} / \mathrm{s})$ & $113,00 \pm 6,72^{\mathrm{ab}}$ & $86,03 \pm 7,99^{b}$ & $14,92 \pm 14,92^{c}$ & $8,97 \pm 8,97^{c}$ & $109,22 \pm 14,13^{a b}$ & $18,53 \pm 10,02^{c}$ & $33,12 \pm 14,87^{c}$ & $133,78 \pm 18,43^{\mathrm{a}}$ & $89,18 \pm 9,69^{b}$ & $86,28 \pm 2,98^{b}$ \\
\hline $\mathrm{ALH}(\mu \mathrm{m})$ & $5,52 \pm 0,37^{\mathrm{ab}}$ & $2,67 \pm 1,39^{\mathrm{cd}}$ & $0,00 \pm 0,00^{a}$ & $0,00 \pm 0,00^{d}$ & $5,67 \pm 1,30^{\mathrm{ab}}$ & $0,00 \pm 0,00^{d}$ & $1,55 \pm 1,55^{\mathrm{cd}}$ & $7,30 \pm 0,62^{a}$ & $3,17 \pm 1,16^{\mathrm{bc}}$ & $5,75 \pm 1,27^{\mathrm{ab}}$ \\
\hline $\mathrm{BCF}(\mathrm{Hz})$ & $36,02 \pm 1,35^{\mathrm{abc}}$ & $42,33 \pm 1,83^{\mathrm{ab}}$ & $10,00 \pm 10,00^{d}$ & $8,00 \pm 8,00^{d}$ & $43,83 \pm 1,26^{\mathrm{ab}}$ & $18,90 \pm 11,98^{\mathrm{cd}}$ & $26,18 \pm 12,20^{\text {bcd }}$ & $42,83 \pm 0,91^{\mathrm{ab}}$ & $49,92 \pm 2,44^{\mathrm{a}}$ & $40,53 \pm 1,43^{\mathrm{ab}}$ \\
\hline MOT (\%) & $24,33 \pm 7,26^{\mathrm{ab}}$ & $15,33 \pm 5,28^{\mathrm{b}}$ & $0,00 \pm 0,00^{c}$ & $0,00 \pm 0,00^{c}$ & $35,67 \pm 7,05^{\mathrm{a}}$ & $0,67 \pm 0,67^{\mathrm{c}}$ & $0,00 \pm 0,00^{c}$ & $30,17 \pm 6,84^{a}$ & $15,00 \pm 4,96^{\mathrm{b}}$ & $15,67 \pm 3,00^{b}$ \\
\hline PROG(\%) & $9,17 \pm 3,04^{\mathrm{a}}$ & $0,33 \pm 0,21^{b}$ & $0,00 \pm 0,00^{b}$ & $0,00 \pm 0,00^{b}$ & $1,00 \pm 0,63^{b}$ & $0,00 \pm 0,00^{b}$ & $0,00 \pm 0,00^{b}$ & $2,17 \pm 0,95^{b}$ & $0,33 \pm 0,33^{b}$ & $0,50 \pm 0,22^{b}$ \\
\hline RAP (\%) & $15,67 \pm 3,86^{a}$ & $2,17 \pm 1,33^{\mathrm{bc}}$ & $0,00 \pm 0,00^{c}$ & $0,00 \pm 0,00^{c}$ & $10,50 \pm 6,03^{\mathrm{ab}}$ & $0,00 \pm 0,00^{c}$ & $0,00 \pm 0,00^{c}$ & $15,00 \pm 7,30^{a}$ & $1,83 \pm 1,28^{\mathrm{bc}}$ & $1,00 \pm 0,52^{c}$ \\
\hline MED (\%) & $8,67 \pm 3,73^{\mathrm{bc}}$ & $13,33 \pm 4,18^{b}$ & $0,00 \pm 0,00^{d}$ & $0,00 \pm 0,00^{d}$ & $25,33 \pm 4,42^{\mathrm{a}}$ & $0,67 \pm 0,67^{\mathrm{cd}}$ & $0,00 \pm 0,00^{d}$ & $15,17 \pm 2,60^{b}$ & $13,00 \pm 4,56^{b}$ & $14,50 \pm 2,57^{b}$ \\
\hline STATIC (\%) & $49,50 \pm 11,07^{d}$ & $62,67 \pm 9,29^{\mathrm{bcd}}$ & $83,67 \pm 5,76^{a}$ & $78,17 \pm 5,86^{\mathrm{abc}}$ & $46,67 \pm 5,74^{d}$ & $82,00 \pm 4,20^{\mathrm{ab}}$ & $63,83 \pm 8,25^{\mathrm{abcd}}$ & $59,00 \pm 7,61^{\mathrm{cd}}$ & $65,83 \pm 4,72^{\mathrm{abcd}}$ & $55,50 \pm 5,60^{d}$ \\
\hline
\end{tabular}

: Letras diferentes indicam diferenças estatísticas dentro de uma mesma linha $(p<0,05$; teste LSD)

Na avaliação realizada após 96 horas de refrigeração (Tabela 6), observou-se uma menor porcentagem de células DAB I nos diluidores 8160 e FP40, nas concentrações 0,05\% e 0,1\%, quando comparada com a gema de ovo. No entanto, também em relação à gema de ovo, houve uma melhora na atividade mitocondrial nos diluidores FP40 0,01\% e Solec F 0,05\% e 0,1\%. Observou-se também que os diluidores 8160 0,05\% e 0,1\% foram deletérios para atividade mitocondrial como demonstrado pela maior porcentagem de células DAB IV. Do mesmo modo que nos tempos 2, 24, 48 e 72 horas, todos os diluidores apresentaram uma menor porcentagem de células com motilidade progressiva em comparação com o diluidor com gema de ovo. 
Tabela 7 - Comparação entre diluidor a base de lecitina de soja em diferentes apresentações (8160, FP40, Solec F) e concentrações (0,01\%, 0,05\% e 0,1\%) e o diluidor a base de gema de ovo na atividade mitocondrial (DAB I, atividade total; DAB II, atividade alta; DAB III, atividade baixa; DAB IV atividade nula) e nas variáveis analisadas pelo CASA (VAP, VSL, VCL, ALH, BCF, MOT, PROG, RAP, MED, STATIC), em amostras de sêmen de cães refrigeradas $\left(5^{\circ} \mathrm{C}\right)$ por 120 horas - São Paulo - 2012

\begin{tabular}{|c|c|c|c|c|c|c|c|c|c|c|}
\hline & \multirow[b]{2}{*}{ ovo } & \multicolumn{3}{|c|}{8160} & \multicolumn{3}{|c|}{ FP40 } & \multicolumn{3}{|c|}{ SOLEC F } \\
\hline & & $0,01 \%$ & $0,05 \%$ & $0,1 \%$ & $0,01 \%$ & $0,05 \%$ & $0,1 \%$ & $0,01 \%$ & $0,05 \%$ & $0,1 \%$ \\
\hline$\overline{\mathrm{DABI}}(\%)$ & $33,33 \pm 7,68^{\mathrm{bC}}$ & $63,50 \pm 12,70^{a}$ & $13,83 \pm 11,06^{c}$ & $11,83 \pm 11,63^{c}$ & $51,17 \pm 11,56^{\mathrm{ab}}$ & $19,33 \pm 9,64^{c}$ & $16,33 \pm 12,31^{\mathrm{c}}$ & $58,67 \pm 11,75^{\text {ab }}$ & $52,83 \pm 8,56^{\mathrm{ab}}$ & $61,83 \pm 5,69^{\mathrm{ab}}$ \\
\hline DABII (\%) & $49,50 \pm 4,53^{a}$ & $24,17 \pm 8,32^{\mathrm{bc}}$ & $10,33 \pm 4,82^{\mathrm{cd}}$ & $4,83 \pm 4,64^{d}$ & $37,83 \pm 8,86^{\mathrm{ab}}$ & $20,83 \pm 5,34^{\mathrm{bcd}}$ & $11,17 \pm 4,53^{\mathrm{cd}}$ & $35,17 \pm 9,95^{\mathrm{ab}}$ & $37,50 \pm 6,52^{\mathrm{ab}}$ & $27,17 \pm 3,64^{\mathrm{bc}}$ \\
\hline DABIII (\%) & $14,67 \pm 4,70^{\mathrm{bc}}$ & $8,50 \pm 3,70^{c}$ & $29,33 \pm 9,07^{\mathrm{ab}}$ & $19,17 \pm 9,26^{\mathrm{abc}}$ & $9,67 \pm 3,00^{c}$ & $33,33 \pm 7,61^{a}$ & $32,83 \pm 10,31^{a}$ & $4,50 \pm 1,84^{c}$ & $8,50 \pm 1,84^{c}$ & $7,17 \pm 1,25^{\mathrm{c}}$ \\
\hline DABIV (\%) & $2,50 \pm 0,43^{c}$ & $4,00 \pm 1,51^{c}$ & $46,50 \pm 13,21^{\mathrm{ab}}$ & $64,17 \pm 15,49^{a}$ & $2,17 \pm 0,75^{c}$ & $26,50 \pm 12,53^{\mathrm{bc}}$ & $39,67 \pm 14,40^{\mathrm{ab}}$ & $1,67 \pm 0,33^{c}$ & $2,00 \pm 0,77^{c}$ & $4,00 \pm 2,02^{c}$ \\
\hline $\operatorname{VAP}(\mu \mathrm{m} / \mathrm{s})$ & $61,25 \pm 2,20^{a}$ & $35,25 \pm 0,63^{b c}$ & $8,83 \pm 5,80^{\mathrm{de}}$ & $0,00 \pm 0,00^{\mathrm{e}}$ & $31,78 \pm 3,14^{\mathrm{cd}}$ & $28,40 \pm 20,54^{\mathrm{cd}}$ & $16,08 \pm 8,28^{\mathrm{cde}}$ & $57,20 \pm 11,90^{\mathrm{ab}}$ & $34,65 \pm 2,73^{\mathrm{bc}}$ & $31,30 \pm 1,04^{\mathrm{cd}}$ \\
\hline $\operatorname{VSL}(\mu \mathrm{m} / \mathrm{s})$ & $40,12 \pm 2,63^{\mathrm{a}}$ & $14,80 \pm 2,19^{c}$ & $3,65 \pm 2,73^{\mathrm{et}}$ & $0,00 \pm 0,00^{\dagger}$ & $11,30 \pm 3,19^{\mathrm{cde}}$ & $4,87 \pm 2,98^{\mathrm{et}}$ & $6,17 \pm 3,14^{\mathrm{det}}$ & $30,02 \pm 5,47^{\mathrm{b}}$ & $17,67 \pm 3,32^{c}$ & $13,63 \pm 0,81^{\mathrm{cd}}$ \\
\hline $\operatorname{VCL}(\mu \mathrm{m} / \mathrm{s})$ & $106,83 \pm 5,23^{\mathrm{ab}}$ & $78,30 \pm 8,77^{\mathrm{bc}}$ & $23,13 \pm 15,02^{\mathrm{de}}$ & $0,00 \pm 0,00^{\mathrm{e}}$ & $84,95 \pm 7,27^{\mathrm{bc}}$ & $49,48 \pm 30,65^{c d}$ & $34,72 \pm 19,28^{\mathrm{de}}$ & $129,92 \pm 22,02^{a}$ & $87,88 \pm 5,44^{\mathrm{abc}}$ & $82,65 \pm 2,17^{\mathrm{bc}}$ \\
\hline $\operatorname{ALH}(\mu \mathrm{m})$ & $5,27 \pm 0,28^{\mathrm{bc}}$ & $4,17 \pm 1,53^{\mathrm{cd}}$ & $0,00 \pm 0,00^{e}$ & $0,00 \pm 0,00^{\mathrm{e}}$ & $1,48 \pm 1,06^{\mathrm{de}}$ & $0,00 \pm 0,00^{\mathrm{e}}$ & $0,00 \pm 0,00^{e}$ & $5,53 \pm 1,31^{\mathrm{bc}}$ & $7,58 \pm 1,02^{b}$ & $10,78 \pm 1,86^{\mathrm{a}}$ \\
\hline $\mathrm{BCF}(\mathrm{Hz})$ & $36,02 \pm 2,89^{a}$ & $40,55 \pm 2,65^{a}$ & $8,93 \pm 6,42^{\mathrm{bc}}$ & $0,00 \pm 0,00^{c}$ & $36,68 \pm 7,54^{a}$ & $13,10 \pm 8,63^{b c}$ & $17,93 \pm 11,45^{\mathrm{b}}$ & $39,17 \pm 2,84^{\mathrm{a}}$ & $39,68 \pm 1,05^{a}$ & $41,05 \pm 1,62^{\mathrm{a}}$ \\
\hline MOT (\%) & $8,33 \pm 1,84^{b c}$ & $17,83 \pm 4,64^{b}$ & $0,00 \pm 0,00^{c}$ & $0,00 \pm 0,00^{c}$ & $11,50 \pm 4,29^{b c}$ & $0,00 \pm 0,00^{c}$ & $0,00 \pm 0,00^{c}$ & $30,00 \pm 10,69^{a}$ & $18,00 \pm 2,10^{b}$ & $13,67 \pm 3,07^{b}$ \\
\hline PROG(\%) & $2,17 \pm 0,60^{\mathrm{ab}}$ & $0,33 \pm 0,21^{c}$ & $0,00 \pm 0,00^{c}$ & $0,00 \pm 0,00^{c}$ & $0,50 \pm 0,50^{\mathrm{bc}}$ & $0,00 \pm 0,00^{c}$ & $0,00 \pm 0,00^{c}$ & $3,33 \pm 1,61^{a}$ & $1,67 \pm 0,88^{\mathrm{abc}}$ & $0,17 \pm 0,17^{c}$ \\
\hline RAP (\%) & $4,83 \pm 1,19^{b}$ & $2,33 \pm 1,02^{b}$ & $0,00 \pm 0,00^{b}$ & $0,00 \pm 0,00^{b}$ & $1,67 \pm 1,31^{b}$ & $0,00 \pm 0,00^{b}$ & $0,00 \pm 0,00^{b}$ & $18,50 \pm 9,00^{a}$ & $2,33 \pm 1,02^{b}$ & $1,00 \pm 0,37^{b}$ \\
\hline MED (\%) & $3,17 \pm 0,70^{b}$ & $15,50 \pm 3,72^{\mathrm{a}}$ & $0,00 \pm 0,00^{b}$ & $0,00 \pm 0,00^{b}$ & $9,83 \pm 3,38^{\mathrm{a}}$ & $0,00 \pm 0,00^{b}$ & $0,00 \pm 0,00^{b}$ & $11,50 \pm 2,35^{\mathrm{a}}$ & $15,50 \pm 1,93^{\mathrm{a}}$ & $12,83 \pm 2,85^{a}$ \\
\hline STATIC (\%) & $82,33 \pm 5,90^{a b}$ & $65,33 \pm 6,58^{\mathrm{abc}}$ & $65,67 \pm 9,63^{\mathrm{abc}}$ & $87,17 \pm 3,61^{a}$ & $69,67 \pm 6,44^{\mathrm{abc}}$ & $64,83 \pm 11,31^{\mathrm{bc}}$ & $68,83 \pm 6,00^{\mathrm{abc}}$ & $53,00 \pm 11,40^{c}$ & $56,00 \pm 6,60^{c}$ & $53,67 \pm 6,58^{c}$ \\
\hline
\end{tabular}

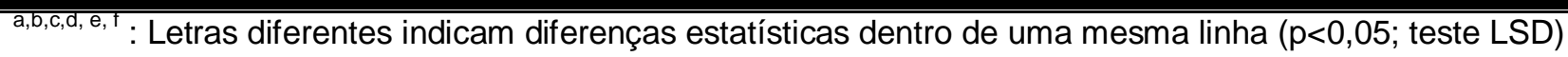

Nas amostras avaliadas 5 dias (120 horas) após a refrigeração (Tabela 7), verificou-se uma porcentagem maior de células DAB I no diluidor 8160 0,01\% quando comparado com o diluidor contendo gema de ovo. Ademais, houve uma maior porcentagem de células DAB IV nos diluidores 8160 0,05\% e 0,1\% e FP40 0,1\% em comparação com a gema de ovo. Em relação à motilidade, houve uma maior porcentagem de células móveis no diluidor Solec F 0,01\% assim em comparação com a gema de ovo. 
Tabela 8 - Efeito do tempo (2, 24, 48, 96, 120 horas) na atividade mitocondrial (DAB I atividade total, DAB II atividade alta, DAB III atividade baixa, DAB IV atividade nula) e nas variáveis analisadas pelo CASA (VAP, VSL, VCL, ALH, BCF, MOT, PROG, RAP, MED, STATIC), em amostras de sêmen de cães refrigeradas $\left(5^{\circ} \mathrm{C}\right)$ em diluidor a base de gema de ovo São Paulo - 2012

\begin{tabular}{lcccccc} 
& \multicolumn{1}{c}{ 2 horas } & 24 horas & 48 horas & 72 horas & 96 horas & 120 horas \\
\hline DABI (\%) & $86,50 \pm 3,55^{\mathrm{a}}$ & $79,50 \pm 3,78^{\mathrm{a}}$ & $56,17 \pm 3,88^{\mathrm{b}}$ & $29,83 \pm 5,39^{\mathrm{c}}$ & $39,83 \pm 2,88^{\mathrm{c}}$ & $33,33 \pm 7,68^{\mathrm{c}}$ \\
DABII (\%) & $10,67 \pm 3,42^{\mathrm{b}}$ & $18,00 \pm 3,64^{\mathrm{b}}$ & $37,33 \pm 4,79^{\mathrm{a}}$ & $49,50 \pm 5,94^{\mathrm{a}}$ & $48,00 \pm 5,85^{\mathrm{a}}$ & $49,50 \pm 4,53^{\mathrm{a}}$ \\
DABIII (\%) & $0,83 \pm 0,31^{\mathrm{c}}$ & $2,00 \pm 0,73^{\mathrm{c}}$ & $7,17 \pm 2,09^{\mathrm{bc}}$ & $15,67 \pm 4,50^{\mathrm{a}}$ & $8,00 \pm 1,77^{\mathrm{abc}}$ & $14,67 \pm 4,70^{\mathrm{ab}}$ \\
DABIV (\%) & $2,00 \pm 0,52$ & $0,50 \pm 0,22$ & $1,17 \pm 0,75$ & $5,00 \pm 3,24$ & $4,17 \pm 2,24$ & $2,50 \pm 0,43$ \\
VAP ( $\mu \mathrm{m} / \mathrm{s})$ & $112,45 \pm 3,89^{\mathrm{a}}$ & $108,85 \pm 5,00^{\mathrm{a}}$ & $94,52 \pm 4,61^{\mathrm{b}}$ & $78,08 \pm 3,53^{\mathrm{c}}$ & $72,98 \pm 3,63^{\mathrm{c}}$ & $61,25 \pm 2,20^{\mathrm{a}}$ \\
VSL $(\mu \mathrm{m} / \mathrm{s})$ & $87,50 \pm 5,37^{\mathrm{a}}$ & $62,27 \pm 5,14^{\mathrm{b}}$ & $57,32 \pm 4,95^{\mathrm{b}}$ & $52,80 \pm 5,15^{\mathrm{bc}}$ & $52,27 \pm 2,98^{\mathrm{bc}}$ & $40,12 \pm 2,63^{\mathrm{c}}$ \\
VCL $(\mu \mathrm{m} / \mathrm{s})$ & $157,25 \pm 10,17^{\mathrm{a}}$ & $170,02 \pm 13,44^{\mathrm{a}}$ & $145,48 \pm 5,68^{\mathrm{ab}}$ & $124,32 \pm 6,83^{\mathrm{bc}}$ & $113,00 \pm 6,72^{\mathrm{c}}$ & $106,83 \pm 5,23^{\mathrm{c}}$ \\
ALH $(\mu \mathrm{m})$ & $7,92 \pm 0,58^{\mathrm{a}}$ & $7,17 \pm 0,61^{\mathrm{a}}$ & $5,73 \pm 0,38^{\mathrm{b}}$ & $5,82 \pm 0,38^{\mathrm{b}}$ & $5,52 \pm 0,37^{\mathrm{b}}$ & $5,27 \pm 0,28^{\mathrm{b}}$ \\
BCF $(\mathrm{Hz})$ & $25,97 \pm 1,94^{\mathrm{b}}$ & $35,10 \pm 2,12^{\mathrm{a}}$ & $37,13 \pm 1,51^{\mathrm{a}}$ & $38,45 \pm 1,74^{\mathrm{a}}$ & $36,02 \pm 1,35^{\mathrm{a}}$ & $36,02 \pm 2,89^{\mathrm{a}}$ \\
MOT (\%) & $70,67 \pm 6,29^{\mathrm{a}}$ & $60,83 \pm 9,63^{\mathrm{ab}}$ & $48,67 \pm 5,53^{\mathrm{b}}$ & $44,33 \pm 9,78^{\mathrm{bc}}$ & $24,33 \pm 7,26^{\mathrm{cd}}$ & $8,33 \pm 1,84^{\mathrm{d}}$ \\
PROG $\%)$ & $42,67 \pm 5,96^{\mathrm{a}}$ & $21,50 \pm 6,40^{\mathrm{b}}$ & $17,67 \pm 4,18^{\mathrm{b}}$ & $16,17 \pm 5,17^{\mathrm{b}}$ & $9,17 \pm 3,04^{\mathrm{bc}}$ & $2,17 \pm 0,60^{\mathrm{c}}$ \\
RAP (\%) & $58,83 \pm 5,50^{\mathrm{a}}$ & $54,17 \pm 9,33^{\mathrm{ab}}$ & $41,00 \pm 4,86^{\mathrm{bc}}$ & $29,33 \pm 5,39^{\mathrm{cd}}$ & $15,67 \pm 3,86^{\mathrm{de}}$ & $4,83 \pm 1,19^{\dagger}$ \\
MED (\%) & $11,67 \pm 3,70^{\mathrm{ab}}$ & $6,83 \pm 1,87^{\mathrm{ab}}$ & $7,67 \pm 1,52^{\mathrm{ab}}$ & $15,00 \pm 5,08^{\mathrm{a}}$ & $8,67 \pm 3,73^{\mathrm{ab}}$ & $3,17 \pm 0,70^{\mathrm{b}}$ \\
STATIC (\%) & $16,83 \pm 5,26^{\mathrm{c}}$ & $23,83 \pm 7,73^{\mathrm{c}}$ & $26,83 \pm 8,60^{\mathrm{c}}$ & $27,67 \pm 7,06^{\mathrm{bc}}$ & $49,50 \pm 11,07^{\mathrm{b}}$ & $82,33 \pm 5,90^{\mathrm{a}}$ \\
\hline
\end{tabular}

\footnotetext{
a,b,c, $\bar{c}:$ Letras diferentes indicam diferenças estatísticas dentro de uma mesma linha ( $p<0,05 ;$ teste LSD)
}

Nas amostras de sêmen de cães refrigeradas com diluidor contendo gema de ovo (Tabela 8), a porcentagem de células com atividade total (DABI) se manteve até 24 horas de refrigeração. No entanto, ocorreu uma diminuição na porcentagem de células móveis a partir de 48 horas e a porcentagem de células progressivas foi reduzida a partir de 24 horas. 
Tabela 9 - Efeito do tempo (2, 24, 48, 96, 120 horas) na atividade mitocondrial (DAB I, atividade total; DAB II, atividade alta; DAB III, atividade baixa; DAB IV atividade nula) e nas variáveis analisadas pelo CASA (VAP, VSL, VCL, ALH, BCF, MOT, PROG, RAP, MED, STATIC), em amostras de sêmen de cães refrigeradas $\left(5^{\circ} \mathrm{C}\right)$ em diluidor a base de lecitina de soja 8160 0,01\% - São Paulo - 2012

\begin{tabular}{|c|c|c|c|c|c|c|}
\hline & 2 horas & 24 horas & 48 horas & 72 horas & 96 horas & 120 horas \\
\hline DABI (\%) & $61,83 \pm 12,50$ & $62,40 \pm 8,84$ & $53,17 \pm 12,49$ & $47,67 \pm 13,51$ & $55,17 \pm 10,54$ & $63,50 \pm 12,70$ \\
\hline DABII (\%) & $35,83 \pm 12,95$ & $35,80 \pm 9,11$ & $38,83 \pm 10,41$ & $40,83 \pm 9,86$ & $37,17 \pm 9,11$ & $24,17 \pm 8,32$ \\
\hline DABIII (\%) & $1,17 \pm 0,83^{b}$ & $1,20 \pm 0,37^{b}$ & $6,67 \pm 3,61^{\mathrm{ab}}$ & $9,33 \pm 3,06^{a}$ & $5,33 \pm 2,47^{\mathrm{ab}}$ & $8,50 \pm 3,70^{a b}$ \\
\hline DABIV (\%) & $1,17 \pm 0,75$ & $0,60 \pm 0,40$ & $1,33 \pm 0,99$ & $2,17 \pm 1,78$ & $2,33 \pm 0,84$ & $4,00 \pm 1,51$ \\
\hline $\operatorname{VAP}(\mu \mathrm{m} / \mathrm{s})$ & $96,80 \pm 7,23^{\mathrm{a}}$ & $85,25 \pm 10,35^{a}$ & $56,38 \pm 10,10^{b}$ & $50,68 \pm 6,11^{\mathrm{bc}}$ & $31,10 \pm 2,20^{c}$ & $35,25 \pm 0,63^{c}$ \\
\hline $\operatorname{VSL}(\mu \mathrm{m} / \mathrm{s})$ & $41,95 \pm 2,82^{a}$ & $38,00 \pm 1,90^{a}$ & $25,07 \pm 4,00^{b}$ & $22,88 \pm 3,70^{\mathrm{bc}}$ & $12,72 \pm 1,85^{\mathrm{a}}$ & $14,80 \pm 2,19^{\mathrm{cd}}$ \\
\hline $\operatorname{VCL}(\mu \mathrm{m} / \mathrm{s})$ & $200,02 \pm 11,14^{a}$ & $185,00 \pm 13,18^{a}$ & $142,02 \pm 19,15^{b}$ & $127,53 \pm 14,24^{b}$ & $86,03 \pm 7,99^{c}$ & $78,30 \pm 8,77^{\circ}$ \\
\hline $\mathrm{ALH}(\mu \mathrm{m})$ & $8,77 \pm 0,27^{a}$ & $7,68 \pm 0,28^{a}$ & $7,62 \pm 0,39^{a}$ & $6,70 \pm 0,46^{\mathrm{ab}}$ & $2,67 \pm 1,39^{c}$ & $4,17 \pm 1,5^{\mathrm{bc}}$ \\
\hline $\mathrm{BCF}(\mathrm{Hz})$ & $35,92 \pm 2,20^{b}$ & $35,18 \pm 2,03^{b}$ & $38,20 \pm 2,53^{\mathrm{ab}}$ & $40,43 \pm 1,73^{\mathrm{ab}}$ & $42,33 \pm 1,83^{a}$ & $40,55 \pm 2,65^{\mathrm{ab}}$ \\
\hline МOT (\%) & $76,67 \pm 5,22^{\mathrm{ab}}$ & $81,83 \pm 4,55^{a}$ & $61,33 \pm 13,64^{\mathrm{ab}}$ & $57,67 \pm 6,93^{b}$ & $15,33 \pm 5,28^{c}$ & $17,83 \pm 4,64^{c}$ \\
\hline PROG(\%) & $7,50 \pm 1,65^{a b}$ & $9,00 \pm 1,06^{a}$ & $4,67 \pm 1,41^{\mathrm{bc}}$ & $3,83 \pm 0,95^{c}$ & $0,33 \pm 0,21^{a}$ & $0,33 \pm 0,21^{d}$ \\
\hline RAP (\%) & $62,00 \pm 6,68^{a}$ & $63,50 \pm 7,84^{\mathrm{a}}$ & $35,67 \pm 13,51^{b}$ & $25,50 \pm 8,94^{b}$ & $2,17 \pm 1,33^{c}$ & $2,33 \pm 1,02^{\mathrm{C}}$ \\
\hline MED (\%) & $14,33 \pm 3,14^{b}$ & $18,50 \pm 4,40^{b}$ & $25,83 \pm 6,57^{\mathrm{ab}}$ & $32,00 \pm 4,69^{a}$ & $13,33 \pm 4,18^{b}$ & $15,50 \pm 3,72^{b}$ \\
\hline STATIC (\%) & $14,83 \pm 2,71^{b}$ & $12,00 \pm 3,30^{b}$ & $25,33 \pm 8,71^{b}$ & $29,50 \pm 6,78^{b}$ & $62,67 \pm 9,29^{a}$ & $65,33 \pm 6,58^{a}$ \\
\hline
\end{tabular}
LSD)

No diluidor 8160 0,01\% (Tabela 9) não foi observado efeito significante do tempo na porcentagem de células com atividade mitocondrial total (DABI) ou com atividade mitocondrial nula (DABIV), indicando que este diluidor é capaz de manter a atividade mitocondrial por até 5 dias. Além disto, a motilidade foi mantida por até 72 horas de refrigeração, sendo que não houve diferenças em relação às avaliações realizadas 2 e 48 horas após a refrigeração (57,67 \pm 6,93; 76,67 \pm 5,22; 61,33 \pm 13,64, respectivamente). No entanto, o padrão de motilidade progressiva apresentou alterações mais precocemente, com a porcentagem de células progressivas sendo mantida até o tempo 48 horas e a porcentagem de células rápidas até 24 horas. 
Tabela 10 - Efeito do tempo (2, 24, 48, 96, 120 horas) na atividade mitocondrial (DAB I atividade total, DAB II atividade alta, DAB III atividade baixa, DAB IV atividade nula) e nas variáveis analisadas pelo CASA (VAP, VSL, VCL, ALH, BCF, MOT, PROG, RAP, MED, STATIC), em amostras de sêmen de cães refrigeradas $\left(5^{\circ} \mathrm{C}\right)$ em diluidor a base de lecitina de soja 8160 0,05\% - São Paulo - 2012

\begin{tabular}{|c|c|c|c|c|c|c|}
\hline & 2 horas & 24 horas & 48 horas & 72 horas & 96 horas & 120 horas \\
\hline DABI (\%) & $56,33 \pm 8,34^{a}$ & $22,80 \pm 9,13^{b}$ & $10,00 \pm 4,34^{b}$ & $9,17 \pm 5,31^{b}$ & $5,83 \pm 4,17^{0}$ & $13,83 \pm 11,06^{b}$ \\
\hline DABII (\%) & $34,00 \pm 6,41^{\mathrm{ab}}$ & $49,20 \pm 14,82^{\mathrm{a}}$ & $36,67 \pm 12,06^{a b}$ & $36,50 \pm 11,68^{\mathrm{ab}}$ & $20,67 \pm 12,26^{a b}$ & $10,33 \pm 4,82^{b}$ \\
\hline DABIII (\%) & $5,00 \pm 3,33^{c}$ & $7,00 \pm 3,74^{\mathrm{bc}}$ & $41,00 \pm 9,49^{a}$ & $36,50 \pm 10,93^{a}$ & $28,17 \pm 7,54^{\mathrm{abc}}$ & $29,33 \pm 9,07^{\mathrm{ab}}$ \\
\hline DABIV (\%) & $4,67 \pm 3,32^{c}$ & $21,00 \pm 19,76^{\mathrm{abc}}$ & $12,50 \pm 6,34^{\mathrm{bc}}$ & $17,83 \pm 8,60^{\mathrm{abc}}$ & $45,33 \pm 14,19^{a b}$ & $46,50 \pm 13,21^{a}$ \\
\hline $\operatorname{VAP}(\mu \mathrm{m} / \mathrm{s})$ & $67,53 \pm 11,47^{a}$ & $9,27 \pm 6,05^{b}$ & $4,50 \pm 4,50^{b}$ & $8,00 \pm 5,08^{b}$ & $3,60 \pm 3,60^{b}$ & $8,83 \pm 5,80^{b}$ \\
\hline $\operatorname{VSL}(\mu \mathrm{m} / \mathrm{s})$ & $31,90 \pm 6,53^{a}$ & $5,58 \pm 3,54^{b}$ & $1,15 \pm 1,15^{b}$ & $6,00 \pm 3,93^{b}$ & $1,45 \pm 1,45^{b}$ & $3,65 \pm 2,73^{b}$ \\
\hline $\operatorname{VCL}(\mu \mathrm{m} / \mathrm{s})$ & $162,63 \pm 19,45^{a}$ & $25,05 \pm 18,44^{b}$ & $10,98 \pm 10,98^{\mathrm{b}}$ & $14,58 \pm 9,39^{b}$ & $14,92 \pm 14,92^{\mathrm{b}}$ & $23,13 \pm 15,02^{b}$ \\
\hline $\mathrm{ALH}(\mu \mathrm{m})$ & $6,70 \pm 1,42^{\mathrm{a}}$ & $1,78 \pm 1,78^{b}$ & $0,00 \pm 0,00^{b}$ & $0,00 \pm 0,00^{b}$ & $0,00 \pm 0,00^{b}$ & $0,00 \pm 0,00^{b}$ \\
\hline $\mathrm{BCF}(\mathrm{Hz})$ & $36,45 \pm 2,31^{a}$ & $6,33 \pm 6,33^{b}$ & $7,75 \pm 7,75^{b}$ & $11,47 \pm 9,81^{b}$ & $10,00 \pm 10,00^{b}$ & $8,93 \pm 6,42^{\mathrm{D}}$ \\
\hline МОТ (\%) & $62,50 \pm 10,85^{a}$ & $6,83 \pm 6,83^{b}$ & $0,17 \pm 0,17^{b}$ & $0,00 \pm 0,00^{b}$ & $0,00 \pm 0,00^{b}$ & $0,00 \pm 0,00^{b}$ \\
\hline PROG(\%) & $5,00 \pm 1,57^{a}$ & $0,17 \pm 0,17^{b}$ & $0,00 \pm 0,00^{b}$ & $0,00 \pm 0,00^{b}$ & $0,00 \pm 0,00^{b}$ & $0,00 \pm 0,00^{b}$ \\
\hline RAP (\%) & $40,67 \pm 10,97^{a}$ & $0,50 \pm 0,50^{b}$ & $0,00 \pm 0,00^{b}$ & $0,00 \pm 0,00^{b}$ & $0,00 \pm 0,00^{b}$ & $0,00 \pm 0,00^{b}$ \\
\hline MED (\%) & $21,67 \pm 6,62^{a}$ & $6,33 \pm 6,33^{b}$ & $0,17 \pm 0,17^{b}$ & $0,00 \pm 0,00^{b}$ & $0,00 \pm 0,00^{b}$ & $0,00 \pm 0,00^{b}$ \\
\hline STATIC (\%) & $26,33 \pm 10,40^{b}$ & $69,83 \pm 10,43^{a}$ & $79,33 \pm 3,59^{a}$ & $79,33 \pm 7,18^{a}$ & $83,67 \pm 5,76^{a}$ & $65,67 \pm 9,63^{a}$ \\
\hline
\end{tabular}

Nas amostras refrigeradas com o diluidor 8160 0,05\% foram observados uma diminuição significativa nas porcentagens de células $D A B I$, móveis e progressivas a partir de 24 horas de refrigeração, e um aumento na porcentagem de células DABIV a partir de 96 horas de refrigeração. Tais resultados indicam que este diluidor, nessa concentração, não é capaz de manter a viabilidade espermática a partir de 24 horas de refrigeração (Tabela 10). 
Tabela 11 - Efeito do tempo (2, 24, 48, 96, 120 horas) na atividade mitocondrial (DAB I, atividade total; DAB II, atividade alta; DAB III, atividade baixa; DAB IV, atividade nula) e nas variáveis analisadas pelo CASA (VAP, VSL, VCL, ALH, BCF, MOT, PROG, RAP, MED, STATIC), em amostras de sêmen de cães refrigeradas $\left(5^{\circ} \mathrm{C}\right)$ em diluidor a base de lecitina de soja 8160 0,1\% - São Paulo - 2012

\begin{tabular}{|c|c|c|c|c|c|c|}
\hline & 2 horas & 24 horas & 48 horas & 72 horas & 96 horas & 120 horas \\
\hline DABI (\%) & $45,33 \pm 11,39^{a}$ & $14,17 \pm 7,67^{b}$ & $3,83 \pm 3,25^{b}$ & $7,33 \pm 2,46^{6}$ & $0,33 \pm 0,21^{b}$ & $11,83 \pm 11,63^{b}$ \\
\hline DABII (\%) & $43,33 \pm 10,73^{\mathrm{ab}}$ & $57,50 \pm 11,58^{a}$ & $23,00 \pm 9,34^{b c}$ & $19,50 \pm 7,31^{\mathrm{bc}}$ & $11,33 \pm 9,96^{c}$ & $4,83 \pm 4,64^{c}$ \\
\hline DABIII (\%) & $5,17 \pm 2,64^{c}$ & $21,00 \pm 6,76^{\mathrm{bc}}$ & $49,00 \pm 5,93^{a}$ & $37,17 \pm 6,23^{\mathrm{ab}}$ & $25,00 \pm 8,02^{b}$ & $19,17 \pm 9,26^{\mathrm{bc}}$ \\
\hline DABIV (\%) & $6,17 \pm 4,07^{\mathrm{D}}$ & $7,33 \pm 2,50^{b}$ & $24,17 \pm 9,56^{b}$ & $36,00 \pm 10,21^{a}$ & $63,50 \pm 14,53^{a}$ & $64,17 \pm 15,49^{a}$ \\
\hline $\operatorname{VAP}(\mu \mathrm{m} / \mathrm{s})$ & $44,63 \pm 8,80^{a}$ & $3,43 \pm 3,43^{\mathrm{bc}}$ & $0,00 \pm 0,00^{c}$ & $15,08 \pm 6,85^{\mathrm{b}}$ & $4,18 \pm 4,18^{\mathrm{bc}}$ & $0,00 \pm 0,00^{c}$ \\
\hline $\operatorname{VSL}(\mu \mathrm{m} / \mathrm{s})$ & $18,15 \pm 4,10^{a}$ & $1,37 \pm 1,37^{\mathrm{b}}$ & $0,00 \pm 0,00^{b}$ & $7,80 \pm 4,01^{b}$ & $3,33 \pm 3,33^{b}$ & $0,00 \pm 0,00^{\mathrm{b}}$ \\
\hline $\operatorname{VCL}(\mu \mathrm{m} / \mathrm{s})$ & $112,67 \pm 22,01^{a}$ & $5,05 \pm 5,05^{b}$ & $0,00 \pm 0,00^{b}$ & $27,85 \pm 13,59^{b}$ & $8,97 \pm 8,97^{b}$ & $0,00 \pm 0,00^{b}$ \\
\hline ALH $(\mu \mathrm{m})$ & $4,93 \pm 1,75^{a}$ & $0,00 \pm 0,00^{b}$ & $0,00 \pm 0,00^{b}$ & $0,00 \pm 0,00^{b}$ & $0,00 \pm 0,00^{b}$ & $0,00 \pm 0,00^{b}$ \\
\hline $\mathrm{BCF}(\mathrm{Hz})$ & $37,18 \pm 2,65^{a}$ & $0,00 \pm 0,00^{c}$ & $0,00 \pm 0,00^{c}$ & $18,20 \pm 8,56^{\mathrm{b}}$ & $8,00 \pm 8,00^{b c}$ & $0,00 \pm 0,00^{c}$ \\
\hline MOT (\%) & $37,67 \pm 10,12^{\mathrm{a}}$ & $0,00 \pm 0,00^{b}$ & $0,00 \pm 0,00^{b}$ & $0,17 \pm 0,17^{b}$ & $0,00 \pm 0,00^{b}$ & $0,00 \pm 0,00^{b}$ \\
\hline PROG(\%) & $0,83 \pm 0,48^{a}$ & $0,00 \pm 0,00^{b}$ & $0,00 \pm 0,00^{b}$ & $0,00 \pm 0,00^{b}$ & $0,00 \pm 0,00^{b}$ & $0,00 \pm 0,00^{\mathrm{b}}$ \\
\hline RAP (\%) & $14,67 \pm 8,13^{\mathrm{a}}$ & $0,00 \pm 0,00^{b}$ & $0,00 \pm 0,00^{b}$ & $0,00 \pm 0,00^{b}$ & $0,00 \pm 0,00^{b}$ & $0,00 \pm 0,00^{b}$ \\
\hline MED (\%) & $23,17 \pm 6,55^{\mathrm{a}}$ & $0,00 \pm 0,00^{b}$ & $0,00 \pm 0,00^{b}$ & $0,17 \pm 0,17^{b}$ & $0,00 \pm 0,00^{b}$ & $0,00 \pm 0,00^{b}$ \\
\hline STATIC (\%) & $36,33 \pm 6,26^{b}$ & $77,83 \pm 7,32^{\mathrm{a}}$ & $76,00 \pm 11,90^{a}$ & $72,33 \pm 7,24^{\mathrm{a}}$ & $78,17 \pm 5,86^{\mathrm{a}}$ & $87,17 \pm 3,61^{a}$ \\
\hline
\end{tabular}

Na concentração de $0,1 \%$ do diluidor a base de lecitina 8160 (Tabela 11), notou-se que as porcentagens de células DABI, móveis e progressivas, se mantiveram apenas no tempo 2 horas, havendo uma diminuição expressiva após este período. Também foi demonstrado um aumento substancial na porcentagem de células DAB IV a partir de 72 horas de refrigeração. 
Tabela 12 - Efeito do tempo (2, 24, 48, 96, 120 horas) na atividade mitocondrial (DAB I, atividade total; DAB II, atividade alta; DAB III, atividade baixa; DAB IV atividade nula) e nas variáveis analisadas pelo CASA (VAP, VSL, VCL, ALH, BCF, MOT, PROG, RAP, MED, STATIC), em amostras de sêmen de cães refrigeradas $\left(5^{\circ} \mathrm{C}\right)$ em diluidor a base de lecitina de soja FP40 0,01\% - São Paulo - 2012

\begin{tabular}{lcccccc} 
& 2 horas & 24 horas & 48 horas & 72 horas & 96 horas & 120 horas \\
\hline DABI (\%) & $53,80 \pm 15,85$ & $69,00 \pm 2,92$ & $60,67 \pm 10,43$ & $46,33 \pm 10,05$ & $71,67 \pm 4,54$ & $51,17 \pm 11,56$ \\
DABII (\%) & $24,60 \pm 11,12$ & $27,20 \pm 2,82$ & $35,50 \pm 10,85$ & $41,17 \pm 7,85$ & $20,83 \pm 3,59$ & $37,83 \pm 8,86$ \\
DABIII (\%) & $0,80 \pm 0,49^{\mathrm{c}}$ & $2,60 \pm 1,54^{\mathrm{c}}$ & $4,50 \pm 1,09^{\mathrm{bc}}$ & $10,33 \pm 2,59^{\mathrm{a}}$ & $4,50 \pm 1,54^{\mathrm{bc}}$ & $9,67 \pm 3,00^{\mathrm{ab}}$ \\
DABIV (\%) & $20,80 \pm 19,55$ & $1,20 \pm 0,73$ & $1,00 \pm 0,45$ & $2,17 \pm 0,95$ & $3,00 \pm 1,34$ & $2,17 \pm 0,75$ \\
VAP $(\mu \mathrm{m} / \mathrm{s})$ & $78,83 \pm 8,73^{\mathrm{a}}$ & $57,37 \pm 10,42^{\mathrm{ab}}$ & $50,30 \pm 10,38^{\mathrm{bc}}$ & $42,47 \pm 6,03^{\mathrm{bc}}$ & $43,23 \pm 7,56^{\mathrm{bc}}$ & $31,78 \pm 3,14^{\mathrm{c}}$ \\
VSL $(\mu \mathrm{m} / \mathrm{s})$ & $39,52 \pm 6,07^{\mathrm{a}}$ & $27,97 \pm 5,21^{\mathrm{ab}}$ & $19,18 \pm 4,49^{\mathrm{bc}}$ & $19,27 \pm 3,38^{\mathrm{bc}}$ & $16,12 \pm 3,50^{\mathrm{bc}}$ & $11,30 \pm 3,19^{\mathrm{c}}$ \\
VCL $(\mu \mathrm{m} / \mathrm{s})$ & $170,22 \pm 13,50^{\mathrm{a}}$ & $146,52 \pm 16,12^{\mathrm{ab}}$ & $129,55 \pm 15,79^{\mathrm{b}}$ & $115,57 \pm 12,42^{\mathrm{bc}}$ & $109,22 \pm 14,13^{\mathrm{bc}}$ & $84,95 \pm 7,27^{\mathrm{c}}$ \\
ALH $(\mu \mathrm{m})$ & $7,92 \pm 0,59^{\mathrm{a}}$ & $6,60 \pm 1,34^{\mathrm{a}}$ & $5,95 \pm 0,56^{\mathrm{a}}$ & $5,25 \pm 1,15^{\mathrm{a}}$ & $5,67 \pm 1,30^{\mathrm{a}}$ & $1,48 \pm 1,06^{\mathrm{b}}$ \\
BCF $(\mathrm{Hz})$ & $35,42 \pm 2,38$ & $37,30 \pm 2,97$ & $43,62 \pm 0,71$ & $39,60 \pm 2,20$ & $43,83 \pm 1,26$ & $36,68 \pm 7,54$ \\
MOT $(\%)$ & $75,33 \pm 6,71^{\mathrm{a}}$ & $57,17 \pm 12,20^{\mathrm{ab}}$ & $53,83 \pm 6,24^{\mathrm{ab}}$ & $50,50 \pm 10,57^{\mathrm{b}}$ & $35,67 \pm 7,05^{\mathrm{b}}$ & $11,50 \pm 4,29^{\mathrm{c}}$ \\
PROG(\%) & $7,83 \pm 2,20^{\mathrm{a}}$ & $5,33 \pm 2,32^{\mathrm{ab}}$ & $2,33 \pm 1,17^{\mathrm{bc}}$ & $3,17 \pm 1,30^{\mathrm{bc}}$ & $1,00 \pm 0,63^{\mathrm{bc}}$ & $0,50 \pm 0,50^{\mathrm{c}}$ \\
RAP $(\%)$ & $51,67 \pm 7,86^{\mathrm{a}}$ & $31,33 \pm 10,08^{\mathrm{ab}}$ & $20,00 \pm 9,32^{\mathrm{bc}}$ & $17,67 \pm 8,08^{\mathrm{bc}}$ & $10,50 \pm 6,03^{\mathrm{bc}}$ & $1,67 \pm 1,31^{\mathrm{c}}$ \\
MED $(\%)$ & $23,50 \pm 3,76^{\mathrm{ab}}$ & $26,00 \pm 7,43^{\mathrm{a}}$ & $33,83 \pm 6,36^{\mathrm{a}}$ & $32,50 \pm 5,44^{\mathrm{a}}$ & $25,33 \pm 4,42^{\mathrm{a}}$ & $9,83 \pm 3,38^{\mathrm{b}}$ \\
STATIC $(\%)$ & $17,17 \pm 6,02^{\mathrm{c}}$ & $25,67 \pm 8,06^{\mathrm{bc}}$ & $31,67 \pm 5,64^{\mathrm{bc}}$ & $35,17 \pm 10,63^{\mathrm{bc}}$ & $46,67 \pm 5,74^{\mathrm{b}}$ & $69,67 \pm 6,44^{\mathrm{a}}$ \\
\hline \hline
\end{tabular}

: Letras diferentes indicam diferenças estatísticas dentro de uma mesma linha ( $p<0,05 ;$ teste LSD)

As porcentagens de células DABI e DABIV não apresentaram efeito significativo ao longo dos 5 dias quando refrigeradas no diluidor FP40 0,01\%. No entanto, a porcentagem de células móveis se manteve por até 48 horas, apresentando $50 \%$ de motilidade até 72 horas. No entanto, a porcentagem de células progressivas e rápidas se manteve por até 24 horas (Tabela 12). 
Tabela 13 - Efeito do tempo (2, 24, 48, 96, 120 horas) na atividade mitocondrial (DAB I, atividade total; DAB II, atividade alta; DAB III, atividade baixa; DAB IV, atividade nula) e nas variáveis analisadas pelo CASA (VAP, VSL, VCL, ALH, BCF, MOT, PROG, RAP, MED, STATIC), em amostras de sêmen de cães refrigeradas $\left(5^{\circ} \mathrm{C}\right)$ em diluidor a base de lecitina de soja FP40 0,05\% - São Paulo - 2012

\begin{tabular}{|c|c|c|c|c|c|c|}
\hline & 2 horas & 24 horas & 48 horas & 72 horas & 96 horas & 120 horas \\
\hline DABI (\%) & $63,17 \pm 13,73^{a}$ & $51,40 \pm 13,08^{\mathrm{ab}}$ & $30,50 \pm 12,09^{a b}$ & $29,33 \pm 14,00^{a b}$ & $17,17 \pm 9,43^{b}$ & $19,33 \pm 9,64^{b}$ \\
\hline DABII (\%) & $16,83 \pm 5,02^{b}$ & $25,60 \pm 7,08^{\mathrm{ab}}$ & $39,00 \pm 6,50^{\mathrm{a}}$ & $34,50 \pm 10,71^{a b}$ & $29,17 \pm 8,80^{\mathrm{ab}}$ & $20,83 \pm 5,34^{a b}$ \\
\hline DABIII (\%) & $2,67 \pm 2,28^{c}$ & $3,00 \pm 1,38^{\mathrm{bc}}$ & $24,17 \pm 8,82^{\mathrm{ab}}$ & $27,67 \pm 10,14^{\mathrm{a}}$ & $27,50 \pm 7,90^{\mathrm{a}}$ & $33,33 \pm 7,61^{\mathrm{a}}$ \\
\hline DABIV (\%) & $17,33 \pm 16,54$ & $20,00 \pm 20,00$ & $6,33 \pm 3,75$ & $8,50 \pm 3,32$ & $26,33 \pm 14,49$ & $26,50 \pm 12,53$ \\
\hline $\operatorname{VAP}(\mu \mathrm{m} / \mathrm{s})$ & $74,63 \pm 8,38^{a}$ & $24,93 \pm 8,15^{b}$ & $14,38 \pm 6,50^{\mathrm{b}}$ & $4,75 \pm 4,75^{b}$ & $12,00 \pm 5,45^{b}$ & $28,40 \pm 20,54^{b}$ \\
\hline $\operatorname{VSL}(\mu \mathrm{m} / \mathrm{s})$ & $35,47 \pm 2,94^{a}$ & $13,72 \pm 5,25^{b}$ & $7,98 \pm 3,99^{\mathrm{bc}}$ & $1,30 \pm 1,30^{c}$ & $8,35 \pm 4,36^{\mathrm{bc}}$ & $4,87 \pm 2,98^{\mathrm{bc}}$ \\
\hline $\operatorname{VCL}(\mu \mathrm{m} / \mathrm{s})$ & $171,05 \pm 15,38^{a}$ & $61,28 \pm 20,87^{b}$ & $34,37 \pm 18,48^{b}$ & $13,37 \pm 13,37^{b}$ & $18,53 \pm 10,02^{b}$ & $49,48 \pm 30,65^{b}$ \\
\hline $\mathrm{ALH}(\mu \mathrm{m})$ & $8,02 \pm 0,32^{a}$ & $2,40 \pm 1,31^{\mathrm{bc}}$ & $3,27 \pm 2,23^{b}$ & $0,00 \pm 0,00^{c}$ & $0,00 \pm 0,00^{c}$ & $0,00 \pm 0,00^{c}$ \\
\hline $\mathrm{BCF}(\mathrm{Hz})$ & $33,60 \pm 1,50^{a}$ & $25,88 \pm 8,32^{\mathrm{ab}}$ & $13,83 \pm 8,90^{\mathrm{ab}}$ & $8,28 \pm 8,28^{b}$ & $18,90 \pm 11,98^{\mathrm{ab}}$ & $13,10 \pm 8,63^{a b}$ \\
\hline МOT (\%) & $74,50 \pm 3,87^{a}$ & $25,00 \pm 11,44^{b}$ & $12,00 \pm 8,30^{\mathrm{bc}}$ & $3,83 \pm 3,83^{c}$ & $0,67 \pm 0,67^{c}$ & $0,00 \pm 0,00^{c}$ \\
\hline PROG(\%) & $6,17 \pm 1,38^{a}$ & $2,00 \pm 1,03^{b}$ & $0,00 \pm 0,00^{b}$ & $0,00 \pm 0,00^{b}$ & $0,00 \pm 0,00^{b}$ & $0,00 \pm 0,00^{b}$ \\
\hline RAP (\%) & $49,17 \pm 7,16^{a}$ & $4,83 \pm 2,61^{b}$ & $0,33 \pm 0,21^{b}$ & $0,00 \pm 0,00^{b}$ & $0,00 \pm 0,00^{b}$ & $0,00 \pm 0,00^{b}$ \\
\hline MED (\%) & $25,17 \pm 4,89^{a}$ & $20,17 \pm 8,92^{\mathrm{a}}$ & $11,50 \pm 7,96^{\mathrm{ab}}$ & $3,83 \pm 3,83^{b}$ & $0,67 \pm 0,67^{b}$ & $0,00 \pm 0,00^{b}$ \\
\hline STATIC (\%) & $14,83 \pm 2,63^{c}$ & $53,67 \pm 8,98^{b}$ & $67,50 \pm 9,79^{\mathrm{ab}}$ & $75,17 \pm 10,16^{a b}$ & $82,00 \pm 4,20^{a}$ & $64,83 \pm 11,31^{a b}$ \\
\hline
\end{tabular}

: Letras diferentes indicam diferenças estatísticas dentro de uma mesma linha $(p<0,05 ;$ teste LSD)

Uma diminuição na porcentagem de células DABI foi observada a partir de 96 horas de refrigeração no diluidor FP40 0,05\% (Tabela 13). Por outro lado, ocorreu uma queda na porcentagem de células móveis e progressivas a partir de 24 horas. 
Tabela 14 - Efeito do tempo (2, 24, 48, 96, 120 horas) na atividade mitocondrial (DAB I, atividade total; DAB II, atividade alta; DAB III, atividade baixa; DAB IV atividade nula) e nas variáveis analisadas pelo CASA (VAP, VSL, VCL, ALH, BCF, MOT, PROG, RAP, MED, STATIC), em amostras de sêmen de cães refrigeradas $\left(5^{\circ} \mathrm{C}\right)$ em diluidor a base de lecitina de soja FP40 0,1\% - São Paulo - 2012

\begin{tabular}{lcccccc} 
& \multicolumn{1}{c}{ 2 horas } & 24 horas & 48 horas & 72 horas & 96 horas & 120 horas \\
\hline DABI (\%) & $64,67 \pm 10,11^{\mathrm{a}}$ & $38,33 \pm 8,59^{\mathrm{b}}$ & $15,50 \pm 7,42^{\mathrm{bc}}$ & $15,67 \pm 5,36^{\mathrm{bc}}$ & $9,17 \pm 5,31^{\mathrm{c}}$ & $16,33 \pm 12,31^{\mathrm{bc}}$ \\
DABII (\%) & $28,83 \pm 8,92^{\mathrm{ab}}$ & $49,17 \pm 7,32^{\mathrm{a}}$ & $47,50 \pm 6,96^{\mathrm{a}}$ & $45,17 \pm 10,32^{\mathrm{a}}$ & $31,33 \pm 10,95^{\mathrm{ab}}$ & $11,17 \pm 4,53^{\mathrm{b}}$ \\
DABIII (\%) & $4,83 \pm 1,99^{\mathrm{ab}}$ & $9,50 \pm 2,57^{\mathrm{a}}$ & $32,00 \pm 8,45^{\mathrm{ab}}$ & $30,00 \pm 9,43^{\mathrm{ab}}$ & $39,33 \pm 7,14^{\mathrm{ab}}$ & $32,83 \pm 10,31^{\mathrm{b}}$ \\
DABIV (\%) & $1,67 \pm 0,67^{\mathrm{b}}$ & $3,17 \pm 0,87^{\mathrm{b}}$ & $5,00 \pm 1,86^{\mathrm{b}}$ & $9,17 \pm 2,99^{\mathrm{b}}$ & $20,17 \pm 7,88^{\mathrm{ab}}$ & $39,67 \pm 14,40^{\mathrm{a}}$ \\
VAP $(\mu \mathrm{m} / \mathrm{s})$ & $71,18 \pm 8,3^{\mathrm{a}}$ & $25,38 \pm 5,34^{\mathrm{b}}$ & $14,28 \pm 6,91^{\mathrm{b}}$ & $11,10 \pm 4,98^{\mathrm{b}}$ & $16,15 \pm 8,82^{\mathrm{b}}$ & $16,08 \pm 8,28^{\mathrm{b}}$ \\
VSL $(\mu \mathrm{m} / \mathrm{s})$ & $32,05 \pm 3,02^{\mathrm{a}}$ & $10,48 \pm 2,44^{\mathrm{b}}$ & $7,98 \pm 3,76^{\mathrm{b}}$ & $7,00 \pm 3,46^{\mathrm{b}}$ & $10,40 \pm 6,71^{\mathrm{b}}$ & $6,17 \pm 3,14^{\mathrm{b}}$ \\
VCL $(\mu \mathrm{m} / \mathrm{s})$ & $165,73 \pm 13,36^{\mathrm{a}}$ & $66,42 \pm 15,35^{\mathrm{b}}$ & $27,08 \pm 13,07^{\mathrm{b}}$ & $27,73 \pm 14,60^{\mathrm{b}}$ & $33,12 \pm 14,87^{\mathrm{b}}$ & $34,72 \pm 19,28^{\mathrm{b}}$ \\
ALH $(\mu \mathrm{m})$ & $7,92 \pm 0,50^{\mathrm{a}}$ & $4,65 \pm 2,42^{\mathrm{ab}}$ & $1,82 \pm 1,82^{\mathrm{bc}}$ & $0,00 \pm 0,00^{\mathrm{c}}$ & $1,55 \pm 1,55^{\mathrm{bc}}$ & $0,00 \pm 0,00^{\mathrm{c}}$ \\
BCF (Hz) & $33,28 \pm 1,41$ & $36,62 \pm 8,26$ & $17,77 \pm 11,37$ & $22,23 \pm 10,79$ & $26,18 \pm 12,20$ & $17,93 \pm 11,45$ \\
MOT (\%) & $67,50 \pm 5,80^{\mathrm{a}}$ & $12,50 \pm 7,70^{\mathrm{b}}$ & $0,50 \pm 0,50^{\mathrm{c}}$ & $0,17 \pm 0,17^{\mathrm{c}}$ & $0,00 \pm 0,00^{\mathrm{c}}$ & $0,00 \pm 0,00^{\mathrm{c}}$ \\
PROG(\%) & $4,00 \pm 0,77^{\mathrm{a}}$ & $0,33 \pm 0,21^{\mathrm{b}}$ & $0,00 \pm 0,00^{\mathrm{b}}$ & $0,00 \pm 0,00^{\mathrm{b}}$ & $0,00 \pm 0,00^{\mathrm{b}}$ & $0,00 \pm 0,00^{\mathrm{b}}$ \\
RAP (\%) & $44,33 \pm 7,90^{\mathrm{a}}$ & $1,00 \pm 0,63^{\mathrm{b}}$ & $0,00 \pm 0,00^{\mathrm{b}}$ & $0,00 \pm 0,00^{\mathrm{b}}$ & $0,00 \pm 0,00^{\mathrm{b}}$ & $0,00 \pm 0,00^{\mathrm{b}}$ \\
MED $(\%)$ & $23,67 \pm 4,37^{\mathrm{a}}$ & $11,50 \pm 7,07^{\mathrm{b}}$ & $0,50 \pm 0,50^{\mathrm{c}}$ & $0,17 \pm 0,17^{\mathrm{c}}$ & $0,00 \pm 0,00^{\mathrm{c}}$ & $0,00 \pm 0,00^{\mathrm{c}}$ \\
STATIC (\%) & $18,33 \pm 3,78^{\mathrm{b}}$ & $52,00 \pm 11,51^{\mathrm{a}}$ & $66,17 \pm 9,80^{\mathrm{a}}$ & $52,33 \pm 11,70^{\mathrm{a}}$ & $63,83 \pm 8,25^{\mathrm{a}}$ & $68,83 \pm 6,00^{\mathrm{a}}$ \\
\hline \hline a,b,C $:$ Letras
\end{tabular}

: Letras diferentes indicam diferenças estatísticas dentro de uma mesma linha ( $p<0,05 ;$ teste LSD)

De forma similar ao diluidor 8160 nas concentrações 0,05\% (Tabela 10) e $0,1 \%$ (Tabela 11), pode-se observar no diluidor FP40 0,1\% (Tabela 14) que as altas concentrações dessas apresentações de lecitina não são eficientes na manutenção da qualidade espermática sob refrigeração por tempo superior a 2 horas, como demonstrado pela diminuição da porcentagem de células DABI, células móveis e progressivas na avaliação realizada 24 horas após o início de refrigeração. 
Tabela 15 - Efeito do tempo (2, 24, 48, 96, 120 horas) na atividade mitocondrial (DAB I, atividade total; DAB II, atividade alta; DAB III, atividade baixa; DAB IV, atividade nula) e nas variáveis analisadas pelo CASA (VAP, VSL, VCL, ALH, BCF, MOT, PROG, RAP, MED, STATIC), em amostras de sêmen de cães refrigeradas $\left(5^{\circ} \mathrm{C}\right)$ em diluidor a base de lecitina de soja Solec F 0,01\% - São Paulo - 2012

\begin{tabular}{lcccccc} 
& 2 horas & 24 horas & 48 horas & 72 horas & 96 horas & 120 horas \\
\hline DABI (\%) & $77,60 \pm 5,21^{\mathrm{a}}$ & $59,00 \pm 7,46^{\mathrm{ab}}$ & $46,00 \pm 10,19^{\mathrm{b}}$ & $44,67 \pm 9,36^{\mathrm{b}}$ & $50,33 \pm 10,03^{\mathrm{ab}}$ & $58,67 \pm 11,75^{\mathrm{ab}}$ \\
DABII (\%) & $16,60 \pm 4,04^{\mathrm{b}}$ & $36,20 \pm 6,40^{\mathrm{ab}}$ & $45,50 \pm 9,19^{\mathrm{a}}$ & $43,67 \pm 6,44^{\mathrm{a}}$ & $27,33 \pm 5,74^{\mathrm{ab}}$ & $35,17 \pm 9,95^{\mathrm{ab}}$ \\
DABIII (\%) & $1,20 \pm 0,73^{\mathrm{b}}$ & $3,40 \pm 1,99^{\mathrm{ab}}$ & $5,83 \pm 1,58^{\mathrm{ab}}$ & $8,67 \pm 4,56^{\mathrm{a}}$ & $3,00 \pm 1,26^{\mathrm{ab}}$ & $4,50 \pm 1,84^{\mathrm{ab}}$ \\
DABIV (\%) & $4,00 \pm 2,61$ & $1,60 \pm 0,81$ & $2,67 \pm 0,84$ & $3,00 \pm 1,41$ & $19,33 \pm 15,68$ & $1,67 \pm 0,33$ \\
VAP $(\mu \mathrm{m} / \mathrm{s})$ & $98,22 \pm 6,48^{\mathrm{a}}$ & $87,95 \pm 4,17^{\mathrm{ab}}$ & $87,30 \pm 11,39^{\mathrm{ab}}$ & $65,68 \pm 10,46^{\mathrm{bc}}$ & $53,72 \pm 11,23^{\mathrm{c}}$ & $57,20 \pm 11,90^{\mathrm{c}}$ \\
VSL $(\mu \mathrm{m} / \mathrm{s})$ & $49,73 \pm 8,49^{\mathrm{a}}$ & $28,40 \pm 1,89^{\mathrm{b}}$ & $34,15 \pm 7,42^{\mathrm{ab}}$ & $28,47 \pm 4,28^{\mathrm{b}}$ & $23,72 \pm 4,69^{\mathrm{b}}$ & $30,02 \pm 5,47^{\mathrm{b}}$ \\
VCL $(\mu \mathrm{m} / \mathrm{s})$ & $185,48 \pm 13,10^{\mathrm{a}}$ & $189,12 \pm 8,69^{\mathrm{a}}$ & $181,02 \pm 9,27^{\mathrm{a}}$ & $157,02 \pm 15,81^{\mathrm{ab}}$ & $133,78 \pm 18,43^{\mathrm{b}}$ & $129,92 \pm 22,02^{\mathrm{b}}$ \\
ALH $(\mu \mathrm{m})$ & $8,28 \pm 0,86$ & $7,20 \pm 0,56$ & $7,35 \pm 0,88$ & $5,77 \pm 1,42$ & $7,30 \pm 0,62$ & $5,53 \pm 1,31$ \\
BCF (Hz) & $35,02 \pm 1,28^{\mathrm{b}}$ & $38,15 \pm 1,41^{\mathrm{ab}}$ & $39,38 \pm 2,43^{\mathrm{ab}}$ & $40,12 \pm 1,54^{\mathrm{ab}}$ & $42,83 \pm 0,91^{\mathrm{a}}$ & $39,17 \pm 2,84^{\mathrm{ab}}$ \\
MOT (\%) & $65,50 \pm 7,59^{\mathrm{a}}$ & $46,67 \pm 7,29^{\mathrm{ab}}$ & $55,17 \pm 10,73^{\mathrm{ab}}$ & $43,67 \pm 9,91^{\mathrm{ab}}$ & $30,17 \pm 6,84^{\mathrm{b}}$ & $30,00 \pm 10,69^{\mathrm{b}}$ \\
PROG(\%) & $11,67 \pm 4,92^{\mathrm{a}}$ & $3,00 \pm 0,86^{\mathrm{b}}$ & $6,00 \pm 3,67^{\mathrm{ab}}$ & $2,33 \pm 1,17^{\mathrm{b}}$ & $2,17 \pm 0,95^{\mathrm{b}}$ & $3,33 \pm 1,61^{\mathrm{b}}$ \\
RAP $(\%)$ & $50,00 \pm 9,43^{\mathrm{a}}$ & $33,17 \pm 5,65^{\mathrm{abc}}$ & $41,67 \pm 11,49^{\mathrm{ab}}$ & $24,83 \pm 9,06^{\mathrm{abc}}$ & $15,00 \pm 7,30^{\mathrm{c}}$ & $18,50 \pm 9,00^{\mathrm{bc}}$ \\
MED $(\%)$ & $15,50 \pm 3,54$ & $13,50 \pm 2,00$ & $13,50 \pm 1,77$ & $18,67 \pm 3,04$ & $15,17 \pm 2,60$ & $11,50 \pm 2,35$ \\
STATIC $(\%)$ & $22,33 \pm 6,24^{\mathrm{b}}$ & $42,50 \pm 5,28^{\mathrm{ab}}$ & $37,00 \pm 9,67^{\mathrm{ab}}$ & $45,50 \pm 8,86^{\mathrm{ab}}$ & $59,00 \pm 7,61^{\mathrm{a}}$ & $53,00 \pm 11,40^{\mathrm{a}}$ \\
\hline
\end{tabular}

a,b,c : Letras diferentes indicam diferenças estatísticas dentro de uma mesma linha ( $p<0,05 ;$ teste LSD)

No diluidor Solec F 0,01\% (Tabela 15), apesar de algumas oscilações, pode ser observado que não houve diferença estatística na porcentagem de células DABI e DABIV entre os tempos 2 horas e 120 horas, indicando que essa lecitina é bastante eficiente na manutenção da atividade mitocondrial por um tempo considerável. Além disso, as porcentagens de células móveis e com movimentos rápidos se mantiveram até 72 horas de refrigeração. 
Tabela 16 - Efeito do tempo (2, 24, 48, 96, 120 horas) na atividade mitocondrial (DAB I, atividade total; DAB II, atividade alta; DAB III, atividade baixa; DAB IV atividade nula) e nas variáveis analisadas pelo CASA (VAP, VSL, VCL, ALH, BCF, MOT, PROG, RAP, MED, STATIC), em amostras de sêmen de cães refrigeradas $\left(5^{\circ} \mathrm{C}\right)$ em diluidor a base de lecitina de soja Solec F 0,05\% - São Paulo - 2012

\begin{tabular}{|c|c|c|c|c|c|c|}
\hline & 2 horas & 24 horas & 48 horas & 72 horas & 96 horas & 120 horas \\
\hline DABI (\%) & $46,00 \pm 9,26^{b}$ & $55,20 \pm 8,49^{a b}$ & $53,50 \pm 9,02^{b}$ & $46,50 \pm 11,44^{b}$ & $79,67 \pm 3,55^{a}$ & $52,83 \pm 8,56^{b}$ \\
\hline DABII (\%) & $45,60 \pm 13,18^{a}$ & $39,00 \pm 7,48^{\mathrm{ab}}$ & $41,33 \pm 8,43^{\mathrm{a}}$ & $42,50 \pm 7,41^{\mathrm{a}}$ & $17,83 \pm 2,57^{\mathrm{b}}$ & $37,50 \pm 6,52^{\mathrm{ab}}$ \\
\hline DABIII (\%) & $2,40 \pm 1,47^{b}$ & $3,00 \pm 1,14^{\mathrm{ab}}$ & $4,67 \pm 1,71^{a b}$ & $8,83 \pm 4,03^{a}$ & $3,00 \pm 0,37^{\mathrm{ab}}$ & $8,50 \pm 1,84^{a b}$ \\
\hline DABIV (\%) & $2,40 \pm 1,69$ & $2,80 \pm 1,71$ & $0,67 \pm 0,33$ & $2,17 \pm 0,91$ & $1,33 \pm 0,42$ & $2,00 \pm 0,77$ \\
\hline $\operatorname{VAP}(\mu \mathrm{m} / \mathrm{s})$ & $93,17 \pm 5,50^{a}$ & $83,28 \pm 8,05^{a b}$ & $66,47 \pm 10,61^{b}$ & $43,62 \pm 4,78^{c}$ & $33,48 \pm 3,34^{c}$ & $34,65 \pm 2,73^{c}$ \\
\hline $\operatorname{VSL}(\mu \mathrm{m} / \mathrm{s})$ & $45,88 \pm 3,98^{a}$ & $40,60 \pm 5,23^{a b}$ & $30,65 \pm 7,28^{\mathrm{bc}}$ & $19,18 \pm 2,86^{\mathrm{cd}}$ & $11,20 \pm 2,42^{d}$ & $17,67 \pm 3,32^{\mathrm{cd}}$ \\
\hline $\operatorname{VCL}(\mu \mathrm{m} / \mathrm{s})$ & $192,55 \pm 6,48^{\mathrm{a}}$ & $179,15 \pm 13,26^{a b}$ & $152,93 \pm 15,77^{b}$ & $121,48 \pm 6,46^{\mathrm{c}}$ & $89,18 \pm 9,69^{d}$ & $87,88 \pm 5,44^{d}$ \\
\hline $\mathrm{ALH}(\mu \mathrm{m})$ & $8,70 \pm 0,61^{a}$ & $7,38 \pm 0,27^{\mathrm{ab}}$ & $5,57 \pm 1,23^{\mathrm{bc}}$ & $5,07 \pm 1,12^{\mathrm{bc}}$ & $3,17 \pm 1,16^{c}$ & $7,58 \pm 1,02^{\mathrm{ab}}$ \\
\hline $\mathrm{BCF}(\mathrm{Hz})$ & $35,02 \pm 1,71^{d}$ & $36,43 \pm 0,94^{\mathrm{cd}}$ & $42,68 \pm 2,76^{b}$ & $41,57 \pm 2,05^{\mathrm{bc}}$ & $49,92 \pm 2,44^{\mathrm{a}}$ & $39,68 \pm 1,05^{\mathrm{bcc}}$ \\
\hline МОТ (\%) & $70,50 \pm 7,57^{\mathrm{a}}$ & $76,33 \pm 5,42^{a}$ & $53,67 \pm 5,79^{b}$ & $34,00 \pm 6,21^{c}$ & $15,00 \pm 4,96^{d}$ & $18,00 \pm 2,10^{c d}$ \\
\hline PROG(\%) & $8,67 \pm 2,44^{a}$ & $9,83 \pm 2,71^{a}$ & $5,33 \pm 2,53^{a b}$ & $0,67 \pm 0,49^{b}$ & $0,33 \pm 0,33^{b}$ & $1,67 \pm 0,88^{b}$ \\
\hline RAP (\%) & $56,33 \pm 7,05^{a}$ & $56,17 \pm 7,94^{\mathrm{a}}$ & $29,17 \pm 8,27^{b}$ & $10,00 \pm 4,23^{c}$ & $1,83 \pm 1,28^{c}$ & $2,33 \pm 1,02^{c}$ \\
\hline MED (\%) & $13,83 \pm 0,87^{\mathrm{ab}}$ & $20,33 \pm 4,51^{\mathrm{ab}}$ & $24,67 \pm 5,24^{a}$ & $24,00 \pm 4,24^{\mathrm{ab}}$ & $13,00 \pm 4,56^{\mathrm{b}}$ & $15,50 \pm 1,93^{\mathrm{ab}}$ \\
\hline STATIC (\%) & $13,17 \pm 4,56^{\mathrm{de}}$ & $11,17 \pm 2,21^{\mathrm{e}}$ & $29,33 \pm 4,90^{c d}$ & $44,50 \pm 8,53^{\mathrm{bc}}$ & $65,83 \pm 4,72^{\mathrm{a}}$ & $56,00 \pm 6,60^{a b}$ \\
\hline
\end{tabular}
LSD)

Da mesma forma que no diluidor Solec $\mathrm{F}$ 0,01\% (Tabela 15), nas amostras refrigeradas com a concentração $0,05 \%$ na mesma apresentação (Tabela 16), notou-se que as porcentagens de células DABI e DABIV não apresentaram diferenças estatísticas entre os tempos 2 horas e 120 horas. Além disso, a porcentagem de células progressivas apresentou uma diminuição a partir de 72 horas. No entanto, a porcentagem de células móveis foi mantida até 48 horas de refrigeração, 24 horas a menos que na concentração 0,01\%. 
Tabela 17 - Efeito do tempo (2, 24, 48, 96, 120 horas) na atividade mitocondrial (DAB I, atividade total; DAB II, atividade alta; DAB III, atividade baixa; DAB IV atividade nula) e nas variáveis analisadas pelo CASA (VAP, VSL, VCL, ALH, BCF, MOT, PROG, RAP, MED, STATIC), em amostras de sêmen de cães refrigeradas $\left(5^{\circ} \mathrm{C}\right)$ em diluidor a base de lecitina de soja Solec F 0,1\% - São Paulo - 2012

\begin{tabular}{|c|c|c|c|c|c|c|}
\hline & 2 horas & 24 horas & 48 horas & 72 horas & 96 horas & 120 horas \\
\hline DABI (\%) & $59,00 \pm 11,24$ & $53,00 \pm 8,16$ & $55,50 \pm 9,58$ & $52,33 \pm 10,76$ & $64,67 \pm 4,10$ & $61,83 \pm 5,69$ \\
\hline DABII (\%) & $34,00 \pm 10,74$ & $44,83 \pm 8,67$ & $32,50 \pm 5,60$ & $35,67 \pm 9,39$ & $27,50 \pm 2,38$ & $27,17 \pm 3,64$ \\
\hline DABIII (\%) & $2,50 \pm 1,15^{\mathrm{bc}}$ & $1,17 \pm 0,54^{c}$ & $10,33 \pm 4,78^{a}$ & $8,83 \pm 2,68^{a b}$ & $6,00 \pm 2,22^{\mathrm{abc}}$ & $7,17 \pm 1,25^{a b c}$ \\
\hline DABIV (\%) & $4,50 \pm 2,36$ & $1,00 \pm 0,52$ & $1,67 \pm 0,99$ & $3,17 \pm 1,38$ & $2,00 \pm 1,29$ & $4,00 \pm 2,02$ \\
\hline $\operatorname{VAP}(\mu \mathrm{m} / \mathrm{s})$ & $83,97 \pm 4,05^{a}$ & $71,50 \pm 7,68^{a}$ & $57,23 \pm 5,37^{b}$ & $30,95 \pm 6,32^{c}$ & $32,20 \pm 0,78^{c}$ & $31,30 \pm 1,04^{c}$ \\
\hline $\operatorname{VSL}(\mu \mathrm{m} / \mathrm{s})$ & $36,37 \pm 3,17^{a}$ & $27,08 \pm 2,90^{b}$ & $28,37 \pm 2,80^{b}$ & $14,20 \pm 3,28^{c}$ & $14,87 \pm 1,90^{c}$ & $13,63 \pm 0,81^{c}$ \\
\hline $\operatorname{VCL}(\mu \mathrm{m} / \mathrm{s})$ & $171,05 \pm 8,94^{a}$ & $169,17 \pm 11,16^{a}$ & $137,83 \pm 7,68^{b}$ & $88,27 \pm 17,82^{c}$ & $86,28 \pm 2,98^{c}$ & $82,65 \pm 2,17^{c}$ \\
\hline $\mathrm{ALH}(\mu \mathrm{m})$ & $8,12 \pm 0,38^{a b}$ & $7,48 \pm 0,25^{a b}$ & $6,52 \pm 0,49^{b}$ & $6,20 \pm 1,54^{b}$ & $5,75 \pm 1,27^{b}$ & $10,78 \pm 1,86^{a}$ \\
\hline $\mathrm{BCF}(\mathrm{Hz})$ & $36,00 \pm 2,25$ & $38,55 \pm 2,11$ & $38,85 \pm 2,17$ & $34,92 \pm 7,08$ & $40,53 \pm 1,43$ & $41,05 \pm 1,62$ \\
\hline МOT (\%) & $68,33 \pm 8,62^{a}$ & $55,67 \pm 9,80^{a}$ & $49,83 \pm 7,33^{\mathrm{a}}$ & $25,83 \pm 6,91^{b}$ & $15,67 \pm 3,00^{b}$ & $13,67 \pm 3,07^{b}$ \\
\hline PROG(\%) & $5,67 \pm 1,15^{a}$ & $3,17 \pm 0,87^{\mathrm{b}}$ & $3,50 \pm 1,34^{\mathrm{ab}}$ & $1,17 \pm 0,40^{\mathrm{bc}}$ & $0,50 \pm 0,22^{c}$ & $0,17 \pm 0,17^{c}$ \\
\hline RAP (\%) & $47,17 \pm 6,99^{\mathrm{a}}$ & $37,00 \pm 8,18^{\mathrm{ab}}$ & $26,00 \pm 7,18^{b}$ & $5,00 \pm 1,91^{c}$ & $1,00 \pm 0,52^{c}$ & $1,00 \pm 0,37^{c}$ \\
\hline MED (\%) & $21,17 \pm 4,55^{\mathrm{ab}}$ & $18,83 \pm 2,83^{\mathrm{ab}}$ & $23,83 \pm 1,78^{\mathrm{a}}$ & $20,83 \pm 5,17^{\mathrm{ab}}$ & $14,50 \pm 2,57^{\mathrm{ab}}$ & $12,83 \pm 2,85^{b}$ \\
\hline STATIC (\%) & $18,00 \pm 7,08^{c}$ & $18,67 \pm 5,39^{c}$ & $32,33 \pm 6,88^{\mathrm{bc}}$ & $49,33 \pm 12,75^{a b}$ & $55,50 \pm 5,60^{a}$ & $53,67 \pm 6,58^{a b}$ \\
\hline
\end{tabular}

$\overline{a, b, c}:$ Letras diferentes indicam diferenças estatísticas dentro de uma mesma linha $(p<0,05 ;$ teste LSD)

Ao contrário do que ocorreu com as apresentações 8160 e FP40, em que maiores concentrações de lecitina foram deletérias (Tabelas 11 e 14, respectivamente), com a Solec F, nas concentrações 0,01\% (Tabela 15) e 0,05\% (Tabela 16), não foram observadas diferenças estatísticas durante a refrigeração até 120 horas na porcentagem de células DABI e DABIV. Além disso, nessa concentração a porcentagem de células móveis e progressivas se manteve até 72 horas (Tabela 17). 
Tabela 18 - Comparação entre diluidor a base de lecitina de soja em diferentes apresentações (8160, FP40, Solec F) e concentrações $(0,01 \%, 0,05 \%$ e $0,1 \%)$ e o diluidor a base de gema de ovo nas porcentagens de células com membranas plasmática e acrossomal íntegras, nas variáveis analisadas pelo CASA (STR, LIN, SLOW), na susceptibilidade ao estresse oxidativo (TBARS) e na integridade do DNA (ensaio da estrutura da cromatina espermática - SCSA) em amostras de sêmen de cães refrigeradas $\left(5^{\circ} \mathrm{C}\right)$ - São Paulo - 2012

\begin{tabular}{|c|c|c|c|c|c|c|c|c|c|c|}
\hline & \multirow{2}{*}{ ovo } & \multicolumn{3}{|c|}{8160} & \multicolumn{3}{|c|}{ FP40 } & \multicolumn{3}{|c|}{ SOLEC F } \\
\hline & & $0,01 \%$ & $0,05 \%$ & $0,1 \%$ & $0,01 \%$ & $0,05 \%$ & $0,1 \%$ & $0,01 \%$ & $0,05 \%$ & $0,1 \%$ \\
\hline MEMBRANA (\%) & $60,41 \pm 2,36^{\mathrm{ab}}$ & $57,06 \pm 3,40^{\mathrm{ab}}$ & $18,88 \pm 3,49^{d}$ & $13,65 \pm 3,23^{\mathrm{d}}$ & $64,71 \pm 3,18^{\mathrm{a}}$ & $32,97 \pm 4,00^{c}$ & $28,62 \pm 3,91^{\mathrm{C}}$ & $62,79 \pm 3,60^{\text {ab }}$ & $60,91 \pm 2,92^{\mathrm{ab}}$ & $54,59 \pm 3,06^{b}$ \\
\hline ACROSSOMA (\%) & $79,61 \pm 3,41^{a}$ & $77,69 \pm 4,32^{\mathrm{abc}}$ & $59,08 \pm 5,85^{\text {de }}$ & $49,64 \pm 5,73^{\mathrm{e}}$ & $78,94 \pm 4,34^{a b}$ & $66,94 \pm 5,15^{\mathrm{bcd}}$ & $66,06 \pm 5,12^{\mathrm{cd}}$ & $80,64 \pm 3,45^{a}$ & $81,61 \pm 3,22^{a}$ & $81,06 \pm 3,18^{a}$ \\
\hline STR (\%) & $67,64 \pm 1,81^{a}$ & $43,08 \pm 1,66^{\mathrm{b}}$ & $19,44 \pm 4,50^{d}$ & $14,11 \pm 3,88^{\mathrm{d}}$ & $42,11 \pm 2,16^{\mathrm{b}}$ & $29,17 \pm 5,53^{c}$ & $32,47 \pm 4,98^{\mathrm{c}}$ & $45,56 \pm 1,86^{\mathrm{b}}$ & $44,47 \pm 1,90^{\mathrm{b}}$ & $43,19 \pm 2,03^{b}$ \\
\hline LIN (\%) & $45,44 \pm 1,76^{a}$ & $19,56 \pm 0,85^{b}$ & $8,89 \pm 2,40^{c}$ & $7,44 \pm 2,13^{c}$ & $18,08 \pm 1,25^{b}$ & $17,44 \pm 4,26^{b}$ & $16,92 \pm 3,61^{b}$ & $22,22 \pm 1,46^{b}$ & $20,72 \pm 1,32^{b}$ & $19,89 \pm 1,32^{b}$ \\
\hline SLOW (\%) & $19,28 \pm 2,32^{\mathrm{bcd}}$ & $13,36 \pm 2,16^{\mathrm{de}}$ & $20,94 \pm 2,64^{\mathrm{bc}}$ & $22,36 \pm 2,95^{\mathrm{b}}$ & $14,92 \pm 1,63^{\mathrm{cde}}$ & $21,00 \pm 3,03^{\mathrm{bc}}$ & $32,75 \pm 3,61^{a}$ & $11,36 \pm 1,85^{\mathrm{e}}$ & $18,78 \pm 1,72^{\mathrm{bcd}}$ & $23,83 \pm 2,08^{\mathrm{b}}$ \\
\hline TBARS (ng/106) & $1371,27 \pm 395,38^{\mathrm{a}}$ & $330,91 \pm 64,76^{b}$ & $232,45 \pm 20,46^{b}$ & $204,64 \pm 14,76^{b}$ & $197,11 \pm 16,75^{\mathrm{b}}$ & $229,46 \pm 35,62^{b}$ & $231,91 \pm 17,20^{b}$ & $387,20 \pm 82,23^{b}$ & $223,10 \pm 20,05^{\mathrm{b}}$ & $259,97 \pm 25,71^{b}$ \\
\hline SCSA (\%) & $12,99 \pm 2,29^{\mathrm{ab}}$ & $17,17 \pm 2.51^{a}$ & $12,45 \pm 2,05^{a b}$ & $9,88 \pm 1,92^{b}$ & $11,37 \pm 2,05^{a b}$ & $13,21 \pm 2,42^{\mathrm{ab}}$ & $14,03 \pm 2,60^{a b}$ & $12,99 \pm 2,34^{\mathrm{ab}}$ & $13,45 \pm 2,62^{a b}$ & $10,83 \pm 2,12^{\mathrm{ab}}$ \\
\hline
\end{tabular}

${ }^{a, b, c, d, e}$ : Letras diferentes indicam diferenças estatísticas dentro de uma mesma linha ( $p<0,05 ;$ teste LSD)

Os diluidores 8160 e FP40 nas concentrações 0,05\% e 0,1\% (Tabela 18) apresentaram uma menor porcentagem de células com membranas plasmática e acrossomal íntegras quando comparados com o diluidor a base de gema de ovo. No entanto, a gema de ovo apresentou uma maior susceptibilidade ao estresse oxidativo (TBARS) em relação a todos os outros diluidores. 
Tabela 19 - Efeito do tempo (2, 24, 48, 96, 120 horas) nas porcentagens de células com membranas plasmática e acrossomal íntegras, nas variáveis analisadas pelo CASA (STR, LIN, SLOW), na susceptibilidade ao estresse oxidativo (TBARS) e na integridade do DNA (ensaio da estrutura da cromatina espermática - SCSA) em amostras de sêmen de cães refrigeradas $\left(5^{\circ} \mathrm{C}\right)$ em diluidores a base de lecitina de soja e gema de ovo - São Paulo 2012

\begin{tabular}{|c|c|c|c|c|c|c|}
\hline & 2 horas & 24 horas & 48 horas & 72 horas & 96 horas & 120 horas \\
\hline MEMBRANA (\%) & $60,05 \pm 3,00^{a}$ & $48,60 \pm 3,27^{b}$ & $43,02 \pm 3,55^{\mathrm{bC}}$ & $39,85 \pm 4,14^{\mathrm{DC}}$ & $43,22 \pm 3,56^{b c}$ & $36,15 \pm 3,31^{c}$ \\
\hline ACROSSOMA (\%) & $82,52 \pm 2,56^{a}$ & $75,22 \pm 3,35^{a}$ & $76,58 \pm 3,40^{\mathrm{a}}$ & $64,97 \pm 4,26^{\mathrm{bc}}$ & $72,90 \pm 3,61^{a b}$ & $60,58 \pm 4,13^{c}$ \\
\hline STR (\%) & $50,60 \pm 1,71^{a}$ & $37,72 \pm 2,83^{b}$ & $34,33 \pm 3,30^{b}$ & $36,92 \pm 3,42^{b}$ & $35,15 \pm 3,55^{b}$ & $34,03 \pm 3,42^{b}$ \\
\hline LIN (\%) & $27,03 \pm 1,70^{\mathrm{a}}$ & $18,80 \pm 1,73^{b}$ & $17,90 \pm 2,20^{b}$ & $18,67 \pm 2,36^{b}$ & $18,40 \pm 2,62^{b}$ & $17,17 \pm 2,02^{b}$ \\
\hline SLOW (\%) & $13,30 \pm 1,22^{b}$ & $18,92 \pm 1,94^{\mathrm{a}}$ & $19,25 \pm 2,01^{a}$ & $22,93 \pm 2,34^{a}$ & $21,47 \pm 1,90^{a}$ & $23,28 \pm 2,38^{a}$ \\
\hline TBARS (ng/10 $\left.0^{6}\right)$ & $\begin{array}{c}228,57 \pm \\
26,41^{\mathrm{b}}\end{array}$ & $\begin{array}{c}290,79 \pm \\
60,35^{\mathrm{ab}}\end{array}$ & $\begin{array}{c}385,42 \pm \\
72,95^{\mathrm{ab}}\end{array}$ & $\begin{array}{c}385,19 \pm \\
78,72^{\mathrm{ab}}\end{array}$ & $\begin{array}{c}343,44 \pm \\
71,23^{\mathrm{ab}}\end{array}$ & $\begin{array}{l}567,40 \pm \\
224,66^{\mathrm{a}}\end{array}$ \\
\hline SCSA (\%) & $11,09 \pm 1,50^{\mathrm{bc}}$ & $15,64 \pm 1,85^{a b}$ & $17,08 \pm 2,14^{\mathrm{a}}$ & $7,18 \pm 1,13^{\mathrm{c}}$ & $12,88 \pm 1,55^{\mathrm{ab}}$ & $13,16 \pm 2,09^{\mathrm{ab}}$ \\
\hline
\end{tabular}

: Letras diferentes indicam diferenças estatísticas dentro de uma mesma linha ( $p<0,05 ;$ teste LSD)

Todas as variáveis avaliadas apresentaram influência do tempo de refrigeração, com uma diminuição na integridade de membrana, STR, LIN a partir de 24 horas. Por outro lado, a porcentagem de células com membrana acrossomal íntegra e a susceptibilidade ao estresse oxidativo foram mantidas por até 96 horas (Tabela 19).

\subsection{Resultados - Experimento 2}

Foram observadas interações significativas $(p<0,05)$ entre momento da criopreservação e diluidor para VAP, VCL, ALH, BCF, LIN, MOT, SLOW, DABII, DABIII, DABIV (Tabela 20). Essas variáveis foram então avaliadas quanto ao efeito do diluidor em cada momento da criopreservação (Tabela 21 a 23) e quanto ao efeito do momento da criopreservação em cada diluidor (Tabela 24 a 33). As variáveis em que não foram observadas interações significantes (Membrana, Acrossoma, VSL, PROG, RAP, MED, STATIC, DABI) foram avaliadas quanto ao diluidor (Tabela 34) e ao momento da criopreservação (Tabela 35), separadamente. 
Tabela 20 - Probabilidades dos efeitos dos momentos da criopreservação (pós-refrigeração, pósglicerolização e pós-descongelação), diluidor e da interação momento da criopreservação * diluidor sobre a porcentagem de células com membrana plasmática e acrossomal íntegra, variáveis analisadas pelo CASA (VAP, VSL, VCL, ALH, BCF, STR, LIN, MOT, PROG, RAP, MED, SLOW, STATIC), e atividade mitocondrial (DAB I, atividade total; DAB II, atividade alta; DAB III, atividade baixa; DAB IV atividade nula) no sêmen criopreservado de cães - São Paulo - 2012

\begin{tabular}{lccc} 
& Diluidor & $\begin{array}{c}\text { Momento da } \\
\text { Criopreservação }\end{array}$ & $\begin{array}{c}\text { Diluidor * } \\
\text { Tempo }\end{array}$ \\
\hline MEMBRANA (\%) & 0,2020 & $<0,0001$ & 0,9749 \\
ACROSSOMA (\%) & 0,4310 & $<0,0001$ & 0,5967 \\
VAP $(\mu \mathrm{m} / \mathrm{s})$ & $<0,0001$ & $<0,0001$ & 0,0490 \\
VSL $(\mu \mathrm{m} / \mathrm{s})$ & $<0,0001$ & $<0,0001$ & 0,6211 \\
VCL $(\mu \mathrm{m} / \mathrm{s})$ & $<0,0001$ & $<0,0001$ & $<0,0001$ \\
ALH $(\mu \mathrm{m} / \mathrm{s})$ & 0,0030 & $<0,0001$ & 0,0213 \\
BCF $(\mathrm{Hz})$ & $<0,0001$ & $<0,0001$ & $<0,0001$ \\
STR $(\%)$ & $<0,0001$ & 0,0005 & $<0,0001$ \\
LIN $(\%)$ & $<0,0001$ & 0,0011 & 0,0302 \\
MOT $(\%)$ & 0,0104 & $<0,0001$ & 0,0309 \\
PROG (\%) & $<0,0001$ & $<0,0001$ & 0,4759 \\
RAP (\%) & 0,0972 & $<0,0001$ & 0,2062 \\
MED (\%) & 0,0091 & $<0,0001$ & 0,0684 \\
SLOW (\%) & 0,1234 & $<0,0001$ & 0,0057 \\
STATIC (\%) & 0,0017 & $<0,0001$ & 0,0720 \\
DABI (\%) & 0,0648 & 0,0003 & 0,2053 \\
DABII (\%) & 0,9896 & 0,0173 & 0,0065 \\
DABIII (\%) & $<0,0001$ & $<0,0001$ & $<0,0001$ \\
DABIV (\%) & 0,6629 & 0,5009 & 0,0234 \\
\hline \hline
\end{tabular}


Tabela 21 - Comparação entre diluidor a base de lecitina de soja em diferentes apresentações (8160, FP40, Solec F) e concentrações $(0,01 \%, 0,05 \%$ e $0,1 \%)$ e o diluidor a base de gema de ovo na atividade mitocondrial (DAB II, atividade alta; DAB III, atividade baixa; DAB IV atividade nula) e nas variáveis analisadas pelo CASA (VAP, VCL, ALH, BCF, STR, LIN, MOT, SLOW), em amostras de sêmen de cães refrigeradas précriopreservação (2 horas, $\left.5^{\circ} \mathrm{C}\right)$ - São Paulo - 2012

\begin{tabular}{|c|c|c|c|c|c|c|c|c|c|c|}
\hline & \multirow{2}{*}{ ovo } & \multicolumn{3}{|c|}{8160} & \multicolumn{3}{|c|}{ FP40 } & \multicolumn{3}{|c|}{ SOLEC F } \\
\hline & & $0,01 \%$ & $0,05 \%$ & $0,1 \%$ & $0,01 \%$ & $0,05 \%$ & $0,1 \%$ & $0,01 \%$ & $0,05 \%$ & $0,1 \%$ \\
\hline DABII (\%) & $14,57 \pm 5,98^{\mathrm{ab}}$ & $18,86 \pm 8,87^{\mathrm{ab}}$ & $25,29 \pm 8,33^{\mathrm{ab}}$ & $29,29 \pm 8,28^{a}$ & $18,29 \pm 7,63^{\mathrm{ab}}$ & $8,43 \pm 3,50^{b}$ & $23,14 \pm 8,53^{\text {ab }}$ & $18,86 \pm 4,97^{\mathrm{ab}}$ & $15,86 \pm 6,39^{a b}$ & $10,14 \pm 5,62^{\mathrm{ab}}$ \\
\hline DABIII (\%) & $3,29 \pm 1,15^{\mathrm{ab}}$ & $4,00 \pm 1,48^{a}$ & $2,00 \pm 0,72^{\mathrm{abc}}$ & $2,00 \pm 0,76^{\mathrm{abc}}$ & $1,57 \pm 0,78^{\mathrm{abc}}$ & $0,86 \pm 0,46^{\mathrm{bc}}$ & $0,57 \pm 0,30^{c}$ & $1,86 \pm 1,70^{\mathrm{abc}}$ & $2,00 \pm 0,62^{a b c}$ & $1,00 \pm 0,58^{\mathrm{bc}}$ \\
\hline DABIV (\%) & $23,00 \pm 9,95^{\mathrm{ab}}$ & $24,71 \pm 15,13^{\mathrm{ab}}$ & $13,00 \pm 11,69^{\mathrm{ab}}$ & $2,57 \pm 0,78^{\mathrm{b}}$ & $24,57 \pm 15,06^{\mathrm{ab}}$ & $31,14 \pm 17,55^{\mathrm{ab}}$ & $6,43 \pm 3,77^{\mathrm{ab}}$ & $24,71 \pm 11,24^{\mathrm{ab}}$ & $19,29 \pm 13,71^{a b}$ & $40,00 \pm 17,88^{a}$ \\
\hline $\operatorname{VAP}(\mu \mathrm{m} / \mathrm{s})$ & $115,66 \pm 1,72^{a}$ & $98,34 \pm 7,38^{\mathrm{ab}}$ & $99,70 \pm 9,79^{a b}$ & $87,57 \pm 5,98^{b}$ & $95,00 \pm 11,18^{\mathrm{ab}}$ & $101,67 \pm 7,01^{\mathrm{ab}}$ & $86,10 \pm 6,35^{\mathrm{b}}$ & $98,64 \pm 3,86^{\mathrm{ab}}$ & $99,67 \pm 6,04^{\mathrm{ab}}$ & $87,07 \pm 12,32^{b}$ \\
\hline $\operatorname{VCL}(\mu \mathrm{m} / \mathrm{s})$ & $178,20 \pm 8,31$ & $197,96 \pm 11,88$ & $203,36 \pm 16,54$ & $193,31 \pm 11,09$ & $181,97 \pm 19,37$ & $202,90 \pm 11,09$ & $184,34 \pm 10,60$ & $194,27 \pm 7,41$ & $192,39 \pm 10,46$ & $174,54 \pm 20,80$ \\
\hline $\mathrm{ALH}(\mu \mathrm{m})$ & $8,86 \pm 0,50$ & $9,09 \pm 0,49$ & $9,14 \pm 0,42$ & $8,90 \pm 0,69$ & $8,04 \pm 0,47$ & $8,56 \pm 0,42$ & $8,66 \pm 0,49$ & $9,24 \pm 0,62$ & $8,91 \pm 0,73$ & $9,01 \pm 0,99$ \\
\hline $\mathrm{BCF}(\mathrm{Hz})$ & $28,17 \pm 2,30^{\mathrm{b}}$ & $36,56 \pm 1,68^{\mathrm{a}}$ & $33,24 \pm 1,72^{\mathrm{a}}$ & $33,64 \pm 1,93^{\mathrm{a}}$ & $36,39 \pm 1,13^{\mathrm{a}}$ & $34,04 \pm 1,29^{\mathrm{a}}$ & $34,00 \pm 1,02^{\mathrm{a}}$ & $35,19 \pm 1,48^{\mathrm{a}}$ & $37,24 \pm 1,19^{\mathrm{a}}$ & $36,14 \pm 1,59^{\mathrm{a}}$ \\
\hline STR (\%) & $73,86 \pm 3,21^{a}$ & $55,14 \pm 2,71^{b}$ & $52,57 \pm 3,82^{b}$ & $50,43 \pm 2,38^{b}$ & $57,86 \pm 3,53^{b}$ & $55,14 \pm 3,64^{b}$ & $54,57 \pm 2,27^{\mathrm{b}}$ & $56,43 \pm 2,01^{b}$ & $56,29 \pm 2,15^{b}$ & $52,14 \pm 2,89^{b}$ \\
\hline LIN (\%) & $50,71 \pm 4,33^{\mathrm{a}}$ & $28,57 \pm 1,84^{\mathrm{bc}}$ & $26,86 \pm 3,03^{\mathrm{bc}}$ & $23,00 \pm 1,45^{c}$ & $32,14 \pm 2,76^{b}$ & $29,43 \pm 3,02^{\mathrm{bc}}$ & $27,00 \pm 1,68^{\mathrm{bc}}$ & $30,29 \pm 1,41^{\mathrm{b}}$ & $30,71 \pm 1,51^{b}$ & $26,57 \pm 2,37^{\mathrm{bc}}$ \\
\hline МOT (\%) & $70,43 \pm 6,77^{\mathrm{abc}}$ & $76,57 \pm 8,01^{\mathrm{abc}}$ & $76,71 \pm 8,62^{\mathrm{abc}}$ & $78,29 \pm 4,71^{\mathrm{abc}}$ & $80,43 \pm 6,78^{\mathrm{abc}}$ & $89,29 \pm 2,49^{a}$ & $79,86 \pm 7,05^{\mathrm{abc}}$ & $85,43 \pm 1,04^{\mathrm{ab}}$ & $67,00 \pm 7,97^{\mathrm{bc}}$ & $63,00 \pm 9,97^{c}$ \\
\hline SLOW (\%) & $13,14 \pm 2,94$ & $9,86 \pm 5,43$ & $7,57 \pm 4,11$ & $11,43 \pm 3,64$ & $7,29 \pm 2,20$ & $4,43 \pm 1,17$ & $9,29 \pm 3,48$ & $6,71 \pm 1,17$ & $14,71 \pm 5,10$ & $12,14 \pm 4,37$ \\
\hline
\end{tabular}

$\overline{a_{a, b, c}}$ : Letras diferentes indicam diferenças estatísticas dentro de uma mesma linha ( $\mathrm{p}<0,05$; teste LSD) 
Tabela 22 - Comparação entre diluidor a base de lecitina de soja em diferentes apresentações (8160, FP40, Solec F) e concentrações (0,01\%, 0,05\% e $0,1 \%$ ) e o diluidor a base de gema de ovo na atividade mitocondrial (DAB II, atividade alta; DAB III, atividade baixa; DAB IV, atividade nula) e nas variáveis analisadas pelo CASA (VAP, VCL, ALH, BCF, STR, LIN, MOT, SLOW), em amostras de sêmen de cães refrigeradas após a adição da fração do diluidor contendo glicerol (pós-glicerolização) pré-criopreservação (2 horas refrigeração + 1 hora glicerolização, $\left.5^{\circ} \mathrm{C}\right)$ - São Paulo - 2012

\begin{tabular}{|c|c|c|c|c|c|c|c|c|c|c|}
\hline & \multirow[b]{2}{*}{ ovo } & \multicolumn{3}{|c|}{8160} & \multicolumn{3}{|c|}{ FP40 } & \multicolumn{3}{|c|}{ SOLEC F } \\
\hline & & $0,01 \%$ & $0,05 \%$ & $0,1 \%$ & $0,01 \%$ & $0,05 \%$ & $0,1 \%$ & $0,01 \%$ & $0,05 \%$ & $0,1 \%$ \\
\hline DABII (\%) & $13,43 \pm 4,26^{b}$ & $23,00 \pm 8,49^{\mathrm{ab}}$ & $32,14 \pm 10,18^{\mathrm{ab}}$ & $31,43 \pm 9,45^{a b}$ & $22,57 \pm 4,57^{\mathrm{ab}}$ & $23,50 \pm 10,23^{\mathrm{ab}}$ & $35,86 \pm 7,45^{a}$ & $25,14 \pm 8,00^{\mathrm{ab}}$ & $19,57 \pm 5,57^{\mathrm{ab}}$ & $19,00 \pm 7,50^{\mathrm{ab}}$ \\
\hline DABIII (\%) & $1,14 \pm 0,46^{\mathrm{b}}$ & $2,71 \pm 1,76^{b}$ & $3,43 \pm 1,49^{\mathrm{ab}}$ & $6,71 \pm 2,15^{\mathrm{a}}$ & $2,43 \pm 0,84^{b}$ & $2,00 \pm 0,86^{b}$ & $1,43 \pm 0,87^{\mathrm{b}}$ & $1,43 \pm 0,61^{b}$ & $2,43 \pm 0,92^{b}$ & $1,71 \pm 0,52^{\mathrm{b}}$ \\
\hline DABIV (\%) & $6,14 \pm 3,74$ & $30,00 \pm 17,95$ & $20,57 \pm 13,85$ & $13,00 \pm 9,27$ & $11,14 \pm 6,90$ & $20,67 \pm 15,98$ & $2,71 \pm 1,30$ & $22,86 \pm 14,08$ & $20,57 \pm 13,43$ & $29,29 \pm 18,00$ \\
\hline $\operatorname{VAP}(\mu \mathrm{m} / \mathrm{s})$ & $81,57 \pm 5,01^{a}$ & $65,71 \pm 6,01^{\mathrm{a}}$ & $64,24 \pm 8,90^{\mathrm{a}}$ & $40,13 \pm 3,94^{b}$ & $65,89 \pm 9,44^{a}$ & $61,79 \pm 9,48^{a}$ & $61,80 \pm 5,65^{a}$ & $69,30 \pm 4,11^{a}$ & $69,37 \pm 8,37^{\mathrm{a}}$ & $67,96 \pm 10,01^{a}$ \\
\hline $\operatorname{VCL}(\mu \mathrm{m} / \mathrm{s})$ & $122,63 \pm 9,16^{\mathrm{ab}}$ & $140,89 \pm 12,18^{\mathrm{a}}$ & $148,21 \pm 12,03^{a}$ & $101,67 \pm 8,58^{b}$ & $143,66 \pm 14,71^{a}$ & $139,16 \pm 16,19^{a}$ & $138,17 \pm 8,44^{\mathrm{a}}$ & $147,27 \pm 10,08^{a}$ & $142,93 \pm 10,84^{a}$ & $142,00 \pm 12,31^{a}$ \\
\hline ALH $(\mu \mathrm{m})$ & $6,93 \pm 0,52^{\mathrm{a}}$ & $7,07 \pm 0,55^{a}$ & $7,20 \pm 0,28^{a}$ & $3,56 \pm 1,35^{b}$ & $6,60 \pm 1,20^{a}$ & $6,83 \pm 0,34^{a}$ & $6,94 \pm 0,35^{a}$ & $7,30 \pm 1,42^{a}$ & $6,34 \pm 1,30^{a}$ & $6,47 \pm 0,87^{a}$ \\
\hline $\mathrm{BCF}(\mathrm{Hz})$ & $25,00 \pm 1,72^{\mathrm{b}}$ & $38,56 \pm 1,58^{a}$ & $37,21 \pm 1,73^{\mathrm{a}}$ & $38,16 \pm 1,54^{a}$ & $36,50 \pm 1,41^{a}$ & $37,17 \pm 1,62^{\mathrm{a}}$ & $35,14 \pm 0,92^{a}$ & $37,27 \pm 0,70^{a}$ & $38,27 \pm 1,72^{\mathrm{a}}$ & $39,23 \pm 2,05^{a}$ \\
\hline STR (\%) & $82,71 \pm 1,70^{\mathrm{a}}$ & $55,00 \pm 4,92^{\mathrm{bc}}$ & $54,29 \pm 3,62^{\mathrm{bc}}$ & $44,29 \pm 3,48^{c}$ & $56,86 \pm 3,18^{\mathrm{b}}$ & $52,71 \pm 5,29^{\mathrm{bc}}$ & $58,43 \pm 3,39^{b}$ & $57,71 \pm 3,01^{\mathrm{b}}$ & $54,57 \pm 4,11^{\mathrm{bc}}$ & $54,43 \pm 4,01^{\mathrm{bc}}$ \\
\hline LIN (\%) & $57,86 \pm 3,10^{a}$ & $26,86 \pm 2,99^{\mathrm{bc}}$ & $24,43 \pm 2,76^{\mathrm{bc}}$ & $19,71 \pm 2,04^{c}$ & $27,43 \pm 2,29^{\mathrm{bc}}$ & $24,00 \pm 3,04^{\mathrm{bc}}$ & $29,29 \pm 2,93^{b}$ & $30,00 \pm 2,79^{b}$ & $29,86 \pm 3,80^{b}$ & $28,29 \pm 3,08^{b}$ \\
\hline МOT (\%) & $40,57 \pm 8,93^{a b}$ & $51,57 \pm 8,63^{a}$ & $61,43 \pm 8,39^{\mathrm{a}}$ & $18,43 \pm 7,14^{b}$ & $61,86 \pm 6,88^{\mathrm{a}}$ & $55,43 \pm 8,88^{a}$ & $53,29 \pm 7,80^{a}$ & $49,86 \pm 10,08^{a}$ & $48,29 \pm 9,51^{a}$ & $39,71 \pm 9,06^{\mathrm{ab}}$ \\
\hline SLOW (\%) & $24,57 \pm 6,42^{\mathrm{a}}$ & $10,43 \pm 1,96^{b}$ & $13,57 \pm 3,37^{\mathrm{ab}}$ & $24,14 \pm 5,86^{a}$ & $15,43 \pm 3,18^{a b}$ & $15,86 \pm 2,56^{\mathrm{ab}}$ & $25,29 \pm 4,58^{a}$ & $22,57 \pm 4,50^{a b}$ & $20,29 \pm 4,95^{\mathrm{ab}}$ & $18,57 \pm 3,38^{\mathrm{ab}}$ \\
\hline
\end{tabular}

$\overline{a, b, c}:$ Letras diferentes indicam diferenças estatísticas dentro de uma mesma linha $(p<0,05 ;$ teste LSD)

Tanto na avaliação após a refrigeração (Tabela 21) quanto após a adição da fração do diluidor contendo glicerol (pósglicerolização) (Tabela 22), pode-se observar que não houve diferença estatística na porcentagem de células DABIV, assim como na porcentagem de células móveis, nos diluidores a base de lecitina de soja quando comparados com o diluidor a base de gema de ovo. No entanto, já a partir da refrigeração, pode-se observar que a porcentagem de STR e LIN foi menor em todos os diluidores a base de lecitina de soja em comparação com a gema de ovo. 
Tabela 23 - Comparação entre diluidor a base de lecitina de soja em diferentes apresentações (8160, FP40, Solec F) e concentrações $(0,01 \%$, 0,05\% e $0,1 \%$ ) e o diluidor a base de gema de ovo na atividade mitocondrial (DAB II, atividade alta; DAB III, atividade baixa; DAB IV, atividade nula), nas variáveis analisadas pelo CASA (VAP, VCL, ALH, BCF, STR, LIN, MOT, SLOW) e na susceptibilidade ao estresse oxidativo (TBARS), em amostras de sêmen de cães criopreservadas após o descongelamento - São Paulo - 2012

\begin{tabular}{|c|c|c|c|c|c|c|c|c|c|c|}
\hline & \multirow{2}{*}{ Ovo } & \multicolumn{3}{|c|}{8160} & \multicolumn{3}{|c|}{ FP40 } & \multicolumn{3}{|c|}{ SOLEC F } \\
\hline & & $0,01 \%$ & $0,05 \%$ & $0,1 \%$ & $0,01 \%$ & $0,05 \%$ & $0,1 \%$ & $0,01 \%$ & $0,05 \%$ & $0,1 \%$ \\
\hline DABII (\%) & $32,86 \pm 4,48^{\mathrm{ab}}$ & $27,86 \pm 5,17^{\mathrm{abc}}$ & $14,57 \pm 4,30^{\mathrm{cd}}$ & $4,57 \pm 2,19^{\mathrm{d}}$ & $30,57 \pm 6,83^{\mathrm{abc}}$ & $29,86 \pm 6,17^{\mathrm{abc}}$ & $17,83 \pm 3,11^{\mathrm{bcd}}$ & $34,43 \pm 6,08^{a}$ & $33,29 \pm 6,69^{a b}$ & $42,57 \pm 8,83^{a}$ \\
\hline DABIII (\%) & $3,57 \pm 0,97^{\dagger}$ & $16,14 \pm 3,02^{\text {cde }}$ & $31,29 \pm 5,81^{\mathrm{ab}}$ & $37,14 \pm 8,53^{\mathrm{a}}$ & $12,14 \pm 2,26^{\mathrm{def}}$ & $19,14 \pm 3,56^{\mathrm{cd}}$ & $25,50 \pm 4,46^{\mathrm{bc}}$ & $12,29 \pm 2,18^{\mathrm{def}}$ & $5,71 \pm 1,15^{\dagger}$ & $8,14 \pm 1,61^{\text {def }}$ \\
\hline DABIV (\%) & $4,29 \pm 0,87^{d}$ & $7,71 \pm 3,15^{d}$ & $30,57 \pm 6,54^{\mathrm{b}}$ & $57,14 \pm 9,39^{a}$ & $4,00 \pm 1,41^{d}$ & $13,14 \pm 3,56^{\mathrm{cd}}$ & $22,33 \pm 3,57^{\mathrm{bc}}$ & $6,00 \pm 1,21^{d}$ & $2,86 \pm 0,67^{d}$ & $5,29 \pm 1,44^{d}$ \\
\hline $\operatorname{VAP}(\mu \mathrm{m} / \mathrm{s})$ & $61,91 \pm 10,26^{a}$ & $44,50 \pm 7,89^{\mathrm{ab}}$ & $14,57 \pm 7,10^{\mathrm{cd}}$ & $0,00 \pm 0,00^{a}$ & $34,47 \pm 12,05^{\mathrm{bc}}$ & $43,97 \pm 3,21^{\mathrm{ab}}$ & $27,07 \pm 8,03^{b c}$ & $58,63 \pm 4,88^{a}$ & $47,56 \pm 4,42^{\mathrm{ab}}$ & $58,33 \pm 6,68^{\mathrm{a}}$ \\
\hline $\operatorname{VCL}(\mu \mathrm{m} / \mathrm{s})$ & $116,69 \pm 13,52^{\mathrm{ab}}$ & $97,91 \pm 17,36^{\mathrm{abc}}$ & $38,76 \pm 18,76^{\mathrm{de}}$ & $0,00 \pm 0,00^{\mathrm{e}}$ & $69,94 \pm 26,33^{c d}$ & $112,36 \pm 5,21^{\mathrm{ab}}$ & $76,34 \pm 20,19^{\mathrm{bcd}}$ & $119,26 \pm 9,87^{\mathrm{a}}$ & $\begin{array}{c}107,21 \pm \\
7,98^{\mathrm{abc}}\end{array}$ & $127,77 \pm 10,32^{\mathrm{a}}$ \\
\hline $\mathrm{ALH}(\mu \mathrm{m})$ & $6,81 \pm 1,26^{a b}$ & $4,71 \pm 1,35^{\mathrm{abcd}}$ & $0,57 \pm 0,57^{\mathrm{de}}$ & $0,00 \pm 0,00^{\mathrm{e}}$ & $2,77 \pm 1,81^{\text {bcde }}$ & $3,26 \pm 1,16^{\text {bcde }}$ & $2,43 \pm 1,60^{\text {cde }}$ & $3,70 \pm 1,32^{\text {abcde }}$ & $5,23 \pm 1,66^{\mathrm{abc}}$ & $7,79 \pm 2,50^{\mathrm{a}}$ \\
\hline $\mathrm{BCF}(\mathrm{Hz})$ & $31,44 \pm 2,27^{\mathrm{ab}}$ & $31,31 \pm 5,63^{\mathrm{ab}}$ & $17,51 \pm 8,56^{b}$ & $0,00 \pm 0,00^{c}$ & $25,49 \pm 6,84^{\mathrm{ab}}$ & $36,71 \pm 2,37^{a}$ & $26,53 \pm 7,33^{\mathrm{ab}}$ & $33,96 \pm 2,86^{a}$ & $37,26 \pm 1,87^{\mathrm{a}}$ & $33,96 \pm 4,19^{\mathrm{a}}$ \\
\hline STR (\%) & $69,86 \pm 7,16^{a}$ & $54,57 \pm 9,56^{\mathrm{ab}}$ & $27,00 \pm 12,94^{c}$ & $0,00 \pm 0,00^{d}$ & $52,71 \pm 15,34^{a b}$ & $55,43 \pm 2,88^{\mathrm{ab}}$ & $39,00 \pm 11,19^{\mathrm{bc}}$ & $62,29 \pm 2,76^{\mathrm{ab}}$ & $59,14 \pm 6,15^{\mathrm{ab}}$ & $59,57 \pm 4,48^{\mathrm{ab}}$ \\
\hline LIN (\%) & $38,86 \pm 5,83^{a}$ & $27,86 \pm 5,84^{\mathrm{abc}}$ & $12,71 \pm 7,59^{\mathrm{cd}}$ & $0,00 \pm 0,00^{d}$ & $32,29 \pm 11,79^{\mathrm{ab}}$ & $23,71 \pm 2,44^{\mathrm{abc}}$ & $16,14 \pm 5,65^{\mathrm{bcd}}$ & $34,14 \pm 3,35^{a}$ & $28,86 \pm 4,29^{a b c}$ & $28,29 \pm 3,41^{\mathrm{abc}}$ \\
\hline МОт (\%) & $15,43 \pm 6,39^{\mathrm{a}}$ & $13,29 \pm 5,06^{a b}$ & $1,57 \pm 1,00^{c}$ & $0,00 \pm 0,00^{c}$ & $8,00 \pm 4,38^{\mathrm{abc}}$ & $8,86 \pm 4,30^{\mathrm{abc}}$ & $3,00 \pm 1,13^{\mathrm{bc}}$ & $15,57 \pm 4,41^{a}$ & $13,00 \pm 4,06^{\mathrm{ab}}$ & $7,86 \pm 2,85^{\mathrm{abc}}$ \\
\hline SLOW (\%) & $7,43 \pm 2,47^{\mathrm{cd}}$ & $25,43 \pm 7,91^{\mathrm{abc}}$ & $16,71 \pm 7,37^{\mathrm{bcd}}$ & $5,29 \pm 2,23^{d}$ & $22,71 \pm 7,37^{\mathrm{abcd}}$ & $34,86 \pm 6,42^{\mathrm{ab}}$ & $29,43 \pm 11,01^{\mathrm{ab}}$ & $20,29 \pm 4,89^{\mathrm{abcd}}$ & $39,57 \pm 7,67^{\mathrm{a}}$ & $23,29 \pm 6,50^{\mathrm{abcd}}$ \\
\hline $\begin{array}{l}\text { TBARS } \\
\left(\mathrm{ng} / 10^{6}\right) \\
\text { SCSA } \%)\end{array}$ & $\begin{array}{c}2519,08 \pm 1567,41^{a} \\
10,05 \pm 4,64^{a b}\end{array}$ & $\begin{array}{c}442,90 \pm 173,43^{\mathrm{b}} \\
10,99 \pm 3,28^{\mathrm{ab}}\end{array}$ & $\begin{array}{c}461,33 \pm \\
188,89^{\mathrm{b}} \\
7,29 \pm 0,94^{\text {ab }}\end{array}$ & $\begin{array}{c}457,57 \pm \\
184,44^{\mathrm{b}} \\
10,99 \pm 3,28^{\mathrm{ab}}\end{array}$ & $\begin{array}{c}500,41 \pm \\
232,84^{\mathrm{b}} \\
6,30 \pm 2,21^{\mathrm{b}}\end{array}$ & $\begin{array}{c}422,74 \pm \\
150,61^{\mathrm{b}} \\
7,13 \pm 1,49^{\mathrm{ab}}\end{array}$ & $\begin{array}{c}492,90 \pm 181,88^{\mathrm{b}} \\
7,38 \pm 1,81^{\mathrm{ab}}\end{array}$ & $\begin{array}{c}632,12 \pm \\
316,08^{\mathrm{b}} \\
7,03 \pm 1,87^{\mathrm{ab}}\end{array}$ & $\begin{array}{c}458,52 \pm \\
169,73^{\mathrm{b}} \\
8,57 \pm 1,99^{\mathrm{ab}}\end{array}$ & $\begin{array}{c}434,83 \pm \\
148,25^{\mathrm{b}} \\
16,02 \pm 6,74^{\mathrm{a}}\end{array}$ \\
\hline & $10,05 \pm 4,64$ & $10,99 \pm 3, \angle 8$ & $1, \angle 9 \pm 0,94$ & $10,99 \pm 3,28$ & $0,3 \cup \pm 2, \angle 1$ & $r, 13 \pm 1,49$ & $1,38 \pm 1,81$ & $7,03 \pm 1,8 /$ & $8,5 / \pm 1,99$ & $16,02 \pm 6,14^{4}$ \\
\hline
\end{tabular}

$\overline{a, b, c, d, e, \uparrow}$ : Letras diferentes indicam diferenças estatísticas dentro de uma mesma linha (p<0,05; teste LSD)

Nas análises após a descongelação do sêmen (Tabela 23), observou-se que a porcentagem de células DABIV foi maior nos diluidores 8160 0,05\%, 0,1\% e no FP40 0,1\%. Além disso, a porcentagem de células móveis foi menor nesses mesmos diluidores em comparação com a gema de ovo, sendo que no diluidor 8160 0,1\% não houve a presença de células móveis. Por outro lado, houve uma maior susceptibilidade ao estresse oxidativo (TBARS) nas células criopreservadas com o diluidor contendo gema de ovo em relação a todos os diluidores a base de lecitina de soja, independente da concentração. 
Tabela 24 - Efeito dos momentos da criopreservação (pós-refrigeração, pós-glicerolização e pósdescongelação) na atividade mitocondrial (DAB II, atividade alta; DAB III, atividade baixa; DAB IV, atividade nula) e nas variáveis analisadas pelo CASA (VAP, VCL, ALH, BCF, STR, LIN, MOT, SLOW), em amostras de sêmen de cães criopreservadas em diluidor a base de gema de ovo - São Paulo - 2012

\begin{tabular}{lccc} 
& Pós-Refrigeração & Pós-Glicerolização & Pós-Descongelação \\
\hline DABII (\%) & $14,57 \pm 5,98^{\mathrm{b}}$ & $13,43 \pm 4,26^{\mathrm{b}}$ & $32,86 \pm 4,48^{\mathrm{a}}$ \\
DABIII (\%) & $3,29 \pm 1,15$ & $1,14 \pm 0,46$ & $3,57 \pm 0,97$ \\
DABIV (\%) & $23,00 \pm 9,95^{\mathrm{a}}$ & $6,14 \pm 3,74^{\mathrm{ab}}$ & $4,29 \pm 0,87^{\mathrm{b}}$ \\
VAP $(\mu \mathrm{m} / \mathrm{s})$ & $115,66 \pm 1,72^{\mathrm{a}}$ & $81,57 \pm 5,01^{\mathrm{b}}$ & $61,91 \pm 10,26^{\mathrm{b}}$ \\
VCL $(\mu \mathrm{m} / \mathrm{s})$ & $178,20 \pm 8,31^{\mathrm{a}}$ & $122,63 \pm 9,16^{\mathrm{b}}$ & $116,69 \pm 13,52^{\mathrm{b}}$ \\
ALH $(\mu \mathrm{m})$ & $8,86 \pm 0,50$ & $6,93 \pm 0,52$ & $6,81 \pm 1,26$ \\
BCF $(\mathrm{Hz})$ & $28,17 \pm 2,30^{\mathrm{ab}}$ & $25,00 \pm 1,72^{\mathrm{b}}$ & $31,44 \pm 2,27^{\mathrm{a}}$ \\
STR $(\%)$ & $73,86 \pm 3,21$ & $82,71 \pm 1,70$ & $69,86 \pm 7,16$ \\
LIN $(\%)$ & $50,71 \pm 4,33^{\mathrm{ab}}$ & $57,86 \pm 3,10^{\mathrm{a}}$ & $38,86 \pm 5,83^{\mathrm{b}}$ \\
MOT $(\%)$ & $70,43 \pm 6,77^{\mathrm{a}}$ & $40,57 \pm 8,93^{\mathrm{b}}$ & $15,43 \pm 6,39^{\mathrm{c}}$ \\
SLOW (\%) & $13,14 \pm 2,94^{\mathrm{ab}}$ & $24,57 \pm 6,42^{\mathrm{a}}$ & $7,43 \pm 2,47^{\mathrm{b}}$ \\
\hline \hline
\end{tabular}

: Letras diferentes indicam diferenças estatísticas dentro de uma mesma linha ( $p<0,05 ;$ teste LSD)

Como pode ser observado na Tabela 24, as amostras criopreservadas com o diluidor contendo gema de ovo apresentaram uma redução na porcentagem de células DABIV após a descongelação. Além disso, apesar de não ser notada diferença estatística, foi possível observar uma diminuição considerável entre o tempo pós-refrigeração $(23,00 \pm 9,95)$ e pós-glicerolização $(6,14 \pm 3,74)$. Porém, após a refrigeração, houve uma diminuição progressiva e significante na porcentagem de células móveis. 
Tabela 25 - Efeito dos momentos da criopreservação (pós-refrigeração, pós-glicerolização e pósdescongelação) na atividade mitocondrial (DAB II, atividade alta; DAB III, atividade baixa; DAB IV, atividade nula) e nas variáveis analisadas pelo CASA (VAP, VCL, ALH, BCF, STR, LIN, MOT, SLOW), em amostras de sêmen de cães criopreservadas em diluidor a base de lecitina de soja 8160 0,01\% - São Paulo - 2012

\begin{tabular}{lccc} 
& Pós-Refrigeração & Pós-Glicerolização & Pós-Descongelação \\
\hline DABII (\%) & $18,86 \pm 8,87$ & $23,00 \pm 8,49$ & $27,86 \pm 5,17$ \\
DABIII (\%) & $4,00 \pm 1,48^{\mathrm{b}}$ & $2,71 \pm 1,76^{\mathrm{b}}$ & $16,14 \pm 3,02^{\mathrm{a}}$ \\
DABIV (\%) & $24,71 \pm 15,13$ & $30,00 \pm 17,95$ & $7,71 \pm 3,15$ \\
VAP $(\mu \mathrm{m} / \mathrm{s})$ & $98,34 \pm 7,38^{\mathrm{a}}$ & $65,71 \pm 6,01^{\mathrm{b}}$ & $44,50 \pm 7,89^{\mathrm{c}}$ \\
VCL $(\mu \mathrm{m} / \mathrm{s})$ & $197,96 \pm 11,88^{\mathrm{a}}$ & $140,89 \pm 12,18^{\mathrm{b}}$ & $97,91 \pm 17,36^{\mathrm{c}}$ \\
ALH $(\mu \mathrm{m})$ & $9,09 \pm 0,49^{\mathrm{a}}$ & $7,07 \pm 0,55^{\mathrm{ab}}$ & $4,71 \pm 1,35^{\mathrm{b}}$ \\
BCF $(\mathrm{Hz})$ & $36,56 \pm 1,68$ & $38,56 \pm 1,58$ & $31,31 \pm 5,63$ \\
STR $(\%)$ & $55,14 \pm 2,71$ & $55,00 \pm 4,92$ & $54,57 \pm 9,56$ \\
LIN $(\%)$ & $28,57 \pm 1,84$ & $26,86 \pm 2,99$ & $27,86 \pm 5,84$ \\
MOT $(\%)$ & $76,57 \pm 8,01^{\mathrm{a}}$ & $51,57 \pm 8,63^{\mathrm{b}}$ & $13,29 \pm 5,06^{\mathrm{c}}$ \\
SLOW (\%) & $9,86 \pm 5,43$ & $10,43 \pm 1,96$ & $25,43 \pm 7,91$ \\
\hline \hline
\end{tabular}

, : Letras diferentes indicam diferenças estatísticas dentro de uma mesma linha ( $p<0,05$; teste LSD)

Quando as amostras foram criopreservadas no diluidor a base de lecitina 8160, na concentração 0,01\% (Tabela 25), não foi observada diferença estatística em relação à porcentagem de células com nenhuma atividade mitocondrial (DABIV) nos 3 tempos: pós-refrigeração, pós-glicerolização e pós-descongelação. No entanto, o tempo pós-refrigeração foi o que apresentou uma maior porcentagem de células móveis, havendo uma diminuição gradual e significante após a glicerolização e após a descongelação. 
Tabela 26 - Efeito dos momentos da criopreservação (pós-refrigeração, pós-glicerolização e pósdescongelação) na atividade mitocondrial (DAB II, atividade alta; DAB III, atividade baixa; DAB IV, atividade nula) e nas variáveis analisadas pelo CASA (VAP, VCL, ALH, BCF, STR, LIN, MOT, SLOW), em amostras de sêmen de cães criopreservadas em diluidor a base de lecitina de soja 8160 0,05\% - São Paulo - 2012

\begin{tabular}{lccc} 
& Pós-Refrigeração & Pós-Glicerolização & Pós-Descongelação \\
\hline DABII (\%) & $25,29 \pm 8,33$ & $32,14 \pm 10,18$ & $14,57 \pm 4,30$ \\
DABIII (\%) & $2,00 \pm 0,72^{\mathrm{b}}$ & $3,43 \pm 1,49^{\mathrm{b}}$ & $31,29 \pm 5,81^{\mathrm{a}}$ \\
DABIV (\%) & $13,00 \pm 11,69$ & $20,57 \pm 13,85$ & $30,57 \pm 6,54$ \\
VAP $(\mu \mathrm{m} / \mathrm{s})$ & $99,70 \pm 9,79^{\mathrm{a}}$ & $64,24 \pm 8,90^{\mathrm{b}}$ & $14,57 \pm 7,10^{\mathrm{c}}$ \\
VCL $(\mu \mathrm{m} / \mathrm{s})$ & $203,36 \pm 16,54^{\mathrm{a}}$ & $148,21 \pm 12,03^{\mathrm{b}}$ & $38,76 \pm 18,76^{\mathrm{c}}$ \\
ALH $(\mu \mathrm{m})$ & $9,14 \pm 0,42^{\mathrm{a}}$ & $7,20 \pm 0,28^{\mathrm{b}}$ & $0,57 \pm 0,57^{\mathrm{c}}$ \\
BCF (Hz) & $33,24 \pm 1,72^{\mathrm{a}}$ & $37,21 \pm 1,73^{\mathrm{a}}$ & $17,51 \pm 8,56^{\mathrm{b}}$ \\
STR $(\%)$ & $52,57 \pm 3,82^{\mathrm{a}}$ & $54,29 \pm 3,62^{\mathrm{a}}$ & $27,00 \pm 12,94^{\mathrm{b}}$ \\
LIN $(\%)$ & $26,86 \pm 3,03$ & $24,43 \pm 2,76$ & $12,71 \pm 7,59$ \\
MOT $(\%)$ & $76,71 \pm 8,62^{\mathrm{a}}$ & $61,43 \pm 8,39^{\mathrm{a}}$ & $1,57 \pm 1,00^{\mathrm{b}}$ \\
SLOW $(\%)$ & $7,57 \pm 4,11$ & $13,57 \pm 3,37$ & $16,71 \pm 7,37$ \\
\hline \hline
\end{tabular}

: Letras diferentes indicam diferenças estatísticas dentro de uma mesma linha $(p<0,05$; teste LSD)

No diluidor 8160 0,05\% (Tabela 26), houve uma diminuição da motilidade somente após a descongelação, sendo que não houve diferença significativa entre os momentos pós-refrigeração e pós-glicerolização.

Tabela 27 - Efeito dos momentos da criopreservação (pós-refrigeração, pós-glicerolização e pósdescongelação) na atividade mitocondrial (DAB II, atividade alta; DAB III, atividade baixa; DAB IV, atividade nula) e nas variáveis analisadas pelo CASA (VAP, VCL, ALH, BCF, STR, LIN, MOT, SLOW), em amostras de sêmen de cães criopreservadas em diluidor a base de lecitina de soja 8160 0,1\% - São Paulo - 2012

\begin{tabular}{lccc} 
& Pós-Refrigeração & Pós-Glicerolização & Pós-Descongelação \\
\hline DABII (\%) & $29,29 \pm 8,28^{\mathrm{a}}$ & $31,43 \pm 9,45^{\mathrm{a}}$ & $4,57 \pm 2,19^{\mathrm{b}}$ \\
DABIII (\%) & $2,00 \pm 0,76^{\mathrm{b}}$ & $6,71 \pm 2,15^{\mathrm{b}}$ & $37,14 \pm 8,53^{\mathrm{a}}$ \\
DABIV (\%) & $2,57 \pm 0,78^{\mathrm{b}}$ & $13,00 \pm 9,27^{\mathrm{b}}$ & $57,14 \pm 9,39^{\mathrm{a}}$ \\
VAP ( $\mu \mathrm{m} / \mathrm{s})$ & $87,57 \pm 5,98^{\mathrm{a}}$ & $40,13 \pm 3,94^{\mathrm{b}}$ & $0,00 \pm 0,00^{\mathrm{c}}$ \\
VCL $(\mu \mathrm{m} / \mathrm{s})$ & $193,31 \pm 11,09^{\mathrm{a}}$ & $101,67 \pm 8,58^{\mathrm{b}}$ & $0,00 \pm 0,00^{\mathrm{c}}$ \\
ALH $(\mu \mathrm{m})$ & $8,90 \pm 0,69^{\mathrm{a}}$ & $3,56 \pm 1,35^{\mathrm{b}}$ & $0,00 \pm 0,00^{\mathrm{c}}$ \\
BCF $(\mathrm{Hz})$ & $33,64 \pm 1,93^{\mathrm{b}}$ & $38,16 \pm 1,54^{\mathrm{a}}$ & $0,00 \pm 0,00^{\mathrm{c}}$ \\
STR (\%) & $50,43 \pm 2,38^{\mathrm{a}}$ & $44,29 \pm 3,48^{\mathrm{a}}$ & $0,00 \pm 0,00^{\mathrm{b}}$ \\
LIN (\%) & $23,00 \pm 1,45^{\mathrm{a}}$ & $19,71 \pm 2,04^{\mathrm{a}}$ & $0,00 \pm 0,00^{\mathrm{b}}$ \\
MOT $(\%)$ & $78,29 \pm 4,71^{\mathrm{a}}$ & $18,43 \pm 7,14^{\mathrm{b}}$ & $0,00 \pm 0,00^{\mathrm{c}}$ \\
SLOW (\%) & $11,43 \pm 3,64^{\mathrm{b}}$ & $24,14 \pm 5,86^{\mathrm{a}}$ & $5,29 \pm 2,23^{\mathrm{b}}$ \\
\hline \hline
\end{tabular}

a,b,c. Letras diferentes indicam diferenças estatísticas dentro de uma mesma linha ( $p<0,05$; teste LSD) 
Em relação ao diluidor 8160 0,1\% (Tabela 27), houve um aumento na porcentagem de células DABIV no tempo pós-descongelação quando comparado com os outros tempos. Todavia, a porcentagem de células móveis apresentou uma diminuição significativa a partir da glicerolização. Além disto, neste diluidor, não foram encontradas células móveis após a descongelação.

Tabela 28 - Efeito dos momentos da criopreservação (pós-refrigeração, pós-glicerolização e pósdescongelação) na atividade mitocondrial (DAB II, atividade alta; DAB III, atividade baixa; DAB IV, atividade nula) e nas variáveis analisadas pelo CASA (VAP, VCL, ALH, BCF, STR, LIN, MOT, SLOW), em amostras de sêmen de cães criopreservadas em diluidor a base de lecitina de soja FP40 0,01\% - São Paulo - 2012

\begin{tabular}{lccc} 
& Pós-Refrigeração & Pós-Glicerolização & Pós-Descongelação \\
\hline DABII (\%) & $18,29 \pm 7,63$ & $22,57 \pm 4,57$ & $30,57 \pm 6,83$ \\
DABIII (\%) & $1,57 \pm 0,78^{\mathrm{b}}$ & $2,43 \pm 0,84^{\mathrm{b}}$ & $12,14 \pm 2,26^{\mathrm{a}}$ \\
DABIV (\%) & $24,57 \pm 15,06$ & $11,14 \pm 6,90$ & $4,00 \pm 1,41$ \\
VAP $(\mu \mathrm{m} / \mathrm{s})$ & $95,00 \pm 11,18^{\mathrm{a}}$ & $65,89 \pm 9,44^{\mathrm{ab}}$ & $34,47 \pm 12,05^{\mathrm{b}}$ \\
VCL $(\mu \mathrm{m} / \mathrm{s})$ & $181,97 \pm 19,37^{\mathrm{a}}$ & $143,66 \pm 14,71^{\mathrm{a}}$ & $69,94 \pm 26,33^{\mathrm{b}}$ \\
ALH $(\mu \mathrm{m})$ & $8,04 \pm 0,47^{\mathrm{a}}$ & $6,60 \pm 1,20^{\mathrm{a}}$ & $2,77 \pm 1,81^{\mathrm{b}}$ \\
BCF $(\mathrm{Hz})$ & $36,39 \pm 1,13$ & $36,50 \pm 1,41$ & $25,49 \pm 6,84$ \\
STR $(\%)$ & $57,86 \pm 3,53$ & $56,86 \pm 3,18$ & $52,71 \pm 15,34$ \\
LIN $(\%)$ & $32,14 \pm 2,76$ & $27,43 \pm 2,29$ & $32,29 \pm 11,79$ \\
MOT $(\%)$ & $80,43 \pm 6,78^{\mathrm{a}}$ & $61,86 \pm 6,88^{\mathrm{b}}$ & $8,00 \pm 4,38^{\mathrm{c}}$ \\
SLOW $(\%)$ & $7,29 \pm 2,20^{\mathrm{b}}$ & $15,43 \pm 3,18^{\mathrm{ab}}$ & $22,71 \pm 7,37^{\mathrm{a}}$ \\
\hline
\end{tabular}

a,b,c. Letras diferentes indicam diferenças estatísticas dentro de uma mesma linha ( $p<0,05$; teste LSD)

Tabela 29 - Efeito dos momentos da criopreservação (pós-refrigeração, pós-glicerolização e pósdescongelação) na atividade mitocondrial (DAB II: atividade alta; DAB III: atividade baixa; DAB IV: atividade nula) e nas variáveis analisadas pelo CASA (VAP, VCL, ALH, BCF, STR, LIN, MOT, SLOW), em amostras de sêmen de cães criopreservadas em diluidor a base de lecitina de soja FP40 0,05\% - São Paulo - 2012

\begin{tabular}{lccc} 
& Pós -Refrigeração & Pós-Glicerolização & Pós-Descongelação \\
\hline DABII (\%) & $8,43 \pm 3,50^{\mathrm{b}}$ & $23,50 \pm 10,23^{\mathrm{ab}}$ & $29,86 \pm 6,17^{\mathrm{a}}$ \\
DABIII (\%) & $0,86 \pm 0,46^{\mathrm{b}}$ & $2,00 \pm 0,86^{\mathrm{b}}$ & $19,14 \pm 3,56^{\mathrm{a}}$ \\
DABIV (\%) & $31,14 \pm 17,55$ & $20,67 \pm 15,98$ & $13,14 \pm 3,56$ \\
VAP $(\mu \mathrm{m} / \mathrm{s})$ & $101,67 \pm 7,01^{\mathrm{a}}$ & $61,79 \pm 9,48^{\mathrm{b}}$ & $43,97 \pm 3,21^{\mathrm{b}}$ \\
VCL $(\mu \mathrm{m} / \mathrm{s})$ & $202,90 \pm 11,09^{\mathrm{a}}$ & $139,16 \pm 16,19^{\mathrm{b}}$ & $112,36 \pm 5,21^{\mathrm{b}}$ \\
ALH $(\mu \mathrm{m})$ & $8,56 \pm 0,42^{\mathrm{a}}$ & $6,83 \pm 0,34^{\mathrm{a}}$ & $3,26 \pm 1,16^{\mathrm{b}}$ \\
BCF $(\mathrm{Hz})$ & $34,04 \pm 1,29$ & $37,17 \pm 1,62$ & $36,71 \pm 2,37$ \\
STR $(\%)$ & $55,14 \pm 3,64$ & $52,71 \pm 5,29$ & $55,43 \pm 2,88$ \\
LIN $(\%)$ & $29,43 \pm 3,02$ & $24,00 \pm 3,04$ & $23,71 \pm 2,44$ \\
MOT $(\%)$ & $89,29 \pm 2,49^{\mathrm{a}}$ & $55,43 \pm 8,88^{\mathrm{b}}$ & $8,86 \pm 4,30^{\mathrm{c}}$ \\
SLOW $(\%)$ & $4,43 \pm 1,17^{\mathrm{b}}$ & $15,86 \pm 2,56^{\mathrm{b}}$ & $34,86 \pm 6,42^{\mathrm{a}}$ \\
\hline
\end{tabular}

a,b,c. Letras diferentes indicam diferenças estatísticas dentro de uma mesma linha ( $p<0,05$; teste LSD) 
Tabela 30 - Efeito dos momentos da criopreservação (pós-refrigeração, pós-glicerolização e pósdescongelação) na atividade mitocondrial (DAB II, atividade alta; DAB III, atividade baixa; DAB IV, atividade nula) e nas variáveis analisadas pelo CASA (VAP, VCL, ALH, BCF, STR, LIN, MOT, SLOW), em amostras de sêmen de cães criopreservadas em diluidor a base de lecitina de soja FP40 0,1\% - São Paulo - 2012

\begin{tabular}{lccc} 
& Pós-Refrigeração & Pós-Glicerolização & Pós-Descongelação \\
\hline DABII (\%) & $23,14 \pm 8,53$ & $35,86 \pm 7,45$ & $17,83 \pm 3,11$ \\
DABIII (\%) & $0,57 \pm 0,30^{\mathrm{b}}$ & $1,43 \pm 0,87^{\mathrm{b}}$ & $25,50 \pm 4,46^{\mathrm{a}}$ \\
DABIV (\%) & $6,43 \pm 3,77^{\mathrm{b}}$ & $2,71 \pm 1,30^{\mathrm{b}}$ & $22,33 \pm 3,57^{\mathrm{a}}$ \\
VAP $(\mu \mathrm{m} / \mathrm{s})$ & $86,10 \pm 6,35^{\mathrm{a}}$ & $61,80 \pm 5,65^{\mathrm{b}}$ & $27,07 \pm 8,03^{\mathrm{c}}$ \\
VCL $(\mu \mathrm{m} / \mathrm{s})$ & $184,34 \pm 10,60^{\mathrm{a}}$ & $138,17 \pm 8,44^{\mathrm{b}}$ & $76,34 \pm 20,19^{\mathrm{c}}$ \\
ALH $(\mu \mathrm{m})$ & $8,66 \pm 0,49^{\mathrm{a}}$ & $6,94 \pm 0,35^{\mathrm{a}}$ & $2,43 \pm 1,60^{\mathrm{b}}$ \\
BCF $(\mathrm{Hz})$ & $34,00 \pm 1,02$ & $35,14 \pm 0,92$ & $26,53 \pm 7,33$ \\
STR $(\%)$ & $54,57 \pm 2,27$ & $58,43 \pm 3,39$ & $39,00 \pm 11,19$ \\
LIN $(\%)$ & $27,00 \pm 1,68^{\mathrm{ab}}$ & $29,29 \pm 2,93^{\mathrm{a}}$ & $16,14 \pm 5,65^{\mathrm{b}}$ \\
MOT $(\%)$ & $79,86 \pm 7,05^{\mathrm{a}}$ & $53,29 \pm 7,80^{\mathrm{b}}$ & $3,00 \pm 1,13^{\mathrm{c}}$ \\
SLOW $(\%)$ & $9,29 \pm 3,48$ & $25,29 \pm 4,58$ & $29,43 \pm 11,01$ \\
\hline \hline
\end{tabular}

${ }^{a, b, c}$ : Letras diferentes indicam diferenças estatísticas dentro de uma mesma linha ( $p<0,05$; teste LSD)

Nas amostras criopreservadas com o diluidor a base de lecitina de soja FP40, nas três concentrações $(0,01 \%, 0,05 \%$ e 0,1\%) (Tabelas 28, 29 e 30, respectivamente), notou-se que a porcentagem de células móveis foi menor após a descongelação. No entanto, a porcentagem de células DABIV foi maior após descongelação na concentração 0,1\% (Tabela 30).

Tabela 31 - Efeito dos momentos da criopreservação (pós-refrigeração, pós-glicerolização e pósdescongelação) na atividade mitocondrial (DAB II, atividade alta; DAB III, atividade baixa; DAB IV, atividade nula) e nas variáveis analisadas pelo CASA (VAP, VCL, ALH, BCF, STR, LIN, MOT, SLOW), em amostras de sêmen de cães criopreservadas em diluidor a base de lecitina de soja Solec F 0,01\% - São Paulo - 2012

\begin{tabular}{lccc} 
& Pós-Refrigeração & Pós-Glicerolização & Pós-Descongelação \\
\hline DABII (\%) & $18,86 \pm 4,97$ & $25,14 \pm 8,00$ & $34,43 \pm 6,08$ \\
DABIII (\%) & $1,86 \pm 1,70^{\mathrm{b}}$ & $1,43 \pm 0,61^{\mathrm{b}}$ & $12,29 \pm 2,18^{\mathrm{a}}$ \\
DABIV (\%) & $24,71 \pm 11,24$ & $22,86 \pm 14,08$ & $6,00 \pm 1,21$ \\
VAP $(\mu \mathrm{m} / \mathrm{s})$ & $98,64 \pm 3,86^{\mathrm{a}}$ & $69,30 \pm 4,11^{\mathrm{b}}$ & $58,63 \pm 4,88^{\mathrm{b}}$ \\
VCL $(\mu \mathrm{m} / \mathrm{s})$ & $194,27 \pm 7,41^{\mathrm{a}}$ & $147,27 \pm 10,08^{\mathrm{b}}$ & $119,26 \pm 9,87^{\mathrm{c}}$ \\
ALH $(\mu \mathrm{m})$ & $9,24 \pm 0,62^{\mathrm{a}}$ & $7,30 \pm 1,42^{\mathrm{a}}$ & $3,70 \pm 1,32^{\mathrm{b}}$ \\
BCF $(\mathrm{Hz})$ & $35,19 \pm 1,48$ & $37,27 \pm 0,70$ & $33,96 \pm 2,86$ \\
STR $(\%)$ & $56,43 \pm 2,01$ & $57,71 \pm 3,01$ & $62,29 \pm 2,76$ \\
LIN $(\%)$ & $61,00 \pm 1,99^{\mathrm{b}}$ & $66,86 \pm 1,14^{\mathrm{a}}$ & $63,57 \pm 2,01^{\mathrm{ab}}$ \\
MOT $(\%)$ & $85,43 \pm 1,04^{\mathrm{a}}$ & $49,86 \pm 10,08^{\mathrm{b}}$ & $15,57 \pm 4,41^{\mathrm{c}}$ \\
SLOW $(\%)$ & $6,71 \pm 1,17^{\mathrm{b}}$ & $22,57 \pm 4,50^{\mathrm{a}}$ & $20,29 \pm 4,89^{\mathrm{a}}$ \\
\hline \hline
\end{tabular}

: Letras diferentes indicam diferenças estatísticas dentro de uma mesma linha ( $p<0,05 ;$ teste LSD) 
Tabela 32 - Efeito dos momentos da criopreservação (pós-refrigeração, pós-glicerolização e pósdescongelação) na atividade mitocondrial (DAB II, atividade alta; DAB III, atividade baixa; DAB IV, atividade nula) e nas variáveis analisadas pelo CASA (VAP, VCL, ALH, BCF, STR, LIN, MOT, SLOW), em amostras de sêmen de cães criopreservadas em diluidor a base de lecitina de soja Solec F 0,05\% - São Paulo - 2012

\begin{tabular}{lccc} 
& Pós-Refrigeração & Pós-Glicerolização & Pós-Descongelação \\
\hline DABII (\%) & $15,86 \pm 6,39$ & $19,57 \pm 5,57$ & $33,29 \pm 6,69$ \\
DABIII (\%) & $2,00 \pm 0,62^{\mathrm{b}}$ & $2,43 \pm 0,92^{\mathrm{b}}$ & $5,71 \pm 1,15^{\mathrm{a}}$ \\
DABIV (\%) & $19,29 \pm 13,71$ & $20,57 \pm 13,43$ & $2,86 \pm 0,67$ \\
VAP $(\mu \mathrm{m} / \mathrm{s})$ & $99,67 \pm 6,04^{\mathrm{a}}$ & $69,37 \pm 8,37^{\mathrm{b}}$ & $47,56 \pm 4,42^{\mathrm{c}}$ \\
VCL $(\mu \mathrm{m} / \mathrm{s})$ & $192,39 \pm 10,46^{\mathrm{a}}$ & $142,93 \pm 10,84^{\mathrm{b}}$ & $107,21 \pm 7,98^{\mathrm{c}}$ \\
ALH $(\mu \mathrm{m})$ & $8,91 \pm 0,73$ & $6,34 \pm 1,30$ & $5,23 \pm 1,66$ \\
BCF $(\mathrm{Hz})$ & $37,24 \pm 1,19$ & $38,27 \pm 1,72$ & $37,26 \pm 1,87$ \\
STR (\%) & $56,29 \pm 2,15$ & $54,57 \pm 4,11$ & $59,14 \pm 6,15$ \\
LIN $(\%)$ & $30,71 \pm 1,51$ & $29,86 \pm 3,80$ & $28,86 \pm 4,29$ \\
MOT $(\%)$ & $67,00 \pm 7,97^{\mathrm{a}}$ & $48,29 \pm 9,51^{\mathrm{a}}$ & $13,00 \pm 4,06^{\mathrm{b}}$ \\
SLOW (\%) & $14,71 \pm 5,10^{\mathrm{b}}$ & $20,29 \pm 4,95^{\mathrm{b}}$ & $39,57 \pm 7,67^{\mathrm{a}}$ \\
\hline \hline
\end{tabular}

a,b,c: Letras diferentes indicam diferenças estatísticas dentro de uma mesma linha ( $p<0,05$; teste LSD)

Tabela 33 - Efeito dos momentos da criopreservação (pós-refrigeração, pós-glicerolização e pósdescongelação) na atividade mitocondrial (DAB II, atividade alta; DAB III, atividade baixa; DAB IV, atividade nula) e nas variáveis analisadas pelo CASA (VAP, VCL, ALH, BCF, STR, LIN, MOT, SLOW), em amostras de sêmen de cães criopreservadas em diluidor a base de lecitina de soja Solec F 0,1\% - São Paulo - 2012

\begin{tabular}{lccc} 
& Pós-Refrigeração & Pós-Glicerolização & Pós-Descongelação \\
\hline DABII (\%) & $10,14 \pm 5,62^{\mathrm{b}}$ & $19,00 \pm 7,50^{\mathrm{b}}$ & $42,57 \pm 8,83^{\mathrm{a}}$ \\
DABIII (\%) & $1,00 \pm 0,58^{\mathrm{b}}$ & $1,71 \pm 0,52^{\mathrm{b}}$ & $8,14 \pm 1,61^{\mathrm{a}}$ \\
DABIV (\%) & $40,00 \pm 17,88$ & $29,29 \pm 18,00$ & $5,29 \pm 1,44$ \\
VAP $(\mu \mathrm{m} / \mathrm{s})$ & $87,07 \pm 12,32$ & $67,96 \pm 10,01$ & $58,33 \pm 6,68$ \\
VCL $(\mu \mathrm{m} / \mathrm{s})$ & $174,54 \pm 20,80^{\mathrm{a}}$ & $142,00 \pm 12,31^{\mathrm{ab}}$ & $127,77 \pm 10,32^{\mathrm{b}}$ \\
ALH $(\mu \mathrm{m})$ & $9,01 \pm 0,99$ & $6,47 \pm 0,87$ & $7,79 \pm 2,50$ \\
BCF $(\mathrm{Hz})$ & $36,14 \pm 1,59$ & $39,23 \pm 2,05$ & $33,96 \pm 4,19$ \\
STR $(\%)$ & $52,14 \pm 2,89$ & $54,43 \pm 4,01$ & $59,57 \pm 4,48$ \\
LIN $(\%)$ & $26,57 \pm 2,37$ & $28,29 \pm 3,08$ & $28,29 \pm 3,41$ \\
MOT $(\%)$ & $63,00 \pm 9,97^{\mathrm{a}}$ & $39,71 \pm 9,06^{\mathrm{a}}$ & $7,86 \pm 2,85^{\mathrm{b}}$ \\
SLOW (\%) & $12,14 \pm 4,37$ & $18,57 \pm 3,38$ & $23,29 \pm 6,50$ \\
\hline \hline
\end{tabular}

a,b: Letras diferentes indicam diferenças estatísticas dentro de uma mesma linha ( $p<0,05 ;$ teste LSD)

A porcentagem de células móveis das amostras criopreservadas com a lecitina Solec F, na concentração de 0,01\% (Tabela 31), demonstrou uma diminuição gradativa desde a refrigeração até após a descongelação, diferentemente das concentrações 0,05\% (Tabela 32) e 0,1\% (Tabela 33), nas quais a porcentagem de células móveis se manteve durante a refrigeração e glicerolização, havendo uma queda somente após a descongelação. 
Tabela 34 - Comparação entre diluidor a base de lecitina de soja em diferentes apresentações (8160, FP40, Solec F) e concentrações (0,01\%, 0,05\% e $0,1 \%$ ) e o diluidor a base de gema de ovo nas porcentagens de células com membranas plasmática e acrossomal íntegras, na atividade mitocondrial (DAB I atividade total) e nas variáveis analisadas pelo CASA (VSL, PROG, RAP, MED, STATIC), em amostras de sêmen de cães criopreservadas - São Paulo - 2012

\begin{tabular}{|c|c|c|c|c|c|c|c|c|c|c|}
\hline & \multirow[b]{2}{*}{ OVo } & \multicolumn{3}{|c|}{8160} & \multicolumn{3}{|c|}{ FP40 } & \multicolumn{3}{|c|}{ SOLEC F } \\
\hline & & $0,01 \%$ & $0,05 \%$ & $0,1 \%$ & $0,01 \%$ & $0,05 \%$ & $0,1 \%$ & $0,01 \%$ & $0,05 \%$ & $0,1 \%$ \\
\hline MEMBRANA (\%) & $60,76 \pm 4,84$ & $64,81 \pm 5,23$ & $56,62 \pm 6,16$ & $54,48 \pm 5,98$ & $58,67 \pm 5,38$ & $57,57 \pm 5,55$ & $52,05 \pm 6,08$ & $57,81 \pm 5,68$ & $59,52 \pm 5,47$ & $57,10 \pm 5,66$ \\
\hline ACROSSOMA (\%) & $77,77 \pm 4,53^{b}$ & $82,90 \pm 4,89^{\mathrm{ab}}$ & $84,85 \pm 2,82^{\mathrm{ab}}$ & $81,00 \pm 4,54^{\mathrm{ab}}$ & $85,52 \pm 3,68^{\mathrm{ab}}$ & $89,10 \pm 2,78^{\mathrm{a}}$ & $88,10 \pm 3,00^{\mathrm{ab}}$ & $87,14 \pm 4,11^{\mathrm{ab}}$ & $84,95 \pm 3,63^{\mathrm{ab}}$ & $86,57 \pm 2,31^{\mathrm{ab}}$ \\
\hline DABI (\%) & $64,95 \pm 4,24^{\mathrm{a}}$ & $47,90 \pm 6,31^{\mathrm{abc}}$ & $42,38 \pm 6,63^{b c}$ & $38,71 \pm 7,29^{c}$ & $57,57 \pm 5,81^{a b}$ & $50,30 \pm 7,49^{\mathrm{abc}}$ & $55,75 \pm 5,23^{\mathrm{abc}}$ & $50,81 \pm 5,56^{\mathrm{abc}}$ & $59,52 \pm 5,61^{\mathrm{ab}}$ & $47,62 \pm 6,96^{\mathrm{bc}}$ \\
\hline $\operatorname{VSL}(\mu \mathrm{m} / \mathrm{s})$ & $69,80 \pm 5,49^{\mathrm{a}}$ & $40,93 \pm 3,85^{\mathrm{b}}$ & $32,45 \pm 5,11^{D}$ & $20,51 \pm 4,20^{c}$ & $38,95 \pm 4,65^{b}$ & $37,59 \pm 3,97^{\mathrm{b}}$ & $32,74 \pm 3,87^{\mathrm{b}}$ & $43,42 \pm 2,52^{b}$ & $41,73 \pm 3,58^{\mathrm{b}}$ & $40,86 \pm 4,29^{b}$ \\
\hline PROG (\%) & $26,24 \pm 4,29^{\mathrm{a}}$ & $9,86 \pm 2,20^{b}$ & $6,81 \pm 2,04^{\mathrm{bc}}$ & $3,14 \pm 1,04^{c}$ & $9,10 \pm 1,95^{\mathrm{bc}}$ & $9,14 \pm 2,53^{\mathrm{bc}}$ & $6,57 \pm 1,61^{\mathrm{bc}}$ & $7,90 \pm 1,62^{\mathrm{bc}}$ & $7,67 \pm 1,54^{\mathrm{DC}}$ & $7,14 \pm 2,13^{\mathrm{bc}}$ \\
\hline RAP (\%) & $34,19 \pm 5,48$ & $33,86 \pm 6,15$ & $34,67 \pm 7,46$ & $22,52 \pm 6,58$ & $34,95 \pm 6,97$ & $37,86 \pm 7,37$ & $31,52 \pm 6,28$ & $33,05 \pm 5,73$ & $29,90 \pm 5,56$ & $24,43 \pm 5,75$ \\
\hline MED (\%) & $8,10 \pm 1,24^{c}$ & $13,38 \pm 1,70^{\mathrm{abc}}$ & $12,00 \pm 2,51^{\mathrm{abc}}$ & $9,86 \pm 2,21^{\mathrm{bc}}$ & $15,10 \pm 2,62^{a b}$ & $13,33 \pm 2,39^{a b c}$ & $13,95 \pm 2,21^{a b c}$ & $17,29 \pm 2,63^{\mathrm{a}}$ & $12,86 \pm 1,46^{\mathrm{abc}}$ & $12,57 \pm 1,88^{\mathrm{abc}}$ \\
\hline STATIC (\%) & $42,76 \pm 7,27^{\mathrm{ab}}$ & $37,43 \pm 6,17^{\mathrm{ab}}$ & $40,76 \pm 7,54^{\mathrm{ab}}$ & $54,19 \pm 8,08^{a}$ & $34,71 \pm 6,58^{\mathrm{b}}$ & $30,57 \pm 6,12^{\mathrm{b}}$ & $33,33 \pm 6,92^{b}$ & $33,24 \pm 6,32^{\mathrm{b}}$ & $32,48 \pm 4,28^{b}$ & $45,05 \pm 6,43^{\mathrm{ab}}$ \\
\hline
\end{tabular}

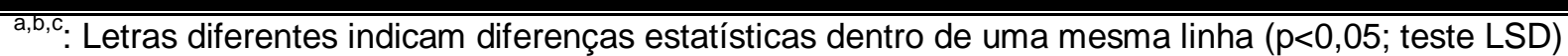

Não houve diferença estatística na porcentagem de células com membrana plasmática íntegra entre os diluidores a base de lecitina de soja e gema de ovo (Tabela 34). No entanto, a porcentagem de células com alta atividade mitocondrial (DABI) foi menor nos diluidores 8160 0,05\%, 0,1\% e Solec F 0,1\% (42,38 \pm 6,63; 38,71 \pm 7,29; 47,62 \pm 6,96, respectivamente) quando comparada com o diluidor gema de ovo $(64,95 \pm 4,24)$. Também em comparação com a gema de ovo, a porcentagem de células com acrossoma íntegro foi maior no diluidor FP40 0,05\% (89,10 $\pm 2,78)$. Apesar disso, a porcentagem de células móveis progressivas foi maior no diluidor com gema de ovo quando comparada com os diluidores a base de lecitina de soja. 
Tabela 35 - Efeito dos momentos da criopreservação (pós-refrigeração, pós-glicerolização e pósdescongelação) nas porcentagens de células com membranas plasmática e acrossomal íntegras, na atividade mitocondrial (DAB I, atividade total) e nas variáveis analisadas pelo CASA (VSL, PROG, RAP, MED, STATIC), em amostras de sêmen de cães criopreservadas em diluidores a base de lecitina de soja e gema de ovo - São Paulo 2012

\begin{tabular}{lccc} 
& Pós -Refrigeração & Pós-Glicerolização & Pós-Descongelação \\
\hline MEMBRANA (\%) & $78,40 \pm 0,98^{\mathrm{a}}$ & $67,39 \pm 1,78^{\mathrm{b}}$ & $28,03 \pm 1,85^{\mathrm{c}}$ \\
ACROSSOMA (\%) & $94,05 \pm 0,49^{\mathrm{a}}$ & $94,06 \pm 0,38^{\mathrm{a}}$ & $68,26 \pm 2,15^{\mathrm{b}}$ \\
DABI (\%) & $58,77 \pm 3,57^{\mathrm{a}}$ & $54,93 \pm 3,46^{\mathrm{a}}$ & $40,81 \pm 2,90^{\mathrm{b}}$ \\
VSL ( $\mu \mathrm{m} / \mathrm{s})$ & $55,76 \pm 2,23^{\mathrm{a}}$ & $38,80 \pm 2,10^{\mathrm{b}}$ & $25,13 \pm 2,33^{\mathrm{c}}$ \\
PROG (\%) & $16,47 \pm 1,53^{\mathrm{a}}$ & $9,66 \pm 1,29^{\mathrm{b}}$ & $1,94 \pm 0,65^{\mathrm{c}}$ \\
RAP (\%) & $60,69 \pm 2,47^{\mathrm{a}}$ & $29,97 \pm 2,52^{\mathrm{b}}$ & $4,43 \pm 0,86^{\mathrm{c}}$ \\
MED (\%) & $16,09 \pm 0,77^{\mathrm{a}}$ & $18,20 \pm 1,28^{\mathrm{a}}$ & $4,24 \pm 0,61^{\mathrm{b}}$ \\
STATIC (\%) & $13,66 \pm 1,55^{\mathrm{c}}$ & $32,87 \pm 2,65^{\mathrm{b}}$ & $68,83 \pm 2,88^{\mathrm{a}}$ \\
\hline \hline
\end{tabular}

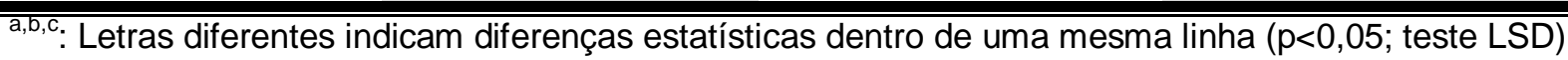

Todas as variáveis analisadas sofreram influência dos momentos da criopreservação, apresentando diferenças estatísticas já a partir da pósglicerolização, com exceção da porcentagem de células com acrossoma íntegro, alta atividade mitocondrial (DABI) e células com movimento médio, que se mantiveram entre os tempos pós-refrigeração e pós-glicerolização, ocorrendo uma diminuição apenas após a descongelação (Tabela 35). 
Discussão 


\section{DISCUSSÃO}

No presente estudo, podemos constatar que o diluidor contendo lecitina de soja na apresentação Solec $F \quad 0,01 \%$ foi superior na preservação dos espermatozóides mantidos em refrigeração por até 5 dias em comparação com o diluidor a base de Tris - Gema de Ovo, comumente utilizado na refrigeração do sêmen de cães.

As lecitinas 8160 e FP40, na menor concentração (0,01\%), e a Solec F nas três concentrações $(0,01 \%, 0,05 \%$ e $0,1 \%)$ foram capazes de manter a atividade mitocondrial durante as 120 horas de refrigeração, diferentemente do diluidor a base de Tris - Gema de Ovo, no qual a atividade mitocondrial se manteve por até 24 horas. Além disto, nesses mesmos diluidores, a porcentagem de células móveis se manteve por até 72 horas, sendo que no diluidor 8160 0,01\% foi mantida uma motilidade de 57\%, demonstrando melhores resultados em comparação com a gema de ovo, que manteve a motilidade por até 48 horas, havendo um declínio gradual e progressivo.

Foi possível notar que nos diluidores a base de lecitina 8160 e FP40 as maiores concentrações $(0,05 \%$ e 0,1\%) foram deletérias para os espermatozóides, não sendo eficientes para manter a qualidade espermática por tempo superior a 2 horas de refrigeração, fato refletido pela diminuição da atividade mitocondrial, porcentagem de células móveis, progressivas, membranas acrossomal e plasmática íntegras quando comparadas com o diluidor gema de ovo. No entanto, a gema de ovo apresentou uma maior susceptibilidade ao estresse oxidativo (TBARS) em relação a todos os outros diluidores a base de lecitina de soja.

No Experimento 2, podemos observar nos momentos pós-refrigeração e pósglicerolização, que os diluidores a base de lecitina de soja foram similares ao diluidor a base de gema de ovo, em relação à atividade mitocondrial nula (DABIV) e porcentagem de células móveis. No entanto, a partir da refrigeração, a \%STR e LIN foram menores nos diluidores a base de lecitina de soja em comparação com a gema de ovo. Já no momento pós-descongelação, todos os diluidores a base de lecitina de soja foram semelhantes ao diluidor contendo gema de ovo, com exceção do diluidor 8160 nas concentrações $0,05 \%$ e 0,1\% e o FP40 na concentração 0,1\%, 
semelhante ao que ocorreu no sêmen refrigerado (Experimento 1). Nestes diluidores, nas maiores concentrações, as amostras apresentaram uma maior porcentagem de células DABIV e uma menor motilidade. Contudo, a gema de ovo apresentou uma maior susceptibilidade ao estresse oxidativo (TBARS). Também para o sêmen pós-descongelação, a atividade mitocondrial foi mantida em todos os diluidores, com exceção dos diluidores 8160 nas concentrações 0,05\% e 0,1\% e Solec F 0,1\%. Todavia, a integridade do acrossomo foi maior no diluidor FP40 0,05\% em relação à gema de ovo. No entanto, a porcentagem de células progressivas foi maior no diluidor contendo gema de ovo em relação a todos os outros diluidores. Todas as outras variáveis avaliadas sofreram influência dos momentos da criopreservação, apresentando diferenças a partir da glicerolização.

A gema de ovo é o principal componente utilizado em diluidores, tanto na refrigeração quanto na criopreservação do sêmen na maioria dos mamíferos. O seu principal componente é uma fração de lipoproteína de baixa densidade que tem como função proteger a integridade da membrana fosfolipídica durante a criopreservação (FOROUZANFAR et al., 2010). No entanto, por ser de origem animal, apresentam diversas desvantagens, entre elas a sua variabilidade e o risco de contaminação.

Devido a essas desvantagens, a busca por diluidores alternativos, que não contenham produtos de origem animal, é de extrema importância. A lecitina de soja por ser um produto de origem vegetal e, assim como a gema de ovo, possuir como componente uma fração de lipoproteína de baixa densidade, pode ser uma alternativa interessante para substituir a gema de ovo. De fato, os resultados encontrados no presente estudo para o sêmen refrigerado (Experimento 1) e criopreservado (Experimento 2) demonstraram que a lecitina pode apresentar resultados semelhantes e até melhores que a gema de ovo. Estudos com refrigeração e criopreservação de sêmen utilizando diluidores a base de lecitina de soja em diversas espécies vêm apresentado resultados promissores (GIL et al., 2000; AMIRAT et al., 2005; BECCAGLIA et al., 2009; KMENTA et al., 2011). Beccaglia et al. (2009) utilizaram diluidores a base de lecitina de soja na concentração de 0,04\% na refrigeração do sêmen de cães por 4 dias e obtiveram resultados similares de motilidade, número de espermatozóides não capacitados e 
penetração de espermatozóides na zona pelúcida quando comparados com a gema de ovo.

A menor eficiência da gema de ovo em relação à lecitina pode ter ocorrido por uma série de fatores. Se por um lado as lipoproteínas de baixa densidade protegem o espermatozóide do choque frio, as proteínas de alta densidade presentes no ovo podem prejudicar a qualidade do espermatozóide, reduzindo a respiração e a motilidade espermática (PACE; GRAHAM, 1974; WATSON; MARTIN, 1975). Além disto, a composição do ovo pode ser extremamente variável, sendo que alterações nesta composição podem influenciar significantemente os resultados (KMENTA et al., 2011). A redução da qualidade dos espermatozóides também pode estar associada aos hormônios esteróides e seus precursores presentes na gema de ovo (SCHWABL, 1993). Por outro lado, pode ocorrer um aumento no risco de contaminação microbiana, o que levaria à produção de endotoxinas que podem reduzir o potencial fertilizante do espermatozóide (AIRES et al., 2003; FOROUZANFAR et al., 2010). Na refrigeração do sêmen este risco pode ser aumentado devido à estocagem por longo período. De fato, Bousseau et al. (1998) observaram a presença de contaminação moderada nos diluidores que continham produtos de origem animal mesmo na associação de antibióticos de amplo espectro.

Além disso, estudos indicam que diluidores contendo gema de ovo levam a um aumento na susceptibilidade dos espermatozóides ao estresse oxidativo (BARROS, 2007), o que foi observado no presente estudo pelo aumento na susceptibilidade dos espermatozóides ao estresse oxidativo quando o sêmen era refrigerado e criopreservado em diluidor a base de gema de ovo. Sabe-se que os espermatozóides geram espécies reativas ao oxigênio (ROS) em quantidades fisiológicas, as quais desempenham um papel importante durante a capacitação espermática, reação acrossômica e fusão de oócitos (AGARWAL et al., 2006). No entanto, quando há uma produção excessiva e descontrolada de ROS, ocorre um desequilíbrio entre o sistema de geração das ROS e os antioxidantes enzimáticos ou não enzimáticos, responsáveis pela remoção das ROS (VERNET; AITKEN; DREVET, 2004), resultando no estresse oxidativo. Este tipo de estresse causa danos estruturais a biomoléculas, DNA, lipídeos, carboidratos e proteínas, assim como outros componentes celulares (HALLIWELL, 1991), podendo comprometer a 
integridade genética, assim como a capacidade de fertilização (VERNET; AITKEN; DREVET, 2004).

Jones e Mann (1977) verificaram que o espermatozóide é particularmente susceptível ao ataque das ROS. Tal fato deve-se à pequena quantidade de citoplasma na célula espermática normal, o que limita a quantidade de antioxidantes, principalmente os enzimáticos (VERNET; AITKEN; DREVET, 2004). A grande quantidade de ácidos graxos poli-insaturados (PUFA) na membrana espermática permite a fluidez necessária para os eventos associados à fertilização (PARKS; HAMMERSTEDT, 1985; LENZI et al., 2000; AGARWAL; SALEH; BEDAIWY, 2003), tornando os espermatozóides ainda mais susceptíveis. Os ácidos graxos são formados por cadeias de átomos de carbono ligados a hidrogênio com um grupo carboxila terminal $(\mathrm{COOH})$. A presença de ligações duplas entre carbonos, também chamadas de insaturação, torna o ácido graxo mais maleável, o que permite uma maior motilidade espermática. No entanto, as ROS oxidam preferencialmente as ligações carbono-hidrogênio no grupo metileno $\left(\mathrm{CH}_{2}\right)$ adjacente à ligação dupla. Depois de iniciado, o processo se torna autocatalítico, levando à formação de hidroperóxidos e produtos secundários, que possuem capacidade oxidante, intensificando o processo oxidativo (DIX; AIKENS, 1993). Além disto, a gema de ovo possui uma quantidade significante de ácidos graxos poli-insaturados, podendo levar a um aumento na produção de hidroperóxidos resultantes da peroxidação lipídica, levando a uma reação em progressão geométrica, com potencial lesivo às células vizinhas.

Por outro lado, outra hipótese para o aumento do TBARS seria que, apesar das lavagens realizadas no sêmen a fim de retirar o diluidor, por ser utilizado um sistema gerador de ROS para avaliar a susceptibilidade das células à peroxidação lipídica, pode ter ocorrido a contaminação por resquícios da gema do ovo, sendo então avaliado de fato o ataque das ROS a lipídeos presentes na gema de ovo.

Alguns trabalhos também indicam que a lecitina de soja possui ação antioxidante, sendo melhores os resultados obtidos quando as amostras de lecitina continham alta concentração de fosfatidilcolina (JUDDE et al., 2003; NASIR; BERNARDS; CHARPENTIER, 2007). Desta forma, a menor produção de TBARS observada nos diluidores a base de lecitina pode ter ocorrido pela proteção antioxidante conferida por esta substância. 
Apesar das lecitinas apresentarem resultados em geral melhores do que a gema de ovo, as lecitinas FP40 e a 8160 em altas concentrações (0,05\% e 0,1\%) demonstraram ser prejudiciais.

A lecitina de soja disponível comercialmente contém em sua composição fosfatidilcolina, fosfatidiletilenoamina, fosfatidilinositol, ácido fosfatídico, fosfatidilserina e derivados de lisofosfatidil (HELMERICH; KOEHLER, 2003). E, por ser de origem vegetal, proporciona diversas vantagens, entre elas a padronização dos componentes e a eliminação dos riscos de contaminação (FUKUl et al., 2008). No entanto, a principal diferença entre as lecitinas utilizadas nos experimentos é a quantidade de fosfatilcolina. Enquanto a lecitina Solec $F$, que apresentou melhores resultados independente da concentração, continha $20 \%$ de fosfatidilcolina, as lecitinas FP40 e 8160 apresentaram 40\% de fosfatidilcolina e 50\% de lisofosfolipídeos, respectivamente (Quadro 1).

Quadro 2 - Composição das lecitinas de soja utilizadas nos experimentos

\begin{tabular}{|c|c|c|}
\hline Solec F & Solec FP40 & Solec 8160 \\
\hline $\begin{array}{l}\text { Lecitina natural deolificada } \\
20 \% \text { fosfatidilcolina } \\
\text { HLB* aprox. } 6 \\
\text { Boa hidratabilidade em água }\end{array}$ & $\begin{array}{l}\text { Lecitina fracionada deolificada } \\
40 \% \text { de fosfatidilcolina } \\
\text { HLB }^{\star} \text { aprox. } 6,5 \\
\text { Melhor hidratabilidade em água }\end{array}$ & $\begin{array}{l}\text { Lecitina hidrolizada em pó } \\
50 \% \text { de lisofosfolipídeos } \\
\text { HLB* aprox. } 7 \\
\text { Boa solubilidade em água }\end{array}$ \\
\hline & \multicolumn{2}{|l|}{ 97\% Insolúveis em acetona } \\
\hline
\end{tabular}

*HLB: Balanço Hidrofílic- Lipofílico <10 solúvel em lipídeo (insolúvel em água)

A fosfatidilcolina é uma classe de fosfolipídeos que incorpora a colina na "cabeça", isto é, na parte polar da sua estrutura (JOSHI; PARATKAR; THORAT, 2006). Os fosfolipídeos são os maiores componentes estruturais da membrana dos espermatozóides, sendo que, na membrana de espermatozóides humanos, a composição dos fosfolipídeos encontrados era de fosfatidilcolina (FC), fosfatidiletiletanoamina (FE), esfingomielina, fosfatidilserina, cardiolipina, fosfatidilinositol, lisofosfatidilcolina, lisofosfatidiletanolamina e fosfatidilglicerol (TAVILANI et al., 2007). Sabe-se que as membranas desempenham um papel ativo 
na capacitação espermática e na fertilização, sendo a reação acrossômica e a fusão espermatozóide-oócito eventos associados a ela. Além disto, os lipídeos são fundamentais para a viabilidade, maturação e função dos espermatozóides (TAVILANI et al., 2007). As fosfatidilcolinas são constituídas por uma extremidade polar formada por um grupo colina e um grupo fosfato ligados à porção hidrofóbica, duas longas cadeias acílicas de 16 a 22 carbonos, por ligações ésteres com o glicerol. As cadeias acílicas podem conter uma ou mais insaturações. Devido à estrutura polar-apolar, ou seja, anfifílica, essas moléculas tendem a se autoorganizar em bicamadas com importantes funções biológicas, como, por exemplo, as membranas celulares de organismos vivos (MERTINS et al., 2008). Pode ser obtida a partir de uma variedade de fontes prontamente disponíveis, tais como gema de ovo ou soja, a partir das quais elas são mecanicamente ou quimicamente extraídas utilizando hexano (JOSHI; PARATKAR; THORAT, 2006).

A menor atividade mitocondrial encontrada nas maiores concentrações das lecitinas 8160 e FP40 pode ter ocorrido pela maior concentração de fosfatidilcolina nesses diluidores. O desenvolvimento da mitocôndria é o evento mais específico que ocorre na espermiogênese, sendo o seu metabolismo energético importante para o movimento flagelar e viabilidade espermática. A fosfatidilcolina é o maior constituinte fosfolipídico dentro e fora da membrana mitocondrial dos mamíferos, sendo que os passos terminais da síntese ocorrem principalmente na superfície citoplasmática do retículo endoplasmático. Consequentemente a biogênese da mitocôndria requer uma eficiente importação da fosfatidilcolina para o retículo endoplasmático. Segundo estudos, acredita-se que essa importação ocorre através do movimento transmembranar que atravessa a barreira de fora para dentro da mitocôndria (DOLIS; DEKROON; DEKRUIJFF, 1996; YAMANAKA et al., 2000). Consequentemente, uma maior concentração de fosfatidilcolina exógena pode causar um desbalanço no equilíbrio intra e extracelular, causando alterações na atividade mitocondrial, explicando uma menor atividade mitocondrial de acordo com o aumento das concentrações das lecitinas contendo altas quantidades de fosfatidilcolina (e.g., 8160 e FP40).

Por outro lado, houve uma maior concentração de células com acrossoma lesionado nas lecitinas contendo maior quantidade de fosfatidilcolina. Cross (1994) observou que a suplementação de um meio de incubação com $100 \mu \mathrm{g} / \mathrm{ml}$ de 
fosfatidilcolina causa um aumento substancial no número de espermatozóides com acrossoma reagido. Tendo em vista que a capacidade de resposta acrossomal reflete-se na capacitação espermática, pode-se concluir que a fosfatidilcolina aumenta o número de espermatozóides capacitados. A fosfatidilcolina pode estar alterando o conteúdo lipídico das membranas espermáticas. O colesterol pode desempenhar um papel importante na regulação da reação acrossômica e na habilidade de fertilização. A fosfatidilcolina aumenta o efluxo de colesterol do espermatozóide, servindo como um dissipador de colesterol no meio.

A diminuição da motilidade observada nas amostras com maiores concentrações de fosfatidilcolina (8160 e FP40) pode estar relacionada à diminuição da atividade mitocondrial. Algumas evidências sugerem que a mitocôndria desempenha um papel chave na manutenção da energia da motilidade espermática, um dos principais determinantes da fertilidade. Os resultados obtidos por Ruiz-Pesini et al. (1998) sugerem fortemente que a motilidade espermática em humanos, depende de toda energia produzida pela mitocôndria, fator que pode estar relacionado com a baixa motilidade e baixa atividade mitocondrial encontrada nas lecitinas FP40 e 8160 nas maiores concentrações assim como na gema de ovo.

Outra hipótese para a diminuição da motilidade espermática nas maiores concentrações seria provavelmente a alta viscosidade da lecitina de soja, o que impediria o movimento do espermatozóide, e também a formação de debris no diluidor (FOROUZANFAR et al., 2010). 
Conclusão 


\section{CONCLUSÃO}

Através dos resultados obtidos podemos concluir que a lecitina de soja pode ser uma alternativa viável para substituir a gema de ovo tanto para a refrigeração quanto para a criopreservação do sêmen de cães. 
Referências 


\section{REFERÊNCIAS}

ABE, Y.; LEE, D. S.; SANO, H.; AKIYAMA, K.; YANAGIMOTO-UETA, Y.; ASANO, T.; SUWA, Y.; SUZUKI, H. Artificial insemination with canine spermatozoa frozen in a skim milk/glucose-based extender. Journal of Reproduction and Development, v. 54, n. 4, p. 290-294, 2008.

AGARWAL, A.; SALEH, R. A.; BEDAIWY, M. A. Role of reactive oxygen species in the pathophysiology of human reproduction. Fertility and Sterility, v. 79, n. 4, p. 829-843, 2003.

AGARWAL, A.; SHARMA, R. K.; NALLELLA, K. P.; THOMAS, A. J., JR.; ALVAREZ, J. G.; SIKKA, S. C. Reactive oxygen species as an independent marker of male factor infertility. Fertility and Sterility, v. 86, n. 4, p. 878-885, 2006.

AIRES, V. A.; HINSCH, K. D.; MUELLER-SCHLOESSER, F.; BOGNER, K.; MUELLER-SCHLOESSER, S.; HINSCH, E. In vitro and in vivo comparison of egg yolk-based and soybean lecithin-based extenders for cryopreservation of bovine semen. Theriogenology, v. 60, n. 2, p. 269-279, 2003.

AMIRAT, L.; ANTON, M.; TAINTURIER, D.; CHATAGNON, G.; BATTUT, I.; COURTENS, J. L. Modifications of bull spermatozoa induced by three extenders: Biociphos, low density lipoprotein and Triladyl, before, during and after freezing and thawing. Reproduction, v. 129, n. 4, p. 535-543, 2005.

AURICH, C.; SEEBER, P.; MULLER-SCHLOSSER, F. Comparison of different extenders with defined protein composition for storage of stallion spermatozoa at 5 degrees C. Reproduction in Domestic Animals, v. 42, n. 4, p. 445-448, 2007.

BARROS, P. M. H. Estresse oxidativo e integridade do DNA em sêmen resfriado de gato-do-mato-pequeno (Leopardus tigrinus, SCHREBER, 1775). 2007. $120 \mathrm{f}$. Tese (Doutorado em Medicina Veterinária) - Faculdade de Medicina Veterinária e Zootecnia, Universidade de São Paulo, São Paulo, 2007.

BECCAGLIA, M.; ANASTASI, P.; CHIGIONI, S.; LUVONI, G. C. TRIS-lecithin extender supplemented with antioxidant catalase for chilling of canine semen. Reproduction in Domestic Animals, v. 44 Suppl 2, n., p. 345-349, 2009. 
BECCAGLIA, M.; ANASTASI, P.; LUVONI, G. C. Freezing of canine semen in an animal-free protein extender. Veterinarian Research Communications, v. 33 Suppl 1, n., p. 77-80, 2009.

BERGERON, A.; CRÊTE, M.-H.; BRINDLE, Y.; MANJUNATH, P. Low-Density Lipoprotein Fraction from Hen's Egg Yolk Decreases the Binding of the Major Proteins of Bovine Seminal Plasma to Sperm and Prevents Lipid Efflux from the Sperm Membrane. Biology of Reproduction, v. 70, n. 3, p. 708-717, 2004.

BITTENCOURT, R. F.; RIBEIRO FILHO, A. D. L.; LIMA, M. C. C.; ALVES, S. G. G.; VASCONCELOS, M. F.; BISCARDE, C. E.; LEAL, L. D. S.; OBA, E. Efeito de um quelante de cálcio, um detergente e da lecitina de soja sobre a qualidade do sêmen caprino congelado-descongelado. Brazilian Journal of Veterinary Research and Animal Science, v. 45, n., p. 305-312, 2008.

BOUSSEAU, S.; BRILLARD, J. P.; MARGUANT-LE GUIENNE, B.; GUERIN, B.; CAMUS, A.; LECHAT, M. Comparison of bacteriological qualities of various egg yolk sources and the in vitro and in vivo fertilizing potential of bovine semen frozen in egg yolk or lecithin based diluents. Theriogenology, v. 50, n. 5, p. 699-706, 1998.

BUCAK, M. N.; ATEŞŞAHIN, A.; VARıŞLı, Ö.; YÜCE, A.; TEKIN, N.; AKÇAY, A. The influence of trehalose, taurine, cysteamine and hyaluronan on ram semen: Microscopic and oxidative stress parameters after freeze-thawing process. Theriogenology, v. 67, n. 5, p. 1060-1067, 2007.

CAMPBELL, R. C.; DOTT, H. M.; GLOVER, T. D. Nigrosin eosin as a stain for differentiating live and dead spermatozoa. The Journal of Agricultural Science, $v$. 48, n. 01, p. 1-8, 1956.

CELEGHINI, E. C. C.; DE ARRUDA, R. P.; DE ANDRADE, A. F. C.; NASCIMENTO, J.; RAPHAEL, C. F.; RODRIGUES, P. H. M. Effects that bovine sperm cryopreservation using two different extenders has on sperm membranes and chromatin. Animal Reproduction Science, v. 104, n. 2-4, p. 119-131, 2008.

CROSS, N. L. Phosphatidylcholine Enhances the Acrosomal Responsiveness of Human Sperm. Journal of Andrology, v. 15, n. 5, p. 484-488, 1994.

DE PAZ, P.; ESTESO, M. C.; ALVAREZ, M.; MATA, M.; CHAMORRO, C. A.; ANEL, $\mathrm{L}$. Development of extender based on soybean lecithin for its application in liquid ram semen. Theriogenology, v. 74, n. 4, p. 663-671, 2010. 
DELEEUW, F. E.; DELEEUW, A. M.; DENDAAS, J. H. G.; COLENBRANDER, B.; VERKLEIJ, A. J. Effects of various cryoprotective agents and membrane-stabilizing compounds on bull sperm membrane integrity after cooling and freezing.

Cryobiology, v. 30, n. 1, p. 32-44, 1993.

DIX, T. A.; AIKENS, J. Mechanisms and biological relevance of lipid peroxidation initiation. Chemical Research in Toxicology, v. 6, n. 1, p. 2-18, 1993.

DOLIS, D.; DEKROON, I. P. M.; DEKRUIJFF, B. Transmembrane movement of phosphatidylcholine in mitochondrial outer membrane vesicles. Journal of Biological Chemistry, v. 271, n. 20, p. 11879-11883, 1996.

EILTS, B. E. Theoretical aspects of canine semen cryopreservation. Theriogenology, v. 64, n. 3, p. 692-697, 2005.

ELLEGREN, H. Genomics: the dog has its day. Nature, v. 438, n. 7069, p. 745-746, 2005.

EVENSON, D. P.; JANCA, F. C.; JOST, L. K.; BAER, R. K.; KARABINUS, D. S. Flow Cytometric Analysis of Effects of 1,3-Dinitrobenzene on Rat Spermatogenesis. Journal of Toxicology and Environmental Health, v. 28, n. 1, p. 81-98, 1989.

EVENSON, D. P.; LARSON, K. L.; JOST, L. K. Sperm chromatin structure assay: its clinical use for detecting sperm DNA fragmentation in male infertility and comparisons with other techniques. Journal of Andrology, v. 23, n. 1, p. 25-43, 2002.

FOROUZANFAR, M.; SHARAFI, M.; HOSSEINI, S. M.; OSTADHOSSEINI, S.; HAJIAN, M.; HOSSEINI, L.; ABEDI, P.; NILI, N.; RAHMANI, H. R.; NASRESFAHANI, M. H. In vitro comparison of egg yolk-based and soybean lecithin-based extenders for cryopreservation of ram semen. Theriogenology, v. 73, n. 4, p. 480487, 2010.

FUKUI, Y.; KOHNO, H.; TOGARI, T.; HIWASA, M.; OKABE, K. Fertility after artificial insemination using a soybean-based semen extender in sheep. Journal of Reproduction and Development, v. 54, n. 4, p. 286-289, 2008. 
GIL, J.; JANUSKAUSKAS, A.; HÅÅRD, M.; HÅÅR, M.; JOHANISSON, A.; SÖDERQUIST, L.; RODRIGUEZ-MÁRTINEZ, H. Functional Sperm Parameters and Fertility of Bull Semen Extended in Biociphos-Plus ${ }^{\circledR}$ and Triladyl $₫$. Reproduction in Domestic Animals, v. 35, n. 2, p. 69-77, 2000.

GOOVAERTS, I. G.; HOFLACK, G. G.; VAN SOOM, A.; DEWULF, J.; NICHI, M.; DE KRUIF, A.; BOLS, P. E. Evaluation of epididymal semen quality using the HamiltonThorne analyser indicates variation between the two caudae epididymides of the same bull. Theriogenology, v. 66, n. 2, p. 323-330, 2006.

HALLIWELL, B. Reactive oxygen species in living systems: source, biochemistry, and role in human disease. American Journal of Medicine, v. 91, n. 3C, p. 14S22S, 1991.

HELMERICH, G.; KOEHLER, P. Comparison of methods for the quantitative determination of phospholipids in lecithins and flour improvers. Journal of Agricultural and Food Chemistry, v. 51, n. 23, p. 6645-6651, 2003.

HERMANSSON, U.; LINDE FORSBERG, C. Freezing of stored, chilled dog spermatozoa. Theriogenology, v. 65, n. 3, p. 584-593, 2006.

HOLT, W. V. Basic aspects of frozen storage of semen. Animal Reproduction Science, v. 62, n. 1-3, p. 3-22, 2000.

HRUDKA, F. Citochemical and ultracytochemical demonstratio of cytochrome-coxidase in spertmatozoa and dynamics of its changes accompanying aging or induced by stress. International Journal of Andrology, v. 10, n. 6, p. 809-828, 1987.

IGUER-OUADA, M.; VERSTEGEN, J. P. Long-term preservation of chilled canine semen: effect of commercial and laboratory prepared extenders. Theriogenology, $\mathrm{v}$. 55, n. 2, p. 671-684, 2001.

JANG, G.; KIM, M. K.; LEE, B. C. Current status and applications of somatic cell nuclear transfer in dogs. Theriogenology, v. 74, n. 8, p. 1311-1320, 2010.

JOHNSTON, S. D.; KUSTRITZ, M. V. R.; OLSON, P. S. Canine and Feline Theriogenology: Saunders, 2001 
JONES, R.; MANN, T. Damage to ram spermatozoa by peroxidation of endogenous phospholipids. Journal of Reproduction and Fertility, v. 50, n. 2, p. 261-268, 1977.

JOSHI, A.; PARATKAR, S. G.; THORAT, B. N. Modification of lecithin by physical, chemical and enzymatic methods. European Journal of Lipid Science and Technology, v. 108, n. 4, p. 363-373, 2006.

JUDDE, A.; VILLENEUVE, P.; ROSSIGNOL-CASTERA, A.; LE GUILLOU, A. Antioxidant effect of soy lecithins on vegetable oil stability and their synergism with tocopherols. Journal of the American Oil Chemists Society, v. 80, n. 12, p. 12091215, 2003.

KMENTA, I.; STROHMAYER, C.; MULLER-SCHLOSSER, F.; SCHAFER-SOMI, S. Effects of a lecithin and catalase containing semen extender and a second dilution with different enhancing buffers on the quality of cold-stored canine spermatozoa. Theriogenology, v. 75, n. 6, p. 1095-1103, 2011.

LEE, C. H.; CHO, Y. H. Aspects of mammalian spermatogenesis: Electrophoretical analysis of protamines in mammalian species. Molecules and Cells, v. 9, n. 5, p. 556-559, 1999.

LENZI, A.; GANDINI, L.; PICARDO, M.; TRAMER, F.; SANDRI, G.; PANFILI, E. Lipoperoxidation damage of spermatozoa polyunsaturated fatty acids (PUFA): scavenger mechanisms and possible scavenger therapies. Frontiers in Bioscience, v. 5, n., p. E1-E15, 2000.

MANJUNATH, P.; NAUC, V.; BERGERON, A.; MENARD, M. Major proteins of bovine seminal plasma bind to the low-density lipoprotein fraction of hen's egg yolk. Biology of Reproduction, v. 67, n. 4, p. 1250-1258, 2002.

MASSOTI, N. Estudo da conservação e fecundação de sêmen de touros diluídos em soro de leite de soja. 1964, 57 f. Tese (Livre-Docência em Medicina Veterinária) - Faculdade de Medicina Veterinária e Zootecnia, Universidade de São Paulo, Pirassununga, 1964.

MERTINS, O.; SEBBEN, M.; HENRIQUE SCHNEIDER, P.; POHLMANN, A. R.; SILVEIRA, N. P. D. Caracterização da pureza de fosfatidilcolina da soja através de RMN de $1 \mathrm{H}$ e de 31P. Química Nova, v. 31, n., p. 1856-1859, 2008. 
MICHAEL, A. J.; ALEXOPOULOS, C.; PONTIKI, E. A.; HADJIPAVLOU-LITINA, D. J.; SARATSIS, P.; VERVERIDIS, H. N.; BOSCOS, C. M. Effect of N-acetyl-L-cysteine supplementation in semen extenders on semen quality and reactive oxygen species of chilled canine spermatozoa. Reproduction in Domestic Animals, v. 45, n. 2, p. 201-207, 2010.

MOUSSA, M.; MARTINET, V.; TRIMECHE, A.; TAINTURIER, D.; ANTON, M. LOW density lipoproteins extracted from hen egg yolk by an easy method: cryoprotective effect on frozen-thawed bull semen. Theriogenology, v. 57, n. 6, p. 1695-1706, 2002.

NASIR, M. I.; BERNARDS, M. A.; CHARPENTIER, P. A. Acetylation of soybean lecithin and identification of components for solubility in supercritical carbon dioxide. Journal of Agricultural and Food Chemistry, v. 55, n. 5, p. 1961-1969, 2007.

NICHI, M.; BOLS, P. E.; ZUGE, R. M.; BARNABE, V. H.; GOOVAERTS, I. G.; BARNABE, R. C.; CORTADA, C. N. Seasonal variation in semen quality in Bos indicus and Bos taurus bulls raised under tropical conditions. Theriogenology, v. 66, n. 4, p. 822-828, 2006.

PACE, M. M.; GRAHAM, E. F. Components in egg yolk which protect bovine spermatozoa during freezing. Journal of Animal Science, v. 39, n. 6, p. 1144-1149, 1974.

PAPA, F. O.; FELICIO, G. B.; MELO-ONA, C. M.; ALVARENGA, M. A.; DE VITA, B.; TRINQUE, C.; PUOLI-FILHO, J. N.; DELL'AQUA, J. A., JR. Replacing egg yolk with soybean lecithin in the cryopreservation of stallion semen. Animal Reproduction

Science, v. 129, n. 1-2, p. 73-77, 2011.

PARKS, J. E.; HAMMERSTEDT, R. H. Development changes occurring in the lipids of ram epididymal spermatozoa plasma membrane. Biology of Reproduction, $v$. 32, n. 3, p. 653-668, 1985.

PONGLOWHAPAN, S.; ESSEN-GUSTAVSSON, B.; LINDE FORSBERG, C. Influence of glucose and fructose in the extender during long-term storage of chilled canine semen. Theriogenology, v. 62, n. 8, p. 1498-1517, 2004.

POPE, C. E.; ZHANG, Y. Z.; DRESSER, B. L. A Simple Staining Method for Evaluating Acrosomal Status of Cat Spermatozoa. Journal of Zoo and Wildlife Medicine, v. 22, n. 1, p. 87-95, 1991. 
PRINOSILOVA, P.; RYBAR, R.; ZAJICOVA, A.; HLAVICOVA, J. DNA integrity in fresh, chilled and frozen-thawed canine spermatozoa. Veterinarni Medicina, v. 57, n. 3, p. 133-142, 2012.

REED, M. L.; EZEH, P. C.; HAMIC, A.; THOMPSON, D. J.; CAPERTON, C. L. Soy lecithin replaces egg yolk for cryopreservation of human sperm without adversely affecting postthaw motility, morphology, sperm DNA integrity, or sperm binding to hyaluronate. Fertility and Sterility, v. 92, n. 5, p. 1787-1790, 2009.

RUIZ-PESINI, E.; DIEZ, C.; LAPENA, A. C.; PEREZ-MARTOS, A.; MONTOYA, J.; ALVAREZ, E.; ARENAS, J.; LOPEZ-PEREZ, M. J. Correlation of sperm motility with mitochondrial enzymatic activities. Clinical Chemistry, v. 44, n. 8, p. 1616-1620, 1998.

SCHWABL, H. Yolk is a source of maternal testosterone for developing birds. Proceedings of the National Academy of Sciences of the United States of America, v. 90, n. 24, p. 11446-11450, 1993.

SEAGER, S. J. W. Successful pregnancies utilizing frozen dog semen. A.l. Digest, v. 17, n., p. 6-16, 1969.

SHAHIDUZZAMAN, A. K.; LINDE-FORSBERG, C. Induced immotility during longterm storage at +5 degrees $C$ does not prolong survival of dog spermatozoa. Theriogenology, v. 68, n. 6, p. 920-933, 2007.

SILVA, A. R. Atualidades sobre a criopreservação do sêmen de cães. Revista Brasileira Reprodução Animal, v. 31, n. 1, p. 119-127, 2007.

SILVA, A. R.; CARDOSO, R. C. S.; SILVA, L. D. M. Principais aspectos ligados à aplicação da inseminação artificial na espécie canina. Revista Portuguesa de Ciências Veterinárias, v. 98, n. 546, p. 53-60, 2003.

TAVILANI, H.; DOOSTI, M.; NOURMOHAMMADI, I.; MAHJUB, H.; VAISIRAYGANI, A.; SALIMI, S.; HOSSEINIPANAH, S. M. Lipid composition of spermatozoa in normozoospermic and asthenozoospermic males. Prostaglandins Leukotrienes and Essential Fatty Acids, v. 77, n. 1, p. 45-50, 2007.

THOMASSEN, R.; FARSTAD, W. Artificial insemination in canids: A useful tool in breeding and conservation. Theriogenology, v. 71, n. 1, p. 190-199, 2009. 
VERNET, P.; AITKEN, R. J.; DREVET, J. R. Antioxidant strategies in the epididymis. Molecular and Cellular Endocrinology, v. 216, n. 1-2, p. 31-39, 2004.

WATSON, P. F. Recent developments and concepts in the cryopreservation of spermatozoa and the assessment of their post-thawing function. Reproduction Fertility and Development, v. 7, n. 4, p. 871-891, 1995.

WATSON, P. F.; MARTIN, I. C. The influence of some fractions of egg yolk on the survival of ram spermatozoa at 5 degrees $C$. Australian Jounal of Biological Sciences, v. 28, n. 2, p. 145-152, 1975.

WITTE, T. S.; SCHAFER-SOMI, S.; KUCHAR, A.; MOSTL, E.; IBEN, C.; AURICH, C. Effect of hen's egg yolk on capacitation and acrosome reaction of diluted canine spermatozoa. Animal Reproduction Science, v. 110, n. 3-4, p. 293-305, 2009.

YAMANAKA, M.; KOGA, M.; TANAKA, H.; NAKAMURA, Y.; OHTA, H.; YOMOGIDA, K.; TSUCHIDA, J.; IGUCHI, N.; NOJIMA, H.; NOZAKI, M.; MATSUMIYA, K.; OKUYAMA, A.; TOSHIMORI, K.; NISHIMUNE, Y. Molecular cloning and characterization of phosphatidylcholine transfer protein-like protein gene expressed in murine haploid germ cells. Biology of Reproduction, v. 62, n. 6, p. 1694-1701, 2000.

ZHANG, S. S.; HU, J. H.; LI, Q. W.; JIANG, Z. L.; ZHANG, X. Y. The cryoprotective effects of soybean lecithin on boar spermatozoa quality. African Journal of Biotechnology, v. 8, n. 22, p. 6476-6480, 2009.

ZINI, A.; KAMAL, K.; PHANG, D.; WILLIS, J.; JARVI, K. Biologic variability of sperm DNA denaturation in infertile men. Urology, v. 58, n. 2, p. 258-261, 2001. 